University of San Diego

Digital USD

Dissertations

Theses and Dissertations

2011-08-01

\title{
The Lived Experiences of 3rd Generation and Beyond U.S.-Born Mexican Heritage College Students: A Qualitative Study
}

Richard Galvan EdD

University of San Diego

Follow this and additional works at: https://digital.sandiego.edu/dissertations

Part of the Leadership Studies Commons

\section{Digital USD Citation}

Galvan, Richard EdD, "The Lived Experiences of 3rd Generation and Beyond U.S.-Born Mexican Heritage College Students: A Qualitative Study" (2011). Dissertations. 822.

https://digital.sandiego.edu/dissertations/822

This Dissertation: Open Access is brought to you for free and open access by the Theses and Dissertations at Digital USD. It has been accepted for inclusion in Dissertations by an authorized administrator of Digital USD. For more information, please contact digital@sandiego.edu. 


\title{
THE $L I V E D$ EXPERIENCES OF $3^{\text {rd }}$ GENERATION AND BEYOND U.S.-BORN MEXICAN HERITAGE COLLEGE STUDENTS: A QUALITATIVE STUDY
}

\author{
By
}

\author{
RICHARD GALVAN
}

\begin{abstract}
A dissertation submitted in partial fulfillment
of the requirements for the degree of

Doctor of Education
\end{abstract}

School of Leadership and Education Sciences

University of San Diego

August 2011

Dissertation Committee

Johanna S. Hunsaker, Ph.D.

Reyes L. Quezada, Ed.D.

Alberto L. Pulído, Ph.D. 
(C) Copyright by Richard Galvan

2011

All Rights Reserved 


\begin{abstract}
The purpose of this study was to describe the psychosocial and identity challenges of $3^{\text {rd }}$ generation and beyond U.S.-born (3GAB-USB) Mexican heritage college students. Alvarez (1973) has written about the psychosocial impact "hybridity" can have on a U.S.born (USB) Mexican individual who incorporates two distinct cultures (American and Mexican) in order to succeed in U.S. society, and yet, few empirical data is available beyond the $1^{\text {st }}$ and $2^{\text {nd }}$ generation on USB Mexican college students. As an example, there is no mention in the literature of two distinct and different worldviews present between immigrant and 3GAB-USB Mexican college students, which would enhance the overall reliability and validity of data when studying Mexican-origin individuals of the United States (Delgado-Romero, Galván, Maschino, \& Rowland, 2005; Umaña-Taylor, \& Fine, 2004, 2001).
\end{abstract}

Therefore, this study focused on the lived experiences of $3^{\text {rd }}$ generation and beyond U.S.-born Mexican heritage college students utilizing a basic interpretive and descriptive qualitative research design (Merriam \& Associates, 2002) in order to: (a) build a picture of the identity elements of the participants by examining the lived experiences they have had from infancy through college; (b) listen to what participants had to say about themselves in relationship to their identity development; (c) see if hybridity had a psychosocial impact on the participants; and (d) explore whether the generalized perceptions from previous research inquiry which commingled the worldview, identity, and lived experience with immigrant Mexican-origin and other Latino college students was valid. 
In order to disaggregate from an immigrant perspective, the participants were nine 3GAB-USB individuals of Mexican heritage who attend colleges and universities located in three California counties. Themes and categories cultivated from the data were examined and used to create a foundation on which to proceed in future research with the 3GAB-USB Mexican, and other USB ethnic college student populations. The study revealed the perceptions, myths, and stereotypes perpetuated by the media, academia, society, and government policy, are not necessarily the reality of this limited sample population of $3^{\text {rd }}$ generation and beyond U.S.-born Mexican heritage college students. 


\section{DEDICATION}

To my beloved sister Margaret, a Breast Cancer survivor, and cancer free for 3 years, I thank you for instilling at a very early age my love of learning. You and our parents never understood what all the incessant "Why" questions meant, which always led to the exasperating refrain from "Huali" our maternal grandmother, and our parents of "Callete el Hocico," politely translated as, SHUT UP! Maybe you will now understand... I just wanted to know about everything. Without you there to plant the seed, this moment in my life would never have happened. 


\section{ACKNOWLEDGEMENTS}

What began as a lark at a community college, my formal educational journey has now encompassed 22 years culminating in this degree. While there have been many sacrifices and hardships along the way, to paraphrase Hilary Rodham Clinton, "it really did take a village" to get me through the process. There have been friends, family, administrators (Dr. Cheryl Getz), and acquaintances, who came through when it appeared the journey would end. There have been educators who inspired and showed me the way, thank you Professor Robert Kasababian from the History Department at Rio Hondo Community College in Whittier, CA and Dr. Iris H. W. Engstrand from the History Department of the University of San Diego.

But it has been the last three years of the journey, which proved to be the most arduous because of unforeseen personal hardships. It is here, that I would like to acknowledge and thank Lurece Hunter for her assistance, kindness, and encouraging words in keeping the journey intact. For my brother from another mother, Michael B. Covington, his wife Margo, their 12-year-old daughter Taylor (my 'assistant'), and Shasta their dog, opening up their home to me in the last year was not only vital for my well-being, but without them, I would never have completed the educational journey. Words cannot express my gratitude and love, so I will not even try.

And then there are the nine students of the study, who gave of their precious free time with their only incentive being, to help me graduate; my former doctoral classmates Dr. Marcia Venegas-Garcia, and Dr. Eliazer Ayala-Austin, whose valuable input and guidance in the last six months have been a godsend; and Esther Aguilar, the 
administrative secretary of the Ethnic Studies department at the University of San Diego who listened, offered encouragement, and allowed me to vent in her office.

Lastly, I would like to acknowledge and thank my dissertation committee members: Dr. Johanna S. Hunsaker, Dr. Reyes L. Quezada, and Dr. Alberto L. Pulído, I am extremely grateful for not only agreeing to be on my committee, but continuing to be there throughout my trials and tribulations, while still allowing me the freedom to present this research project basically as I envisioned it. With patience wearing thin because of the aforementioned challenges in my life, knowing you all were there for help and guidance was one less stressor I had to worry about.

To those who I may have omitted, I apologize...Thank you! 


\section{TABLE OF CONTENTS}

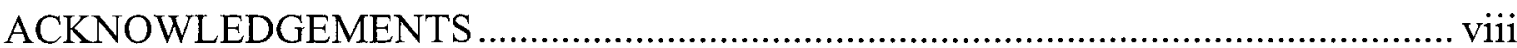

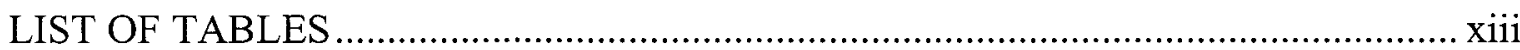

\section{CHAPTER}

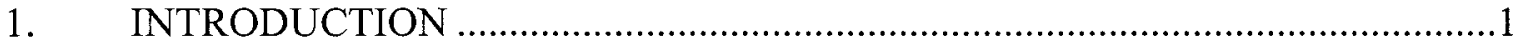

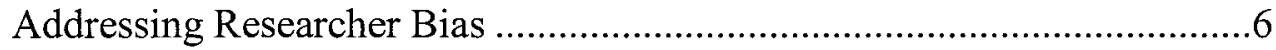

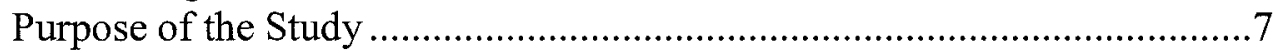

Statement of the Problem........................................................................10

Significance of the Study ........................................................................15

Research Questions ................................................................................

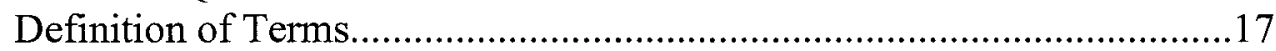

Organization of the Study …………........................................................20

\section{CHAPTER}

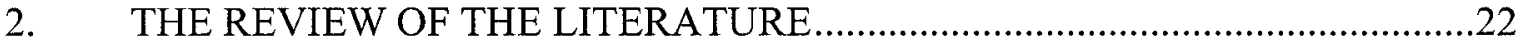

Historical Context ................................................................................24

How Studies on Mexicans in the U.S. Are Linked

to Immigration .............................................................................24

How Hispanization Affects Cultural Identity …………………......29

How Studies on Mixed Sample Mexican

Populations Affect Results.......................................................32

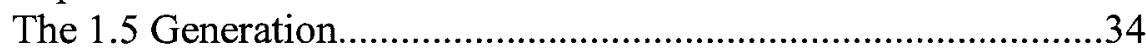

How Ethnic Gloss Affects Studies on U.S.-Born

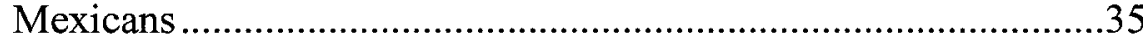

Theoretical Perspective ..............................................................................38

Psychosocial Development .............................................................38

Cultural Identity Development .....................................................40

Ethnic Identity Development ...........................................................41

Studies on Mexican American and Hispanic/Latino

College Students .......................................................................................43

Mexican American College Students.............................................43

Hispanic/Latino College Students...................................................49

Should Latino Groups Be Studied Separately ............................................51

Summary of Literature Review.............................................................54

\section{CHAPTER}

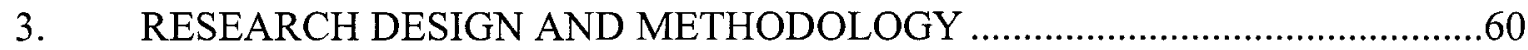

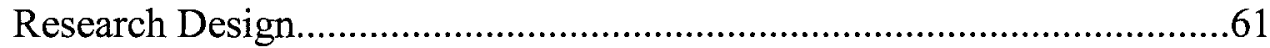

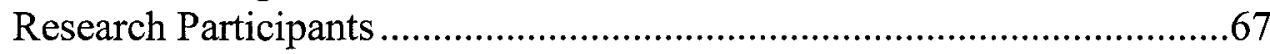


Demographic Profile of Participants................................................70

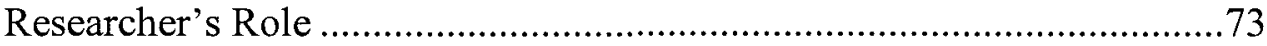

Reliability and Validity ........................................................................

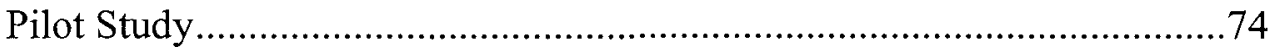

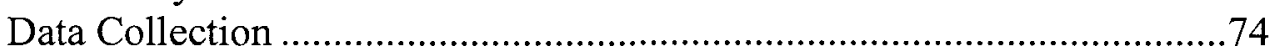

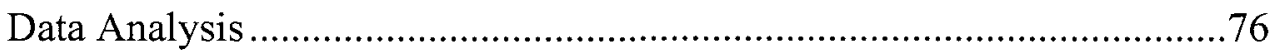

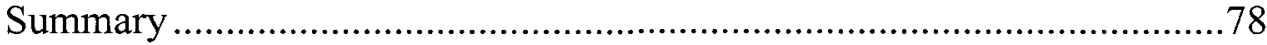

\section{CHAPTER}

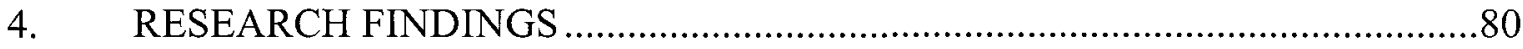

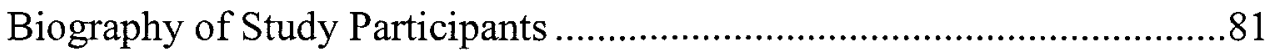

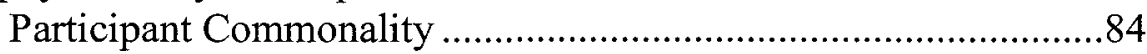

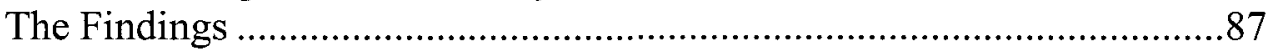

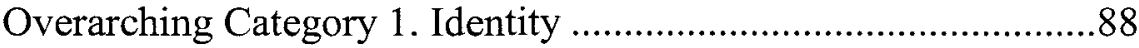

Theme 1 - Identity Confusion .............................................8

Theme 2 - Self-Label.......................................................94

Theme 3 - Hybridity ………………………………........106

Overarching Category 2. Alienation ............................................112

Theme 4 - Feeling Distant ..............................................112

Theme 5 - Discrimination \& Racism .............................115

Theme 6 - Reverse Assimilation ....................................122

Overarching Category 3. Transition to College............................126

Theme 7 - School Experience ...........................................126

Theme 8 - Support Groups ................................................135

Theme 9 - Recommendations...........................................141

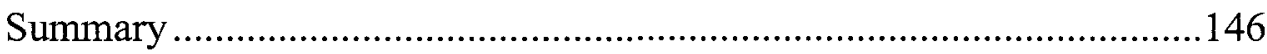

\section{CHAPTER}

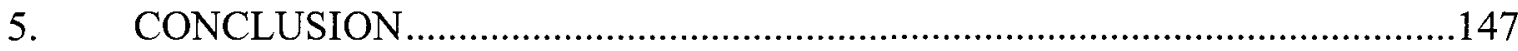

Summary of Findings.......................................................................150

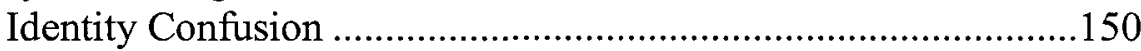

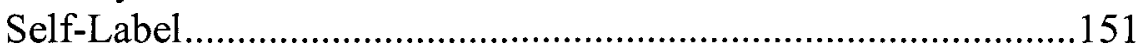

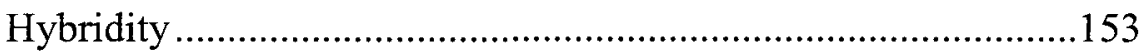

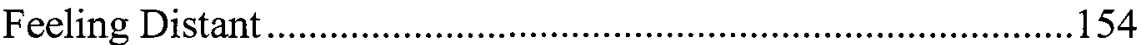

Discrimination \& Racism .....................................................154

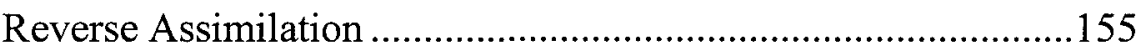

School Experience ………………………………………….....155

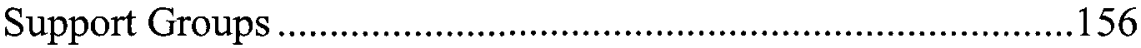

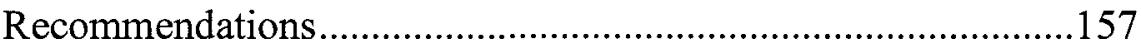

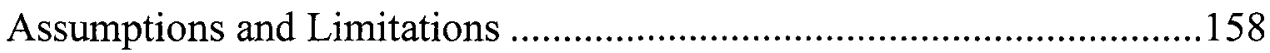

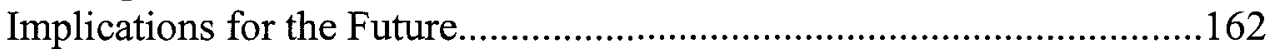

Recommendations for Future Research .................................................164

Recommendations for Transitioning the 3GAB-USB Mexican

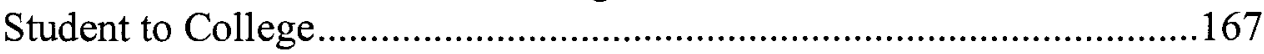




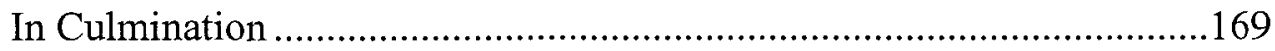

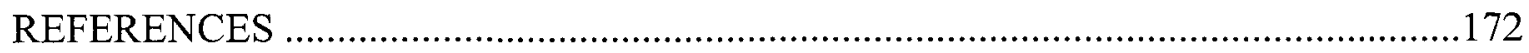

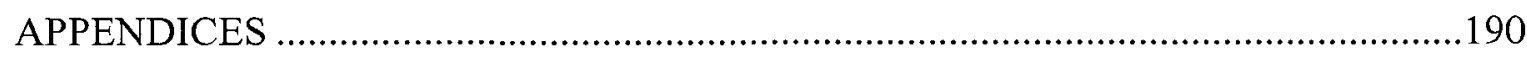

A. Research Participant Consent Form ............................................................190

B. General Demographic Information Form......................................................193

C. Demographic Profile of Participants .............................................................196

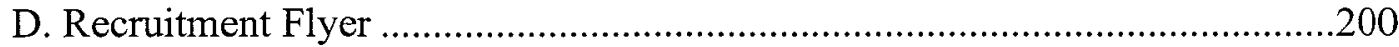

E. Interview Guide ......................................................................................202

F. Recruitment Electronic Mail Sent to Faculty and Campus Organizations ......206

G. Electronic Mail Sent to Potential Sample Participants ....................................208

H. National Center for Education Statistics. Status and Trends in the Education of Racial and Ethnic Minorities, Table 2b. (NCES 2010-015) ..........210 I. National Center for Education Statistics. Status and Trends in the Education of Racial and Ethnic Minorities, Table 2c. (NCES 2010-015)...........212 


\section{LIST OF TABLES}

Table 1. Generational Comparison Chart........................................5 57

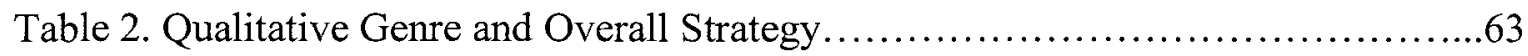

Table 3. Basic Demographics of Study Participants..................................72

Table 4. Emergent Themes and Overarching Categories............................88

Table 5. Generational Comparison Chart vs. Sample Participant Finding..................149 


\section{CHAPTER 1}

\section{INTRODUCTION}

Your people are good with their hands. You don't need to go to college.

Told to Me Many Times by My Teachers in Grades 1-12

In those early years (1961-1967) of my formal "education" I was not sure what the teachers meant by "my people." By the time I arrived at junior high school in September of 1967, I understood the implications. My people meant, those of Mexican heritage regardless if you were American-born or not, and spoke only English. In the eyes and minds of our educators, they were Americans and we were poor unskilled people from Mexico. As for attending college, having a curriculum of predominately industrial vocational classes (i.e., Auto, Electrical, Wood, Graphic Arts) instead of the basic core subjects of History, English, and the Sciences, pretty much ensured that my people and me, would not be accessing the academic pipeline to higher education any time soon. One must understand these teachers and administrators for the most part, were not acting out of malice, they firmly believed it was in our best interest to train us to be the labor force and leave the academics to others who had the mental capacity to succeed. After all, the study of Eugenics, the medical experimentation (e.g., dropping 2 drops of radioiodine into our milk in elementary school), and the data from the yearly rounds of diagnostic tests supported that premise, didn't it? ${ }^{1}$

\footnotetext{
${ }^{1}$ While attending elementary school from September 1961 through June 1967, there were various "health" programs, which were instituted with parental consent. Some were common, like the fluoride treatment for our teeth, and others more obscure. In the $2^{\text {nd }}$ grade during nutrition, we were served milk every day. It was the job of the class "milk monitor" to bring fresh milk from the cafeteria and then place 2 drops of radioiodine into each carton of milk turning it into a "pink" color that we thought was like adding Nestle's Chocolate mix to our milk. Follow-ups at the nurse's office to check our throat periodically throughout the semester just seemed to be routine because we were always being looked at by the school nurse. In 2005 ,
} 
For perspective, in the postwar years after World War II, and especially during the Eisenhower Administration of the late 1950's and early 1960's, changes in corporate structure and productivity caused a shift among the labor forces of the United States. As the percentage of white-collar jobs increased and the middle class expanded, the bluecollar jobs began to decrease weakening organized labor (Miller, 1996). Regardless of this nationwide trend and the threat automation posed to the unskilled and semi-killed worker, there was work to be found in East Los Angeles, California and other neighboring blue-collar communities such as: City of Commerce; Bell Gardens; Vernon; Maywood; and South Gate, CA, because they were home to such industrial complexes as Firestone, Goodyear, Uniroyal, and B.F. Goodrich Tire Companies; Reynolds and Alcoa Aluminum; Bethlehem Steel; General Motors; Lever Brothers; Quaker Oats; Coca-Cola; Nabisco; O'Keefe \& Merritt Stove Company; 3M Tape Company; and the western headquarters and main distribution depot of the Sears Roebuck Company.

as I began to think about a dissertation subject, a preliminary internet search found testing with Iodine-131 had been conducted throughout the United States in research laboratories and hospitals from the late 1940's through approximately the early 1980's to determine its effect on the human thyroid. Funded by various government agencies including the Atomic Energy Commission (now Department of Energy), concerns had developed because of radiation fallout from atmospheric tests conducted in Nevada in the 1950's and 1960 's, which exposed virtually all United States residents to various doses of radiation. Children were the most vulnerable and it is estimated they received anywhere from 6 to 14 rads as compared to the cumulative average dose of 2 rads for the general population. A "rad" is the unit of absorbed dose of radiation. The National Cancer Institute (NCI) estimates a $2 \mathrm{rad}$ exposure as being equivalent to 5 mammograms. The link between Iodine-131 and milk was created by children drinking contaminated milk (cows and goats eat the grass from contaminated fields and pastures) and ingesting more from the fallout then adults, which increased their risk of developing thyroid cancer at a later date. The NCI estimates between 10,000 to 75,000 thyroid cancer cases will be a direct result of this exposure. How this involved my elementary school and where the Iodine-131 was procured is unknown. Further preliminary searches and inquiries I have conducted with the Los Angeles Unified School District, reveal no such records exist of testing done in United States schools or any other school in the general vicinity of East Los Angeles, California. At this time, it is only the word of a few classmates who I contacted for verification and myself, who recall drinking this pink milk. To get sidetracked into finding answers while writing this dissertation is not feasible at this time. For more information on the testing and fallout please see Let Them Drink Milk, by Pat Ortmeyer http://www.ieer.org/sdafiles/vol_6/6-2iodine.html or the National Cancer Institute study on the fallout http://rex.nci.nih.gov/massmedia/Fallout/contents.html. 
In other words, East Los Angeles and its surrounding communities with the exception of a composition of $1^{\text {st }}$ and predominately $2^{\text {nd }}$ generation U.S.-born (USB) persons of Mexican heritage, was the same as any other union blue-collar city in the United States. The husband went to work, the wife took care of the household, and their children watched, played, and listened to the popular U.S. music, sports, and television programs of the day. No one worked in the fields, or failed to conduct their civic duties in English (although some like my father spoke with an accent). There was precedent then, for the children of these blue-collar workers to follow in their footsteps, except many of these parents did not want their children to become "burros" (beasts of burden) as they felt they had become. ${ }^{2}$

No, the parents had higher aspirations for their offspring. They worked hard so their children could go to school, become educated, and live a better life than they ever would. I recall my father telling me (while being hit with his belt) when I came home with unsatisfactory grades or being reprimanded in school that "he wasn't busting his ass" so I could end up a burro. His words to me were that I would not ever work at a job with my hands and get them dirty, "you will get an education, use your head, and wear a white shirt and tie, just like the gringos." Imagine then, my thoughts at school when my teachers would make the reference of being "good" with my hands.

Despite being one of those good hands people, I was one of the fortunate ones who was never assigned to a remedial, or special education class because I had been

\footnotetext{
${ }^{2}$ It is duly noted that from $1942-1964$ as a result of the Bracero Program 4.6 million Mexican immigrants entered the country as seasonal farm labor in response to projections of labor shortages due to World War II. As for their impact on the pro-union unincorporated area of East Los Angeles and its neighboring communities - it was minimal. They were not welcomed. If they did seek employment and take up residence in these communities, it was as it is now, in less desired occupations. For additional information on the Bracero Program, please see Phillip Martin's The Bracero Program: Was It A Failure? at http:/hnn.us/articles/27336.html on the George Mason University History News Network website.
} 
designated a "gifted child" in the first grade (my parents did not enroll me in Kindergarten). Having read every book given to me by my first grade teacher from grade levels one through nine in the first few weeks of the semester, and shown communications and aptitude skills far more advanced than other first graders, school administrators had a conference with my parents and suggested I should skip grades twofive. My parents thought this was ridiculous because I had just turned six years old that November. Not being privy to the conversation, not much more was ever said thereafter by my parents about skipping grades or being a gifted child. I just continued through the various grades levels and when I arrived at junior high school, failed several classes in the seventh grade for no other reason than I chose to do so.

By the tenth grade, I continued to exert little effort in schoolwork. Not helping the situation, in December of the next school year (1971) my father died of a heart attack at the age of 44 , and with his passing, went the threat of being reprimanded for failing in school. Totally bored, without direction or purpose, I unofficially dropped out of school the first part of my senior year in late 1972. Figuring I would get a job, get drafted in the Army (this was during the Vietnam War and I was an early number on the next draft call up), or join the armed services, I just partied and chased girls. It took an intervention by my high school counselor to convince me to graduate, but only after I went to night school to make up the one class credit I was short (I failed Choir, a required class because I refused to sing). Turned out I was not short a class. As a joke played at my expense, my counselor had lied. His comments were basically he wanted to see me "work hard" in at least one class during my high school stay. 
With no college aspirations, I entered the work force upon high school graduation, and despite a successful 15-year white-collar career in retail, I was dissatisfied with the way my life was unfolding. Yes, I escaped the many pitfalls present living in the Barrio of East Los Angeles, owned my home, and disproved my teachers' assertion, but was this enough? To borrow the line from the United States Army, "is that all I could be?" After an introspective journey and the realization I loathed working in retail, I came to the conclusion there is more to life than making money and began my postsecondary educational foray by enrolling at Rio Hondo Community College in Whittier, California about 13 miles east of Los Angeles in 1989.

While the genesis of this study has its roots in those early years of my life, it was not until I began to read the scholarly work in higher education about my people, the constant media and political banter homogenizing Hispanics/Latinos, and the silence regarding within-group animosity and differences, which was the impetus for this dissertation subject. One study in particular, by Niemann, Romero, Arredondo, \& Rodríguez (1999) titled, What Does It Mean To Be "Mexican?" Social Construction of an Ethnic Identity made me realize not much progress has been made in regards to disaggregating Americans of Mexican descent from their immigrant counterparts. In view of the fact their study uncovered differences in life experiences and worldview between an immigrant and U.S.-born Mexican, they nonetheless ignored those findings and chose to comingle the sample population of $78 \%$ immigrant, and $22 \%$ U.S.-born (USB) participants, to explain ethnic identity among Mexican heritage individuals in the United States. 
A more appropriate title of the study should have been, "What Does It Mean To Be a Mexican Immigrant in the United States," because of the predominant ratio of immigrant Mexican participants. The rationale for the title change would be because of the subject matter, "the constructing of an ethnic identity" in the study, emphasized that a person from Mexico refers to themselves as a Mexicano/Mexican, while the USB individual call themselves Mexican American, Chicano, or other labels, which on this inference alone, in regards to ethnic identity, would skew the data gathered and lead to false or inaccurate conclusions. Osei-Kofi, Richards, \& Smith (2004) have stated that educational institutions have failed to provide a complete story rendering "our vision of the world inaccurate, making the histories and experiences of marginalized groups invisible (p. 57)." The same can be said about research, which continues to generalize and perpetuate erroneous or incomplete information.

\section{Addressing Researcher Bias}

The role of the researcher in qualitative research is that of the primary data collection instrument (Merriam \& Associates, 2002). Consequently, identifying personal values, assumptions, and biases, beforehand was of the utmost importance (Creswell, 2003). Since the researcher was a $3^{\text {rd }}$ generation USB Mexican from the Chicano Generation, in order to minimize the bias, it was imperative the participants were allowed to tell their "lived" experience (Van Manen, 1990) without interference from the researcher injecting his. Also, because the researcher was an insider (Venegas-Garcia, 2010; Rosaldo, 1993), it allowed for inquiry specific to the sample population, rather than a reliance on "ethnically glossed (Trimble, 1991)" and inaccurate data collection instruments. 
Additionally, being an insider helped guide the study in ways an outsider could not, because the outsider would be unaware of certain nuances or lived experiences (e.g., while a male may have empathy and may even be an expert on childbirth, he will never know the true essence of giving birth as a female who has), which only an insider has experienced. By virtue of these nuances or experiences, the emergence of new questions and inquiry can lead to data that may never have been acquired if not for the shared experience between the researcher and the participants of the study.

\section{Purpose of the Study}

The purpose of this study was to describe the psychosocial and identity challenges of $3^{\text {rd }}$ generation and beyond U.S.-born (3GAB-USB) Mexican heritage college students and to identify problems and concerns they had in transitioning to college. Phinney's (1990; 1996; 2005) work on ethnicity, its multidimensional nature, and her discussion on how little is known about the psychological impact ethnicity has on groups, guided this study. Phinney contends researchers need to explore three dimensions which vary within and across ethnic groups: (1) how cultural norms and attitudes may influence the psychological processes and membership in particular ethnic groups; (2) measure how "strong the salience and meaning" of belonging to an ethnic group impact the individuals psychological outcomes; and (3) consider the individual's experience as a member of an ethnic group, with lower status and power, and how these individuals respond and deal with those experiences. In the present study, these three dimensions were incorporated to explore a sub-group, within an ethnic group, in order to understand those experiences.

While Phinney's work set a foundation for this study, the research of UmañaTaylor, \& Fine $(2001 ; 2004)$ and Umaña-Taylor, Diversi, \& Fine (2002) refined the focus 
to: (a) Examining ethnic identity empirically beyond childhood because few studies had done so, and (b) studying a sub-group (Mexican) within an entire ethnic group (Latino), would allow for better reliability and validity in the data. Targeting an even more precise result, the participants were non-immigrant 3GAB-USB college students of Mexican heritage.

Alvarez (1973) has written about the psychosocial impact "hybridity" can have on a USB Mexican individual who incorporates two distinct cultures (American and Mexican) in order to succeed in U.S. society, and yet, few empirical data is available beyond the $1^{\text {st }}$ and $2^{\text {nd }}$ generation on USB Mexican college students. As a result, a major focus of this study was to correct this critical omission in the scholarly literature through in-depth interviews of 3GAB-USB Mexican heritage college students, and explore little known factors such as: multigenerational status; a non-immigrant experience; being monolingual (some may speak only English); family dynamics; racial; cultural; and ethnic identity in a non-homogenous manner.

Therefore, this study focused on the lived experiences of 3GAB-USB Mexican heritage college students utilizing a basic interpretive and descriptive qualitative research design (Merriam \& Associates, 2002) in order to: (a) build a picture of the identity elements of the participants by examining the lived experiences they have had from infancy through college; (b) listen to what participants had to say about themselves in relationship to their identity development; (c) see if hybridity had a psychosocial impact on these USB Mexican college students; and (d) explore whether the generalized perceptions from previous research inquiry on Mexican-origin college students was valid. For clarification, the "lived" experience in this study referred to the utilization of the 
participant's life experience as data instead of the reliance on previous data or measurement instruments that may not have adequately captured the heterogeneity of this USB sample population.

Participants were nine 3GAB-USB individuals of Mexican heritage who attend colleges and universities located in the California counties of Los Angeles, San Diego, and San Mateo (San Francisco Bay area). The participants were the "experts" in defining their own identity and challenges faced. Themes and categories cultivated from the data were examined and used to create a foundation on which to proceed in future research with this population. Additionally, the study has the potential to: (a) introduce a subgroup not accounted for in the literature; (b) move research inquiry away from viewing native multigenerational Latino subgroups as immigrants; and (c) allow the participants to talk about their lives, their self-imposed labels, and experiences without using measurement instruments which have been designed for other ethnic groups and "adapted" for use with them.

As an example of adapted instrumentation, the Minnesota Multiphasic Personality Inventory (MMPI-2) is the most used personality test in the mental health field, and along with the Racial Identity Attitude Scale for Blacks (RIAS-B) were both adapted (by substituting Mexican American instead of Black on the RIAS-B, and the term Hispanic on the MMPI-2) for use in the study by Canul \& Cross (1994) in order to determine if acculturation among a "Mexican American" (mixed sample of both USB and immigrant) sample population influenced scores on MMPI-2 clinical and validity scales. The study's findings were "consistent with the acculturation perspective, which postulates that varying degrees of adaption to the American culture will influence scores on the MMPI-2 
scales," and the finding on the racial identity portion of their study, "clearly supports the racial identity perspective, which postulates that varying views of one's ethnicity will predict performance on MMPI-2 scales (p. 742)."

The broader question Canul \& Cross wanted to answer was could the MMPI-2 "be applied to the Mexican American population and be interpreted straightforwardly (p. 737)." They determined it was possible. After analysis of the results obtained by Canul \& Cross with their mixed sample of Mexican-origin college students, they are incorrect, unless the population of Mexican-origin individuals the researchers call Mexican Americans is divided between USB and immigrant and tested separately because they correctly have shown American culture influences results on the MMPI-2.

Keeping this in mind, the objective in the present study was to create a foundation on which to proceed in future research with the $3 \mathrm{GAB}-\mathrm{USB}$, and arrive at recommendations which might be useful for this multigenerational population. The study by design also provided a new perspective to the literature seeking to disaggregate the sample population from an immigrant perspective, which has permeated the literature, perpetuating negative myths, assumptions, and generalizations about an American population, which just happens to be of Mexican descent.

\section{Statement of the Problem}

Latinos are the youngest and fastest growing ethnic group in the United States. Between the years 2002-2005, undergraduate college enrollment for Latinos in the United States increased to nearly $30 \%$, in comparison to $28 \%$ for African Americans, $16 \%$ for Asian/Pacific Islanders, and 10\% for Whites (Santiago, 2007b). It is estimated roughly half $(48 \%)$ of all Latino college students in the United States are of Mexican-origin 
(Santiago \& Cunningham, 2005). In 2007, out of a total U.S. population of $45,378,600$ Latinos, 29,189,300 were of Mexican-origin. Of this Mexican group, 59.5\% were USB, and $89.3 \%$ were under the age of 18 (National Center for Education Statistics, 2010, Tables $2 \mathrm{~b}-2 \mathrm{c}){ }^{3}$

However, these figures will change once the 2010 U.S. Census is tabulated, and do not take into consideration, the undocumented or Mexican/Latino individuals who do not partake in the U.S. Census. ${ }^{4}$ With only $40.5 \%$ of the total Mexican heritage population in the U.S. being non-USB, a multidisciplinary review of the literature reveals numerous studies and articles on Mexican-origin populations in the United States has subsumed the most numerous segment (59.5\%) within the Mexican heritage population of the United States - the U.S.-born individual of Mexican descent. The importance of this void in the literature underscores the continual overgeneralization of Mexican heritage individuals in the United States in research.

As a result of this overgeneralization, stereotypes are perpetuated; the two distinct and different worldviews present between immigrant and multigenerational USB Mexicans are not discussed or considered as a factor in psychosocial or identity formation; and finding solutions to problems faced by the USB individual is hindered, because researchers may not discover problems exist due to their failure to acknowledge the differences between these two groups (Delgado-Romero, Galván, Maschino, \&

\footnotetext{
${ }^{3}$ For full statistics, please see Appendices $\mathrm{H}$ and $\mathrm{I}$ in the Appendix section.

${ }^{4}$ As of May 28, 2011 while conducting the final editing for this dissertation, the U.S Census released one of the first publications of the 2010 Census, revealing the total number of Latinos in the U.S. had increased to $50,477,594$, with $63 \%$ of the total $(31,798,258)$ comprised of Mexican heritage individuals, a $54 \%$ $(11,157,547)$ increase in the U.S. Mexican-origin population in the ten-year period between the 2000 and 2010 Census (United States Census Bureau, 2011). No breakdown between immigrant and U.S.-born had been given.
} 
Rowland, 2005; Umaña-Taylor et al., 2001; 2004). Some of these differences emerge due to "ethnic competition" between ethnic groups (in this case sub-group), as they fight for their place on the socio-economic stratum (Jimenez, 2007; Ono, 2002). While other differences such as internal racism, prejudice (within-group and external), moral values, and dialect, are rarely discussed (Holleran, 2003; Keefe, \& Padilla, 1987; Ochoa, 2000; 2004; Niemann et al., 1999).

The researcher is fully aware there are other groups under the Latino category, which are also USB. However, since the USB Mexican population in the United States is the most numerous (roughly two-thirds) within the Latino USB population, and the researcher himself is a $3^{\text {rd }}$ generation USB Mexican, the study is focusing exclusively on the USB Mexican contingent. A 3GAB-USB Mexican heritage college student in this study means the first generation constitutes the grandparents who were the immigrant generation; the second generation is their U.S.-born offspring; while the third generation is the second generation's U.S.-born children; and those beyond, are the succeeding USB generations thereafter. Previous research has already addressed the $1^{\text {st }}$ generation, and to some extent the $2^{\text {nd }}$ generation, albeit from a homogenous perspective where differences between immigrant and USB are not considered important. As a consequence of this perception, very little has been written about the experiences of USB Americans of Mexican heritage far removed from immigrant status in a non-homogenous manner.

In a study released in December 2009 by the Pew Hispanic Center of Washington, D.C. on Latinos, Two Worlds: How Young Latinos Come of Age, certain trends have begun to emerge from the new data on 3GAB Latinos in the 16-25 age group. Although the study is inclusive of all Latino groups, some of the findings clearly 
reinforce the tenets of this study on USB Mexicans- that the perception is not the same as the reality. For example, the study discusses the discrepancies for females between the ages of 18 and 19 who are mothers and the high school dropout rate between generations 1-3 and beyond. In an analysis of these discrepancies, one could ask why the percentage of mothers is higher in the $1^{\text {st }}$ and $3^{\text {rd }}$ generations than the second, or why the dropout rate drops drastically in the second generation, but rises again in the $3^{\text {rd }}$ generation.

Speculation might assume the reason for the rise of dropouts in the $3 \mathrm{GAB}$, is the curriculum is geared to immigrants and succeeding multigenerational "Americans" do not buy into the curriculum. But without empirical data, no one can prove if this assumption is true. Another finding of the study is the percentage of enrolled Latinos in high school, college, or a university by generational status as of March 2009, with the highest percentage of students $(81.8 \%)$ enrolled in postsecondary education coming from the $3 \mathrm{GAB}$ generation and beyond group. Again, since these are figures pertaining to Latinos as a whole, and USB Mexican heritage individuals in the age group 16-24 encompass approximately $68 \%$ of the total in this age group, it appears there is a critical as well as a practical need for exploring not only 3 GAB-USB Mexican heritage college students, but those of all USB ethnicities in the Latino category.

Further results of the study found:

- Two-thirds of Latinos in the age group of 16-25 are not immigrants. They are USB and $98 \%$ say English is their first language.

- In the $3 \mathrm{GAB}$ cohort, $50 \%$ use the term "American" as their first term of self-description. 
- Latinos "Brown" skin makes assimilation difficult in a country where White remains the racial norm.

- Latinos younger than age 26 do not see race in the same way as their older counterparts, and do not see "a fit" in describing themselves among the racial categories of the U.S. Census.

- More than two-thirds ( $68 \%$ ) of young Latinos are of Mexican heritage.

- The $3^{\text {rd }}$ generation of Latinos median age of 20 is older than the $2^{\text {nd }}$ generation whose median age is 14 .

In summation of the Pew study, projected shares of the Latino 16-25 age population peaks through 2050 among the 1 st through $3 \mathrm{GAB}$ are described, with a prediction that the $3 \mathrm{GAB}$ will account for a $37.4 \%$ share of the total Latino population by the year 2050 leading the authors to surmise,

Never before in this country's history has a minority ethnic group made up so large a share of the youngest Americans. By force of numbers alone, the kinds of adults these young Latinos become will help shape the kind of society America becomes in the $21^{\text {st }}$ century (p. 1).

Additionally the study explored within the Latino ethnic group, what this dissertation has done within a Latino sub-group: explore the attitudes, values, social behaviors, family characteristics, and educational attainment of basically the same aged group 16-25, while concurring with the assessment in this study of the USB by stating,

In this report when we refer to the third and higher generation of Latinos, we are describing a group with diverse family histories vis-à-vis the United States. We estimate that $40 \%$ of this group are grandchildren of immigrants. The rest are more far removed from the immigrants in their families. And a small share comes from families that never immigrated at all - their ancestors were living in what was then Mexico when their land became a part of the 
United States in the $19^{\text {th }}$ century as a result of war, treaty, annexation and/or purchase (p. 2).

\section{Significance of the Study}

This study's significance was, it explored in a non-homogenous manner variables such as multigenerational status, and contributed to developing a foundation for future research with 3GAB-USB college students of Mexican heritage by allowing the participants to speak about their lives, their self-imposed labels, and how they feel about themselves, while simultaneously building a picture of the identity elements of the participants, by examining the lived experiences they have had from infancy through college. In addition, the importance of introducing this sub-group into the academic literature, the possibility exists, other new measurement instruments (instead of adapted ones) might be developed exclusively for these American college students of Mexican heritage that will help studies on Mexican heritage populations not continually result in modest or inconclusive results by measuring them separately, or in comparison to immigrant Mexican sample populations.

The study is also significant because it challenged stereotypes, assumptions, myths, and perceptions, associated with Mexican and Latino heritage groups by introducing a non-immigrant perspective, which has dominated Mexican and Latino ethnic research far too long. While the sample size is limited, and may not reflect the views of other $3 \mathrm{GAB}-\mathrm{USB}$ Mexican heritage college students throughout the country, reading these sample population narratives, clearly illustrates another paradigm shift maybe in the offering because of the fact, that as the most numerous (Mexican) within the largest ethnic group (Latino) in the United States; their ascension into higher education is vital to not only their well-being, but also to the economic well-being of the United States 
because of projections in the year 2050, nearly 1 in 4 Americans will be of Latino extraction (Crockett, Iturbide, Torres Stone, McGinley, Raffaelli, \& Carlo, 2007; Pew Research Center, 2008).

Lastly, this study's research thesis is so much more than about Mexican heritage individuals, and its significance is not just limited to the United States. It could also have significant global implications, for other countries that homogenize their own ethnic groups. Every developed nation has influxes of immigrants into their countries seeking a better existence, and once roots are established, most will be reproducing and having offspring which will become citizens of those countries leading for some, into multigeneration families, whose offspring will think and behave differently because of their own lived experiences and worldview than family members closer to immigrant status.

\section{Research Questions}

Overarching Question

R1: What are the unique psychosocial and identity development challenges of $3^{\text {rd }}$ generation and beyond U.S.-born (3GAB-USB) college students of Mexican heritage?

Underlying Questions

1. How do members of this population identify themselves?

2. How does this self-identification help/hinder their ethnic identity?

3. How does the perception of others influence this self-identification?

4. What specific challenges do 3GAB-USB college students of Mexican heritage experience in their transition to college? 


\section{Definition of Terms}

For clarity, the following terms used in this study will be defined as follows:

American - From the U.S. Some Latinos consider North, Central, or South America, as the Americas.

Anglo - Individuals of White European heritage; Anglo Saxon.

Biracial - As used in this study when describing their omission from the sample population of this study, refers to an individual whose parents may not be totally of Mexican-origin (e.g., a person of Mexican heritage on the maternal side and Puerto Rican heritage on the paternal side).

Chicano(a) - (a) Mexican heritage individual with a "non-Anglo" image of themselves (Salazar, 1970); (b) can be U.S.-born, or one born in Mexico, but raised in the U.S.; (c) Mexican heritage individual who reconnects to his/her indigenous heritage (Hurtado \& Gurin, 2004); (d) person with a political consciousness of their "unique" status (a hybrid of two cultures), in the U.S. (Raso, \& Sobek-Herrera, 2001).

*There is no exact definition for Chicano(a) and the use of the term to describe people of Mexican heritage in the U.S. is highly suggestive, and can be offensive to some.

Cultural Identity - In this study refers to the customs, practices, languages, values, and worldviews, which define an ethnic group.

Ethnic Gloss - The portrayal of an entire ethnic group as being the same when it actually is not (Trimble, 1991).

Ethnic Identity - The way in which one defines him/herself in terms of ethnicity as it relates to the dominant culture; or the feelings of attachment to and pride of one ethnic group and cultural heritage as opposed to others (Keefe, 1992). 
Euro American - Individuals of European heritage.

Hispanic - Term used by the U.S. Census to define those of Latino-origin in the United States.

Hispano - Originally the descendants of Spanish settlers who moved into the most northern reaches of New Spain in the $16^{\text {th }}$ century. Even though through intermarriage with Pueblo and nomadic Indian tribes, Mexican heritage and EuroAmericans, this population continues to exhibit clear cultural differences from the Hispanic or Mexican category they have been homogenized under (Nostrand, 1992). While these individuals are of Mexican heritage, their strong identification with their Spanish heritage could not be considered an attribute shared by other Mexican heritage individuals in the U.S. who acknowledge their indigenous Mestizo (person of Spanish and Amerindian blood) roots.

Hispanization - In this study refers to the literature when the term Hispanic became synonymous for homogenizing all Latino subgroups into one without considering the differences within the sub-groups.

Homogenization - In this study refers to combining all Latino ethnic groups into one category.

Hybridity - In this study describes U.S.-born persons of Mexican heritage incorporating American and Mexican cultural values, morals, and behaviors into their lives.

Identity - A mental structure that acts as a self-regulatory system, which guides behavior (Adams, \& Marshall, 1996). 
Latino(a) - Person of Latino-origin, encompassing the various ethnic groups of the Western Hemisphere.

Lived Experience - refers to the study participant's life experience through their life cycle.

Mestizo - The offspring of Amerindian and Spanish parents as in Hernán Cortéz and his Náhuatl-Mayan interpreter/concubine, La Malinche.

Mexicano(a) - A self-designated term generally used by natives from Mexico.

Mexican American (No hyphen) - The contemporary research term for Mexicanorigin individuals regardless of birthplace living in the United States.

Mexican-American - A self-designated label from the Mexican-American Generation (approximately 1920's - 1950's) to distinguish themselves from the immigrant Mexicans of that Era (Rosales, 2000).

Mexicaness - In this study, a barometer of how "Mexican" a 3GAB-USB Mexican heritage college student is, as determined by Spanish-speaking Mexicans and other Latinos.

Mexican-origin - Anyone regardless of place of birth, from this ethnic group whether or not they reside in the United States.

Multiracial - as used in this study when describing their omission from the sample population of this study, refers to an individual whose parents may not be totally of Mexican-origin (e.g., a person of both Mexican and Irish heritage on the maternal side and Italian, Puerto Rican, and French heritage on the paternal side).

Pocho - Sanchez (1993) defines Pocho, or Pochos, as the offspring of immigrant Mexican parents. But, the term can also have a more derogatory connotation in the 
Mexican community as in half-breed, neither fully Mexican nor American, or to describe Mexican immigrants who came to the U.S. at a young age, and lost much of their Spanish due to the lack of any formal schooling in Spanish in the U.S. Pocho can also be used in the vernacular as Nigga is used in the African American community.

Psychosocial - Relates to one's psychological development in interaction with a social environment.

Reverse Assimilation - In this study is defined as the process a $3^{\text {rd }}$ generation and beyond Mexican heritage college student undertakes to be accepted by Spanish-speaking Mexicans or other Latinos.

Tejano(a) - A Mexican heritage individual whose allegiances lie with being from the state of Texas, not Mexico or the United States.

U.S.-born (USB) - Born in the United States.

U.S. -born Mexican (USBM) - Individual of Mexican heritage born in the United States.

Worldview - The overall perspective from which one sees and interprets the world.

$3 G A B-3^{\text {rd }}$ generation and beyond.

$3 G A B-U S B-3^{\text {rd }}$ generation and beyond U.S.-born.

\section{Organization of the Study}

This qualitative dissertation examined the lived experiences of $3 \mathrm{GAB}-\mathrm{USB}$ Mexican heritage college students and their transition to college. Chapter 1 presented a lived experience in the first person of the investigator and the purpose of the study. Chapter 2 consists of a review of the literature conducted in a multidisciplinary manner 
organized into four sections: (1) A historical perspective; (2) a theoretical perspective on psychosocial, cultural, and ethnic identity development; (3) studies on "Mexican American" and Hispanic/Latino college student experiences; and (4) the merits of studying Latino groups separately.

The research methods used in this study follow in Chapter 3. The research design, recruitment of participants, how interviews were conducted, and how the data was analyzed are addressed in this chapter. Chapter 4 explores the findings and common themes acquired from the exercise. Chapter 5 the conclusionary chapter, includes an overall discussion of the study, what was discovered, future implications, recommendations, and a culmination of the study. 


\section{CHAPTER 2}

\section{THE REVIEW OF THE LITERATURE}

Until we have our own certified savants, we will continue to be defined out of existence by outsiders insensitive to the internal dynamic of our own collectivity.

Rodolfo Alvarez (1973)

As Latinos have become the largest minority group in the United States, and with the number of college students from Latino cultural groups increasing (Bell \& Bautsch, 2011; Fry, 2010; Pew Hispanic Center, 2009), it is imperative for researchers to continue to look at factors associated with their successful ascension to higher education. However, because of the heterogeneity within the Latino group throughout the United States and the Western Hemisphere (e.g., differing places of birth, region, cultures, time in the U.S., etc.), a much closer examination is warranted. A body of research exists looking at college students who identify as Latino or Hispanic but much of the research commingles the various sub-groups into one general category masking possible withingroup differences. $^{5}$

Combining samples of Latino groups does not answer questions about sub-group identities or any psychosocial challenges they may experience. The multidimensionality within the Latino category makes it improbable that a sample combination would capture any within-group differences. As a consequence, sub-group and within-group differences are masked and therefore, some students of color become non-existent in the literature. For example, individuals of Mexican heritage born in the United States who could be burdened with feelings of not belonging because of the perception they are all immigrants

\footnotetext{
${ }^{5}$ Hispanic, Hispanic/Latino, or Latino, will be used interchangeably throughout this study when discussing all ethnicities the United States Census defines as Hispanic or Latino.
} 
to the United States, additional stresses brought on because one is of a different skin color, culture, or ostracized by their own community or family (because of upward mobility), remain undetected. ${ }^{6}$

Another significant factor not considered in the literature when the lives of U.S.born (USB) Mexicans is discussed in composite research studies involving Mexicanorigin or Hispanic/Latinos, is the acculturation process of U.S. natives. Does this group acculturate as defined in the literature? Acculturation is typically defined in the literature as immersion into the host society. But if this group is part of the host society, what do they acculturate to? Do they really acculturate as previous research says they do, or do they undergo a different process? The primary reason many factors associated with USB Mexicans and other Latino natives (e.g., worldview, values, primary language spoken, within-group differences) are not discovered is the fact, research continues to be so imbedded in the immigrant perspective, no consideration is given to any other factors not associated with the immigrant experience.

There are many dimensions to consider when researching ethnic groups. When introducing an invisible sub-group (USB Mexican), within another sub-group (Mexican heritage), within an ethnic group (Latino), only makes the task more arduous. For this reason, the review of the literature for this study was conducted in a multidisciplinary manner, and was organized into four sections: (1) A historical perspective; (2) a theoretical perspective on psychosocial, cultural, and ethnic identity development; (3) a

\footnotetext{
${ }^{6}$ In previous generations, this group has been called Mexican-Americans. However, because contemporary research now labels both immigrant and native-born persons of Mexican heritage living in the United States "Mexican American," for the purposes of this study, and for absolute clarity on the population being studied, they will be referred to as U.S.-born Mexicans, U.S.-born person/individual of Mexican descent/heritage, or native American(s)/population.
} 
review of studies on Mexican American and Hispanic/Latino college students; and (4) a review on the merits of studying Latino groups separately.

\section{Historical Context}

\section{How Studies on Mexicans in the U.S. Are Linked to Immigration}

The history of Mexican individuals in the American Southwest predates the creation of the United States. Scholars such as Umaña-Taylor, et al. (2002) have argued whether the word immigrant is even appropriate for these native individuals since, "they became foreigners' due to boundary changes" brought about by Mexico's War (18461848) with the United States (p. 316). That however, is beyond the scope of this study and for brevity, the emphasis on when the study of Mexican descent individuals began, will date back to the 1920's and 1930's when sociologists took an interest in an attempt to understand the Mexican immigration experience (caused by the Mexican Revolution, political unrest before and after the revolution, and lack of opportunity in Mexico) and their perceived problems of assimilation in the United States (Bogardus, 1934; Galarza, 1929; Gamio, 1930; Gould, 1932; Lyon, 1933; Taylor, 1927).

Approximately three decades later, the Civil Rights and Chicano Movement of the 1950's and 1960's allowed for a paradigm shift and researchers began to de-homogenize ethnic groups and discover not only differences among the groups, but in-group differences as well. Elucidating on the existence of the Mexican heritage people in the United States, Alvarez (1973) in The Psycho-Historical and Socioeconomic Development of the Chicano Community in the United States presented an historical account of 
the plight of the "Mexican American"" people, who in succeeding generations became USB by writing,

The objective is to confront the reality of Mexican American society as we have experienced it and from that basis generate hypotheses for future multidisciplinary research in this area. For this purpose we identify four historical periods and describe the climate of opinion within the generation of Mexican Americans that numerically dominates the period (p. 920).

Alvarez explained each generation experiences a different state of collective consciousness in regards to its relationship with the dominant society because of psychohistorical differences, which can be related or induced by the economic system in place. Beginning with the first generation he calls the "Creation Generation" of the mid-1800's in the Southwest United States, he discusses the psychological experience faced by this generation as it breaks with the culture from the parent country (Mexico) and deals with its subjugation against their will in a land (the new U.S. boundary) they consider "their own," and how that "makes the experience of Mexican Americans different from all other ethnicities that migrated to this country in the nineteenth and twentieth centuries (p. 925).

The next collective consciousness experienced was by the "Migrant Generation" of the 1900's whose cheap labor made it more attractive for farmers than machines, which required far more maintenance. It is in this period, which Alvarez argues against these individuals being called immigrants by social scientists and policymakers because of the peculiar circumstances of their existence as migrants (open border till mid 1930's) and because by living and settling into various areas of the United States, they were socialized into the cultural mode of that period.

\footnotetext{
${ }^{7}$ Alvarez calls them Mexican American in order to distinguish them as those who became "American" because of the border boundary change made as a result of the Mexican American War of 1846-1848 and those who remained in Mexico.
} 
From around the beginning of World War II (1939) through the beginning of the Korean War (1950's) the third state of collective consciousness Alvarez described became known as the "Mexican-American Generation," because this group began to show increasing cultural loyalty to the U.S.,

I am an "American" who happens to be of Mexican descent. I am going to participate fully in this society because, like my descendants of people from so many other lands, I was born here, and my country will guarantee me all the rights and protections of a free and loyal citizen (p. 932).

What the members of this generation did not realize was although they were better off than their parents from the Migrant Generation, they were far behind the African American population, in various social achievement attributes such as: years of education, political efficacy, and annual income per family. Alvarez explains why,

Lack of unions and lack of political effectiveness meant that the Mexican American was earning less than any other group far comparable. Lack of education meant that the Mexican American did not have sufficient understanding of the nature of the society in which he lived and its economic system to even know that he was being treated unfairly (p. 933).

In regards to how the African American had achieved more years of education than the Mexican-American, he referred to the creation of the over 100 Historically Black Colleges (as of 1973 when his article was written) by stating,

That however inadequate the black schools may have been, compared to "white" schools, they provided the institutional foci within which a broad sector of the black population had been trained and certified for middle class status since prior to 1900 (p. 939).

Whereas in comparison, there were no institutions of higher learning designated to serving Mexican heritage individuals. Either they qualified for "white" institutions or they did not go to college. 
The final state of collective consciousness in Alvarez's treatise brings us to the "Chicano Generation" of the late 1960's, where this generation begins to understand certain citizenship rights and protections have been denied to USB Mexicans, but in the process of obtaining those citizenship rights and protections, certain obligations and duties would be required, which traditionally the USB Mexican had "not been in a position to perform," due to being,

Ill-prepared because a high school education is no longer as useful as in previous generations. And even for those positions for which a high school education is sufficient, they were ill-prepared because the high schools located in their neighborhoods were so inadequate compared to those in Anglo neighborhoods (p. 937).

This ill-preparation along with racial discrimination left many to accept working class employment or join the Armed Forces to gain skills and show loyalty to the United States during a time of war, just as in the preceding generations during World War II. The few, who did gain acceptance into college, did so at the prospect of abandoning their ethnicity.

In Alvarez's opinion, "the Chicano Generation was the first generation since the Creation Generation to confront the prospect of large-scale failure (p. 938)." Another contributing aspect to this failure was the enforcement of "Affirmative Action." Having become official when then President Johnson signed Executive Order 11246 on September 24,1965 , the reality was, federal regulations only meant employment was guaranteed for "Spanish Surname" people to fill jobs regardless of place of birth, leaving the USB Mexican out of the middle-class and relegated to working class status because a new influx of educated people from other Spanish-speaking countries came into the U.S. economy to fulfill higher skilled jobs. 
It is at this point in time that Alvarez warns of what will happen to the multigeneration

USB Mexican described as Chicano in this quote,

The threat of cultural extinction has led the Chicano to deep introspection as to what distinguishes him from both Mexicans in Mexico and from "Anglos" in the United States. Until we have our own certified savants, we will continue to be defined out of existence by outsiders insensitive to the internal dynamic of our own collectivity. The willingness to fight may be what will get us there (p. 942).

Alvarez notwithstanding the following year, Ambrecht \& Pachon (1974) noted in their exploratory study on political mobilization in the Mexican community of East Los Angeles, California that there had been increasing attention on ethnicity among academics in contrast to previous decades. Citing the International Political Science Abstracts, the authors reveal only seven articles from 1949-1971 on ethnicity and ethnic voting appeared in the journals indexed by the study. The reason for this disparity say Ambrecht \& Pachon was due to assimilationist ideologies present in American society prior to the "racial crises of the 1960's (p. 500)."

Previously Jose Antonio Villarreal (1959) had taken an introspective look at what Alvarez (1973) has called "hybridity" (living in two cultures) when he wrote what is considered by many to be the first Chicano novel, Pocho. ${ }^{8}$ The books depicts the anguish felt by fictional character Richard Rubio who tries to live his life in two cultures...that of being an American, and the other of not "selling out" on his Mexican heritage. Although this might be the first Chicano novel, the writings of Americo Paredes ${ }^{9}$ appear to be the

\footnotetext{
${ }^{8}$ Simply defined, a "Pocho" among the Mexican community is someone considered a half-breed, neither fully Mexican nor American. Please see section "Definition of Terms" in Chapter 1 for full explanation.

9 "Américo Paredes is generally recognized as one of the seminal Mexican-American scholars of the 20th century. Along with George I. Sánchez, Arthur León Campa, Julian Samora, and Carlos Castañeda, Paredes helped develop the foundations of modern Mexican-American scholarship with his outstanding scholarly contributions. From mid-century onward his studies of corridos, folkloric ballads, machismo, and border stereotypes of Mexicanos formed the basis of a whole school of southwestern folklore most of whose
} 
first published work of someone who acknowledged his hybrid life as a pocho beginning with his first collection of poetry in 1937, titled Cantos de Adolenscía (Tales of Adolescence), according to Olguín (2005).

Other work exploring the dual identity of living in an American and Mexican culture include Madrid-Barela (1976) writing about a pocho who is rejected by both the Mexican and the White community because he is considered a "half breed" neither fully Mexican or White during the period of 1910-1940's, and Luedtke (1977), who writes about the pocho and the American Dream. But it is Shorris (1992) 15 years later who fully defines the negative aspect of being a pocho when he writes,

The pocho lives on the cultural and racial line, a profoundly homeless person, utterly unprotected, despised on every side: too Mexican for the Anglos and too agringado for the Mexicans ( $\mathrm{p}$. 170).

\section{How Hispanization Affects Cultural Identity}

With the introduction of the term "Hispanic" by the United States Census Bureau in the 1970 Decennial census, and the new wave of immigration from Central America fleeing its Civil Wars in the 1980's, the paradigm shifted back in the majority of the literature once again to an immigrant or all inclusive perspective, leading to the accepted perception for some in academia, the media, and American society, that all Mexicans in the United States are immigrants, and as such, whatever psychosocial and identity remedies have been found for immigrant Mexicans or Latinos, will also hold true for USB Mexicans.

investigators he trained." Comments are from the Americo Paredes web page at the University of Texas Nettie Lee Benson Collection web site. For more information see $\mathrm{http} / /$ www.lib.utexas.edu/benson/paredes/index.html 
As a result of this shift, whatever distinctions had been made in previous research among Latino subgroups (Mexican, Cuban, Puerto Rican, Central American, etc.) and within groups (Mexican, Mexicano, Chicano, Tejano, Mexican-American) in the United States, had fallen out of fashion and were replaced by more inclusive studies favoring the new more politically correct "Hispanic" and/or Latino category which can include countries as culturally diverse as Argentina, Spain, and nations in the Caribbean Islands, where differences such as language, dialect, political views, and attitudes on skin color may be not be the same as in the United States. Critics indifferent to the Hispanization ${ }^{10}$ approach in research, argue it is no longer helpful to assume Latino people share the same issues and characteristics. They feel only by examining the psychology of Latino subgroups, can researchers begin to see the differences among them (Delgado-Romero et al., 2005; Guzman, Santiago-Rivera, \& Haase, 2005; McNeill, Prieto, Niemann, Pizarro, Vera, \& Gomez, 2001; Umaña-Taylor et al., 2004).

The following illustrate the all-inclusive trend in studies of Hispanic/Latinos. Corby, Hodge, \& Perry (2007) study on gender identity and adjustment in preadolescents is an example of using a sample of Hispanics to explain behavior for all ethnicities under the Latino category, and comparing those against African Americans and Euro American samples in their study. Participants were 863 fifth graders attending five public elementary schools in southeast Florida. The sample of 863 fifth-grade children included 436 White (212 boys, 224 girls), 260 Black (120 boys, 140 girls), and 167 Hispanics (88 boys, 79 girls). As they discuss the results of their findings, they express the possibility that "one might be tempted to interpret certain results in terms of broad dimensions of

\footnotetext{
${ }^{10}$ Hispanization defined in this study, is the combining of all Latino subgroups into one.
} 
between-culture variability" among the three groups studied (p. 265). What they fail to consider is the possibility their findings apply only to their sample of southeastern Florida Hispanics whose backgrounds are mainly Puerto Rican, but also include Guatemalan, and Mexican immigrants, and not to all Latinos who may or may not be immigrants.

Carter (2006) examines how African American and Latino youths negotiate the boundaries between school and their peer groups. The author states that race, ethnicity, culture and identity "almost guarantee these four factors play a role in the academic wellbeing of all students" but, "how and why they matter continue to elude social science researchers and educators (p.304)." Acknowledging the heterogeneous nature of the experiences of the two ethnic groups, Carter fails to see the heterogeneity within the Latino ethnic group by itself could be a major factor in determining why answers have eluded researchers exploring the role race, ethnicity, culture, and identity play in the academic well-being of students. The sample size of the study was 68 participants, with 26 being Latino composed of first and second generation Puerto Rican and Dominican individuals from Yonkers, New York ranging in ages from 13 to 20 years of age.

Upon further analysis, it appears the majority of the sample populations phenotype was black or dark-skinned because the author states that the racial identification of the Hispanic/Latino youths "varied from black, white, or no race" at all (p. 324). As noted throughout this study utilizing a minute sample from a sub-group (in this, case Black or dark-skinned Caribbean Latinos) to explain behavior for Latinos as a whole, is very misleading because the majority of Latinos in the United States are not of a darker phenotype and as such, the data from this study in all probability would not 
be reflective of the non-Caribbean lighter-skinned Latinos from the Eastern Seaboard or the remainder of the United States.

\section{How Studies on Mixed Sample Mexican Populations Affect Results}

Roosa, Liu, Torres, Gonzalez, Knight, \& Saenz (2008) examined how cultural factors affecting adjustment, health, and development of ethnic minority individuals would be enhanced if study samples reflected the diversity within these groups. Using a multi-step process in their recruitment process, the researchers obtained a sample population of 750 "Mexican American" families that were diverse in cultural orientation, social class, and type of residential communities similar to the United States Census. The design of their study took care to examine the heterogeneity in adherence to culturally related phenomena within the group by selecting samples, which represent the diversity within the sample population. In order to achieve this, "a sufficient number of communities and sufficient number of participants had to be included to accommodate multi-level data analysis along with the use of recruitment processes which result in higher response rates, while also treating the participants in a culturally sensitive manner in order to minimize barriers (p. 295)."

The results of the study revealed the majority of the parents were born in Mexico, described themselves as Mexican, and preferred to speak Spanish. Whereas the majority of the children born in the United States, described themselves as Mexican American, and spoke English. Demographic data showed the sample used in this study was more diverse in various dimensions then what is typical of other studies on this population. Consequently, the authors surmised this result could have been because of the overrepresentation of recent immigrants and the underrepresentation of $3^{\text {rd }}$ generation and 
beyond U.S.-born Mexicans (3GAB-USB). As noted by the authors, the design of their study can serve as a foundation for future studies on USB Mexican individuals in the United States because the study did show the diversity within the Mexican community. However, since the majority of the sample was Mexican immigrants, it failed to show the diversity, within-group differences, and worldview of USB Mexicans whose lived experience is rarely chronicled or known.

Kiang, Yip, Gonzalez-Backen, Witkow, \& Fuligni (2006) examined the protective effects of ethnic identity on the daily psychological well-being of 415 Mexican and Chinese students. Citing the work of Erikson, (1968) they emphasized "a major task during adolescence is to ascertain a sense of identity, theorized to play a vital role in development (p. 1338)." Using ethnic identity as a barometer, the researchers measured through daily diary assessments the impact it may have as a buffer against stressful experiences for these two ethnic groups. Of the final sample, $75 \%$ of the Mexican heritage students and $95 \%$ of the Chinese students were immigrants. Since the sample was overwhelmingly immigrants, the results of the study may differ if the participants were USB because of their different worldview and the non-immigrant status of each ethnic group.

In a similar study, Fuglini, Witkow, \& Garcia (2005) explored ethnic identity and academic adjustment by including Euro-Americans to their sample of Mexican and Chinese students. The sample population from the three groups totaled 589 students. A detailed analysis of the total sample population is as follows: 383 were from immigrant families with 58 Mexicans, 9 Chinese, 127 Europeans being $3^{\text {rd }}$ generation USB, and 14 having an unknown place of birth. The importance of separating the immigrants from the 
non-immigrant sample is vital because it is noted in this study that children from immigrant families tend to avoid American ethnic and racial categories and prefer to retain their original cultural identities (i.e., Mexican or Chinese, instead of MexicanAmerican/Asian-American).

Additionally, citing the work of Gibson \& Bhachu (1991), and Sung (1991), the researchers state, "immigrant parents may use such identifications as a way to keep their children from adopting undesirable 'American' attitudes and behaviors, such as laziness, materialism, and selfishness (p. 799)." If these factors are considered when analyzing this study, how can one accept the results found if by virtue of the uneven sample population (those of color are mostly immigrants), the findings are not accurate? Having already ascertained in the study immigrants identify differently than USB, how can the measurements for ethnic identity and academic adjustment among this sample population be considered reliable.

\section{The 1.5-Generation}

In the decade that followed the Hispanization of studies, the 1990's brought about a new dimension for some researchers who studied Mexican-origin and other Latino subgroups, the "1.5 generation" defined by Rodriguez, Bingham Mira, Paez, \& Myers (2007), as Mexican and Latino immigrants who came to the United States before or at the age of 12. Rumbaut (1994) has suggested distinguishing between the first generation and 1.5 generation because there is a difference in values and identities, whereas HollowayFriesen (2008) has written, that the dual identity of these immigrants has the potential to marginalize them from both their culture of origin and their new U.S. culture, as this quote cited in Padilla (2006) suggests, 
How could I not be an American? From the moment I stepped outside to go to school my entire life was American. The first thing we did everyday was say the Pledge of Allegiance in English. Bingo, right there I knew I was different from my Mexican parents (p. 475).

However, approximately two decades before, Alvarez (1973) had previously discussed how "duel identity" had the potential to marginalize all USB Mexican individuals who incorporated two distinct cultures, American and Mexican in order to succeed in U.S. society when he wrote about hybridity,

Because we live in different circumstances we have evolved different cultural modes; just as we are neither identical to "Anglos" in the United States nor to Mexicans in Mexico, we nevertheless, incorporate into our own ethos much from both societies (p. 920).

Nonetheless to date, few studies exist in the literature, which chronicle the impact psychosocial and identity development has on the psyche of USB multigeneration Mexican heritage college students. As an example, an informative study by Gloria, Castellanos, \& Orozco (2005) which examined the psychological well-being of Latina college undergraduates of which, $79 \%$ were of Mexican heritage, and included 58 participants who were $2^{\text {nd }}$ generation, 11 who were third generation, 6 who were fourth, and 3 who were fifth generation, cannot be generalized as being an accurate predictor of the psychological well-being of USB Mexican females because the sample was a composite of various Latino ethnicities (Central American, South American, Cuban, and Puerto Rican), and not all were USB.

\section{How Ethnic Gloss Affects Studies on U.S.-Born Mexicans}

Supporting the argument against Hispanization and homogenizing all ethnic groups for research simplicity, a group of scholars has posited that some researchers 
when studying ethnic groups have a tendency to overgeneralize them as a whole (Banks, 2006; Diaz, Pelletier, \& Provenzo, 2006; Spencer, 2006). The tendency to portray an entire ethnic group as being the same has become so commonplace in ethnic research the practice has been termed "Ethnic Gloss" (Trimble, 1991). Ethnic gloss is a problem because if researchers do not obtain samples of ethnic groups representing the diversity within the group, the data will lead to an overgeneralization of the ethnic group and the proliferation of stereotypes (Santrock, 2008). Ethnic gloss will also mask differences among the groups such as racial attitudes, prejudice, moral values, dialect, and conflict within the group (Holleran, 2003; Niemann et al., 1999; Ochoa, 2004; Ono, 2002).

Supplementing the above contention, the majority of the literature reviewed for this study had three major limitations: (1) The studies were based on a combination of USB and immigrant respondents to explain Mexican behavior in the United States with no emphasis on exploring differences found between immigrant and USB individuals (Schenk, 2007; Tan, 2008); (2) the majority of research reviewed had been conducted with individuals from Texas (Tejanos) to explain Mexican behavior in the United States as a whole (Cornelius-White \& Garza, 2004; Guzman, Santiago-Rivera, \& Haase, 2005; Holleran, 2003; Love, Yin, Codina, \& Zapata, 2006); and (3) the research had not focused on what it was purported to be, as in researchers using Mexican-origin data to explain all Latino behavior (Gamst, Dana, Der-Karabetian, Aragón, Arellano, \& Kramer, 2002; Gloria et al., 2005).

Rodriguez et al. (2007) illustrates the first disputation of not exploring differences found between immigrant and USB Mexican heritage individuals. The focus of their study was to examine the relationships between three dimensions of familism: 
importance of family, family support, and family conflict with acculturation and how it contributes to the psychological adjustment among their sample of 248 adult Mexicanorigin individuals. Acknowledging the fact previous research on within group comparisons between Mexican-origin and Latinos has produced mixed results the researcher's assessed Mexican and American cultural contributions independently. Stressing throughout their study previous research is inconsistent, they continued to focus on examining the factors associated with the psychological well-being and distress of Mexican-origin adults as a whole, rather than as separate entities because the purpose of the study was not to explore within-group differences among their Mexican-origin sample population, thereby adding to the inconsistent literature they criticized in their study, by not looking deeper at within-group differences between the native and immigrant Mexicans.

The second disputation of studies conducted in Texas to explain Mexican-origin behavior in the United States, Guzman et al. (2005) examined the relationships between ethnic identity, other group orientation, and fatalism among Mexican youths from Austin, Texas. The sample consisted of $20 \%$ immigrant, $78 \%$ USB, and $2 \%$ born elsewhere. Selfidentification terms included, Mexican, Chicano, Hispanic, Latino, American, and Mexican American. The sample also included multi-racial individuals. It would appear in a study involving ethnic identity among these individuals the emphasis should be on having an exact sample of individuals, or exploring the heterogeneity of an inexact sample in order to understand why individuals call themselves what they do because as Phinney \& Alipuria (1996) have discovered, an ethnic self-label refers only to a person's chosen ethnic identity and may vary situationally, as well as regionally (Dowling, 2005). 
The third disputation of ethnically glossed research not being what it purports to be (using Mexican-origin data to explain all Latino behavior), Unger, Ritt-Olson, Wagner, Soto, \& Baezzconde-Garbanati (2007), argue that various self-report measurements on acculturation have been used among Hispanic/Latino adolescents making comparisons across studies difficult. A further argument they seem to have missed, is the use of the majority of participants from one ethnic subgroup (over $92 \%$ were of Mexican-origin) to explain behavior for the entire ethnic group, can also make comparisons across studies difficult. Their results indicated acculturation scales may measure different aspects of acculturation and recommended additional research is needed to "create and validate" acculturation instruments in the future. The researchers also concluded individuals vary in retaining their native culture and adopting and internalizing aspects of the host culture. But what is not discussed is the possibility multigenerational USB individuals who happen to be Hispanic/Latino may not respond in similar fashion because they are, and have been, part of the "host" culture from birth.

\section{Theoretical Perspective}

\section{Psychosocial Development}

College students who question their identity are not a new phenomenon. BaxterMagolda (1999) has written it is not until after college and life experience young adults begin to feel comfortable about whom they are. From this perspective it makes sense that as a person moves through the lifespan cycle they begin to feel comfortable with themselves. But what exactly is identity? Identity as defined by Adams \& Marshall (1996) as cited in Hardy \& Kisling (2006) is a mental structure that acts as a selfregulatory system, which guides behavior. The origin of the study of identity 
development is linked to Sigmund Freud's early writings, but it was Erik Erikson (1950, 1968) who took identity from childhood processes into adolescence and adulthood (Schwartz, 2001).

Although Erikson's thoughts on psychosocial identity were derived from the earlier work of theorists such as James (1892), Cooley (1902), Freud (1930, 1965), and Mead (1934), it was his belief that identity is formed through psychological experiences with the social environment (Schwartz, 2002). While his psychosocial theory of identity development considered the impact external factors (e.g., parents, society, etc.) had on individual's personality development from childhood to adulthood, some critics believed his linear stage process model did not account for qualitative differences or grasp the variety of other possible identity development pathways (Kunnen, \& Bosma, 2003). In a refinement of Erikson's theory, Marcia (1980) argued that the adolescent stage of development consisted neither of identity resolution nor identity confusion, but instead, on the degree one has explored and committed to an identity in a variety of life experiences such as vocation, religion, relationships, and gender roles.

Because Erikson's and other stage models on various variations on identity were normed on white middle-class populations instead of a diverse group (Piaget, 1972; Kohlberg, 1984), it was William E. Cross' (1971) original development of Negro-toBlack Conversion or Nigrescence Model which paved the way for the development of other models in order to look at issues of identity and how it affected ethnic groups in the United States (Canul \& Cross, 1994; Phinney \& Alipuria, 1990; Sue \& Sue, 1990). Additional research on ethnic groups has now expanded in order to explore individual and group development issues in settings such as counseling, student services, and 
employment, and has led to the exploration of other identity dimensions such as, sexual orientation and gender (Gilligan, 1982; Johnson, 2004; Markstrom \& Kalmanir, 2001).

\section{Cultural Identity Development}

Cultural identity refers to the customs, practices, languages, values, and worldviews, which define social groups such as those, based on nationality, ethnicity, region, or common interests (Geertz, 1973; Spradley, 1979). Cultural identity is also important for people's sense of self and how they relate to others, and can contribute to a person's overall well-being (Ministry of Social Development, Government of New Zealand, 2008). Kosmitzki (1996) has investigated the relationship between an individual's sense of self and how they relate to others, and reaffirmed that individuals evaluate more positively the attributes from their own culture than those of another culture. However, cultures vary on what they deem accepted attributes, and how they view an individual's sense of self (Marcus \& Kitayama, 1991; Park \& Guan, 2007) because the traits and types of behaviors on which people self-enhance, are culture specific (Sedikides, Gaertner, \& Toguchi, 2003).

What it means to be of a particular culture can also vary within cultural groups (Tsai, Ying, \& Lee, 2000). Understanding within-group variations is important according to these researchers, because by studying the process of how individuals experience their culture, it can lead to revelations on how psychological mechanisms influenced by cultural variables affect psychological functioning. They argue, if individuals do differ in their experiences of being of a particular culture, their responses to various acculturation and ethnic identity instruments may have different meanings. While Carter, Yeh, and Mazzula (2008) believe, even though theorists have acknowledged the importance of 
cultural values among ethnic groups, few empirical studies have examined the specific role and unique qualities present in Latino cultural values. In their field of counseling psychology, understanding Latino cultural values and how it differs from American cultural values may help explain the failure of Latinos to access available mental health services when facing psychosocial issues.

\section{Ethnic Identity Development}

Ethnic identity is a complex process. According to Keefe (1992) as cited in Niemann et al. (1999, p. 49), Ethnic identity is:

(a) The perception of differences between ethnic groups, (b) the feelings of attachment to and pride of one ethnic group and cultural heritage as opposed to others, and (c) the perception of prejudice and discrimination against one's own ethnic group.

A seminal feature in researching people of color is ethnic identity. Understanding the reasons why individuals of color call themselves what they do is another important aspect of ethnic identity. In the southwestern United States Mexican-origin individuals may selfdescribe themselves as, Chicano(a); Hispanic; Hispano; Latino(a); Mexican; Mexicano(a); Mexican-American; Mexican American; or Tejano. But this is in no way indicative of all self-labels used in the region or nationally (Alcoff, 2005; Niemann et al., 1999; Phinney \& Alipuria, 1996).

Phinney (1996) explains, even when ethnicity is broken down into a complex multidimensional construct, little is known about its psychological impact on ethnic groups. She contends that in order to understand its impact it is necessary to identify and find the aspects of ethnicity, which may affect individuals from American ethnic groups. Phinney recommends researchers need to explore at least three dimensions of difference that vary within and across ethnic groups which are: (1) The cultural norms and attitudes 
that may be influential in the psychological processes, and their association with membership in particular ethnic groups; (2) the measurement of how strong the "salience and meaning" of belonging to an ethnic group impact their psychological outcomes; and (3) consider the individuals' experience as members of an ethnic group with lower status and power, along with the ways these individuals "respond and deal" with these experiences (p. 925).

Phinney (2005) has also acknowledged critics who contend research has not recognized the variability of ethnic identity, while others argue, racial and ethnic identity is the same concept. In opposition to the concept of race and ethnicity being the same, Rodriguez (2000) describes race and ethnicity as having a fluidity and complexity that is not often acknowledged but is always present. Using an example of a Latino in the United States, she states that ethnically a person could be Puerto Rican or Mexican on a personal level, a Latino on an instrumental level, and a Hispanic to the government. Adding in regards to race, this person might also classify to some as a Black, White, Asian, Brown, or Multiracial.

Where Alipuria (2002) contends, race and identity are different concepts in regards to identity, because racial identity is based on how one looks and the way society responds to that appearance, whereas ethnic identity, is dependent upon ancestral origin, and the attitudes associated with that origin. Nevertheless, these two concepts both operate within the research, and can affect results of studies because of the classification of certain groups as "White" under the United States Census, and the United States Judiciary system, leading to the confusion as to the racial status of the group, and in turn, 
creating the connection between race and identity for some researchers and their sample populations (Hitlin, Brown, \& Elder Jr., 2007; Pizarro \& Vera, 2001).

The heterogeneity within the Mexican population of the United States, and the maintenance of a status quo in research based on inaccurate data and assessments may never allow researchers to know the full impact ethnic identity has on the psyche of these Mexican heritage individuals. This particular discourse has prompted Umaña-Taylor et al. (2004), to offer these thoughts in regards to questions of identity,

Because individuals are influenced by (and influence) their surroundings, and because these surroundings are constantly evolving, it is important to think of ethnic identity as a process that is continuous throughout the life course, as opposed to something that become "achieved" never to be explored again (p. 57).

\section{Studies on Mexican American and Hispanic/Latino College Students}

\section{Mexican American College Students}

In the following studies, the researchers assumed the USB Mexican as being the same as their immigrant counterparts by using mixed sample combinations of both populations in their studies on "Mexican American" college student behavior (Canul \& Cross, 1994; Chavez, 2007; Devos, 2006). When differences between the two groups were found, they were discarded because the bicultural sample (USB) size was too small (Canul \& Cross, 1994), would identify as predicted (Devos, 2006), or the differences were from a possible sampling error (Chavez, 2007).

This study by Matheny, Roque-Tovar, \& Curlette (2008) explored perceived stress, coping resources, and life satisfaction in a cross-cultural study between U.S. and Mexican college students. Citing Diaz-Guerrero (1994) who noted no other two nations in the world have had so many comparative studies conducted between them, the 
researchers discovered the literature did not include comparisons of U.S. and Mexican college students. The sample population consisted of 206 Mexican college students (41 males, 165 females) and 241 U.S. college students (69 males, 172 females). Three measurement survey tests were given to the participants to complete: Perceived Stress Scale (PSS), the Coping Resources Inventory for Stress (CRIS), and the Satisfaction with Life Scale (SWLS), which were translated into Spanish and then translated back into English for analysis.

The inclusion of this study in this review of literature is to illustrate as Matheny, Roque-Tovar, \& Curlette discovered in the literature, the lack of cross-cultural studies between U.S. and Mexican college students also translate into a lack of studies in the literature exploring cross-culture within-group differences between USB Mexican college students and Mexican-born or immigrant Mexican college students in the U.S.

These studies are examined to show why their results are questionable. Coker, Sanderson, Cantu, Huerta, \& Fadden (2008) studied the frequency and types of partner violence among 187 "Mexican American" college females aged 18-35 from the Texas border region. Interviews took place over the telephone because student counselors felt honest answers would be more forthcoming than face-to-face interviews. The instruments used to obtain the data were an 11-item revised Conflict Tactics Scale (CTS) structured questionnaire addressing physical violence; a modified version of the Women's' Experience with Battering Scale (WEB); 4 items from the Sexual Experience Survey (SES); 4 items from National Violence Against Women Survey (NVAWS); and 11 items from the Psychological Maltreatment of Woman Inventory (PMWI). 
The findings of the study revealed $43 \%$ of the sample experienced some type of physical violence in the 12-month period before the survey. The researchers felt the findings were significant for college populations because of the proportion of the population sample who experienced physical violence was high, and the majority of the violence $(51 \%)$ was directed at single women. This study illustrates how research which claims to be on Mexican Americans, is really on Mexican-origin individuals as noted by the authors purpose of the study, "to estimate the frequency of physical violence among Mexican or Mexican American women attending college along the Texas-Mexico border (p. 667)."

Without defining what a "Mexican American" is, the researchers clearly are aware of differences between individuals of Mexican descent attending college in their sample. If they were not, there was no need to distinguish between Mexican and Mexican American. The aim of the study was to produce data for interventions among this Mexican American college population. If by their own admission the data includes two distinct populations, how effective would recommended interventions be considering the responses on the instruments were from individuals with different worldviews, identities, and values?

Acculturative stress, social support, coping, and their relationship to psychological adjustment are the focus of Crockett et al. (2007). In a sample of 148 Mexican American college students, the researchers examined the relations these variables had on their sample population. Two Texas and one California state universities were part of the study and participants were restricted to "Mexican or Mexican American origin or descent" between the ages of $18-30$ (p. 349). The majority ( $83 \%)$ was born in 
the U.S., with nearly three quarters $(68 \%)$ of the sample 2 nd generation. The measuring instruments used were a modified version of the Short Acculturation Scale for Hispanics; the Social, Attitudinal, Familial and Environmental Acculturative Stress Scale; the parent and peer scales from the Network of Relationships Inventory; a shortened version of the COPE inventory (a survey instrument developed to assess various coping responses); and the 21-item Beck Anxiety Inventory. The primary analyses were a series of multiple regression procedures for each dependent variable.

The data analysis resulted in the following conclusions, a) acculturative stress was associated with higher levels of anxiety and depressive symptoms; b) active coping was associated with lower depression; c) interaction effects indicated parental support and active coping buffered the effects of high acculturative stress on anxiety and depressive symptoms; d) peer support moderated acculturative and anxiety symptoms. Crockett et al. compared their findings to those of previous studies and found acculturative stress has similar detrimental effects among Mexican heritage college students. As they suggest, more study is needed on understanding the relationships between acculturative stress, anxiety, depression, and academic performance. The authors also feel the available evidence suggests depression and anxiety may have different effects on Latino college students academic performance.

Their suggestions are correct, but require more precision in sample populations. As their results concluded, acculturative stress was associated with higher levels of anxiety and depression. As they also concluded, parental support and peers helped alleviate or buffer these symptoms. But, are these findings the same if they were performed on multigenerational USB Mexican heritage or other USB Latino subgroups? 
Would the levels of stress, anxiety, and depression rise, lessen, or remain static? Would the immigrant contingent of Mexican college students experience more than the USB because of their immigrant status? These are questions, which cannot be answered when using samples of two distinct populations as they have in their study.

Miville \& Constantine (2006) sought to understand why Mexican American college students underutilized mental health services which has been cited by multicultural scholars as a problem in regards to the overall health of this college population. Among the sociocultural issues Miville \& Constantine give as reasons for the underutilization of mental health services are acculturation, language barriers, social support, access to services, and finances. Their study therefore, used sociocultural variables such as acculturation, enculturation, cultural congruity, and perceived social support to serve as predictors for determining the psychological help-seeking attitudes and behaviors of 162 Mexican American college students.

The researchers were vague on the sample population as to the origin of their participants. Did Mexican American mean anyone of Mexican descent native, documented, or not, residing in the United States? The only information given was the students were undergraduate from a large "White" university in the southwest, of which 103 were female, 59 were male, and averaged 19.56 years of age. Instrumentation used was the Stephenson Multigroup Acculturation Scale (SMAS); the Cultural Congruity Scale (CCS); the Multidimensional Scale of Perceived Support (MSPSS); and the Attitudes Toward Seeking Professional Psychological Help-Scale Short Form (ATSPPHS-S). 
Multivariate multiple regression analysis indicated the factors tested were significant predictors of positive help-seeking attitudes. Another finding was higher acculturation, lower perceived support from family, and lower perceived support from friends were also predictors of help-seeking behavior. As the authors suggest, higher acculturation in previous studies has been proven to be a key concept in help-seeking attitudes among Latinos. If this is indeed the case, understanding the problem of underutilization of mental health services by Mexican-origin college students, would need a separate measurement between the USB and the immigrant students in order to ascertain at what point of acculturation or assimilation they do seek mental health services on campus.

Andalón (2005) is a qualitative dissertation examining the risk and success factors that impede Mexican Americans access to higher education and provides an in-depth view that explores the life histories of five male and five female who succeeded in attending a University. Grounded theory and a literature based conceptual framework are the methods that were used for analysis. Upon further review however, the population sample consisted of six USB ( 3 female and 3 male), and 4 immigrant ( 2 female and 2 male) Mexican individuals who he defined as Mexican American. Exploring the psychosocial dynamic the participants discussed their self-concepts, feelings of having to prove themselves, and how they rely on faith and spirituality. Unfortunately, because of the different worldviews involved and the mixed sample, the study is not about addressing psychosocial challenges of USB Mexican college students, but rather Mexican-origin college students as a whole. 
These few examples are by no means a trend of a slowing down of studies on describing mixed sample immigrant and USB Mexican-origin college student populations as Mexican American. A brief look at the academic literature conducted while this dissertation was being edited, studies by McGinley, Carlo, Crockett, Raffaelli, Torres Stone, \& Iturbide (2010); Moilanen \& Raffaelli, (2010); Vuong, Brown-Welty, \& Tracz, (2010); Wallace, Pomery, Latimer (2010); Warren, Castillo, \& Greaves (2010), revealed researchers continue to assume there are no within-group differences between USB and immigrant Mexican college students worth exploring.

\section{Hispanic/Latino College Students}

The literature is filled with articles and studies on Hispanic/Latino college student experiences (Aguirre, 2009; Bensimon \& Dowd, 2009; Gonyea, 2010; Harris \& Tienda, 2010; Robles, 2009; Santiago, 2009; Yosso, Smith, Ceja, \& Solórzano, 2009). However informative and well done this literature may be, it contributes nothing to lessening the effect of subsuming the USB Mexican and any psychosocial challenges they may be experiencing in college. The following four studies are examples as to why the needs of USB Mexican heritage multigeneration college students may not be addressed.

Castillo, Cano, Chen, Blucker, \& Olds, (2008) examined the impact of family conflict and intragroup marginalization on acculturative stress in a sample of 188 undergraduate bicultural Latino college students. While their premise was correct that intragroup marginalization and family conflict are acculturative stressors in Latino students, very little consideration was given to understanding if one subgroup under the Latino category may have different stressors than another. In their limitation discussion 
they acknowledged graduate students might experience acculturative stress differently than the undergraduates, but did not consider what role acculturated stress if any, would have on the $45 \%$ of the sample that were immigrants, or the majority of the sample that was third generation or less. Left unanswered in the study was how each succeeding generation would experience acculturative stress... less, more, differently, or not at all.

Arbona \& Nora (2007) used participants from the National Educational Longitudinal Study of 1988 , which collected data from a nationally representative sample of eighth graders $(26,432$ students) in the spring of 1988 , with additional follow-up data surveys conducted in the years 1990, 1992, 1994, and 2000. Only Hispanic students who participated in the NELS of 1988-2000 and who enrolled in either a community college (517) or a four-year college (408) in 1992 or early 1993 were included in the study. The reason for the study say the authors, is because even as a larger portion of Hispanics gain access to higher education, they have a lower graduating rate (10\%) then African American (18\%), or White populations (34\%) of the United States as of the year 2000. The focus of the study was to examine characteristics believed to impact persistence and degree attainment in relation to Hispanic high school graduates.

As noted throughout this literature review and dissertation study, no true measurement can be accomplished using mixed samples of immigrant and USB Mexican-origin or others under the Hispanic/Latino category because it has been shown the USB and immigrants students measure differently in regards to persistence and other factors involved in K-16 and degree attainment (Ogbu, 1978; Matute-Bianchi, 1986; Padilla, 2001). Some studies such as Castillo, Conoley, Choi-Person, Archuleta, Phoummarath, \& Landingham (2006) give no exact breakdown of the Latino sub-groups 
involved, nor whether the sample includes both native and immigrant participants. Yet, the purpose of their study is to analyze how the university environment can serve as a mediator of Latino ethnic identity and persistence in a predominately "White" university.

The author's proclaim models of student retention along with recent studies suggest noncognitive factors (e.g., social, environmental, interpersonal) help explain Latino persistence in college. There were 180 respondents to their survey representing $23 \%$ of the Hispanic/Latino undergraduate population on campus. Ascertaining whether these students were USB or immigrant were significant variables to consider in this study because some studies have suggested immigrant students outperform USB students academically (Rumbaut, 1995; Fuligni, 2001). While Ogbu (1978), Matute-Bianchi (1986), Padilla (2001), and others, have found immigrant Mexican heritage students outperform USB Mexicans. Thus, if not accounted for in the research on persistence, these additional factors would corrupt the results.

\section{Should Latino Groups Be Studied Separately}

The theoretical development and research on groups of color in the United States has been useful in exploring cultural diversity but has not gone far enough in looking at the differences within major ethnic identity groups. Since the research continues to be homogenized or ethnically glossed, there are some students of color whose questioning of their identity will be a lifelong endeavor simply because research for the most part, has failed to acknowledge some ethnic groups have more diversity within the group, than across the group. 
Examining the merits of separating ethnic groups in studies, Delgado-Romero et al. (2005) reviewed 739 empirical studies, which appeared in the Journal of Counseling Psychology, the Journal of Counseling and Development, and The Counseling Psychologist in the period 1990-1999, and they discovered, only 457 (57\%) reported racial and ethnic characteristics of research participants. Of the participants studied, 78.2\% were White, 5.8\% were Asian American, 6.7\% were African American, 6.6\% were Hispanic, $0.9 \%$ were Native-American, and $0.1 \%$ were multiracial (p. 434). They also subsequently discovered there was little information about how researchers obtained participants' race and ethnic information and how factors such as racial and ethnic identity, multigeneration, and acculturation, might explain the participants lived experiences.

Their conclusions after the review were: (a) There was a lack of standardizations regarding definitions and operating procedures for the assessment and categorization of race and ethnicity along with non-inclusiveness of racial or ethnic minority participants; (b) the use of self-reporting demographic questionnaires was limited and did not allow the participants to "address the salience, centrality, or meaning" of race or ethnicity; and (c) the empirical research in the three journals discussed in the review did not "fully reflect the conceptual and theoretical literature regarding race and ethnicity (p. 443)." In their closing comments the authors' stated there was a need to replace complacency with commitment in the study of racial and ethnic minority issues, and move toward constructs which truly reflect the complex nature of culture and ethnicity, and its relationship to psychology. 
Umaña-Taylor \& Fine (2001) also concur with the separating of ethnic groups in ethnic identity research. Their study examined the ramifications of grouping Latinos into one homogenous population and then measuring their ethnic identity, self-esteem, emotional autonomy, and familial ethnic socialization. By using the following measurement instruments: Phinney's Multigroup Ethnic Identity Measure (MEIM), Rosenberg's Self-Esteem Scale (SES), Steinberg and Silverberg's Emotional Autonomy Measure, and Umaña-Taylor's Familial Ethnic Socialization Measure (FESM), among 1,176 Puerto Rican, Mexican, Honduran, Columbian, Guatemalan, Nicaraguan, and Salvadoran adolescents living in the United States, they were able to show discrepancies among these populations.

Additional discrepancies were found in the MEIM and FESM in terms of the concurrent validity as the results varied among the Latino groups. The authors' believe these findings provide evidence the grouping of all Latinos for research purposes is likely to affect the reliability and validity of instruments because of the diversity of the Latino population. For this reason, they feel despite the limitations of their study (small size of certain Latino sub-groups measured), there is a need to look beyond "the pan-ethnic Latino group and examine individual nationalities (p. 360)."

In a later study by Umaña-Taylor \& Fine (2004) on ethnic identity research has them questioning why researchers, while acknowledging the importance of ethnic identity during adolescence, few empirically examine it past childhood. Moreover, because researchers from various disciplines have studied ethnic identity among adolescents, there are differing conceptualizations of it. In their review, the authors looked at research utilizing the identity formation perspective as postulated by Erikson 
(1968) and Marcia (1980) because they believed it was the best lense in understanding ethnic identity from a developmental framework.

It is their belief however, this approach poses a three-fold problem for the study of Latinos because: (1) Most of the studies have focused on the inclusiveness of an "all Latino" identity and arriving at generalizations for the Latinos as a "whole," instead of identifying the numerous distinctions among the Latino populations; (2) the continual focus on examining the link of ethnic identity achievement and their psychological health, instead of looking at other factors in the adolescents development "that are most critical for ethnic identity formation;" and (3) the need to explore other aspects within adolescent development which "may provide valuable information concerning differences within ethnic groups (p. 39)." They conclude by stating, individual's lives are full of multiple contexts and their identities develop because of their interactions with these contexts. For this reason, the authors' suggest in regards to ethnic identity, it is best to think of it "as a process that is continuous throughout the life course, as opposed to something that becomes 'achieved,' never to be explored again (p. 57)."

\section{Summary of Literature Review}

The review of the literature supports the contention of the author of this study that the redundancy of research on Latinos and Mexican heritage individuals from an immigrant perspective continues to subsume the most numerous segment $(59.5 \%$ are U.S.-born, 40.5\% are immigrant) within the Mexican heritage population of the United States, the U.S.-born (USB) Mexican individual (NCES, 2010, Table 2b). Any attempt to explore psychosocial and identity challenges of multigenerational native-born Mexican heritage college students and identify problems and concerns in their transitioning to 
college using past research would be laborious and might not accurately describe this population because very little data is available, the sample population might be imprecise, and the research could be ethnically glossed (Trimble, 1991).

For example, in the study on acculturative stress by Crockett et al. (2007) acculturative stress was associated with higher levels of anxiety and depression. But, are these findings the same if they are performed on multigenerational USB Mexican heritage or other USB Latino sub-groups? Would the levels of stress, anxiety, and depression rise, lessen, or remain static? Would the immigrant contingent of Mexican college students experience more than the USB because of their immigrant status? These are questions, which cannot be answered when using samples of two distinct populations. Miville \& Constantine (2006) assert higher acculturation is a key concept among Latino college students utilizing mental health service facilities, but fail to measure separately in their study, the USB and the immigrant Mexican students in order to ascertain at what point of acculturation or assimilation these individuals do seek out the mental health services on campus.

Tsai et al. (2000) revealed certain attributes within cultures are culture specific. They feel if individuals differ in their experiences of being of a particular culture, then their responses to acculturation and ethnic identity instruments may have different meanings. If correct, these results raise questions about previous research on ethnic minorities, which assumes cultural group meanings are similar for all individuals within a cultural group. Additionally, if Tsai et al. assumptions on traits and behaviors being culture specific are correct, the possibility exists that the cultural values of sub-groups within cultural groups, are also culture specific. This would also raise questions about 
previous research on ethnic minority populations, in particular among Latinos, because of the various sub-groups within the ethnic group.

Other literature reviewed for this proposal, has undoubtedly shown evidence USB students of Mexican descent have different identity perceptions and experiences than immigrant students (Chavez, 2007; Coker et al., 2008; Niemann et al., 1999; UmañaTaylor et al., 2001). While each USB faces challenges unique to their generational status in the U. S., the $3^{\text {rd }}$ generation and beyond (3GAB) must contend at times with challenges in bi-directional modes. For example, the $3 \mathrm{GAB}$ has to overcome not only the perception of being an immigrant to U.S. mainstream society (due to stereotypes), but also defend and prove their “Mexicaness" as explained by Jimenez (2008),

Mexican immigrants define "authentic" Mexican ethnicity, and Mexican Americans (italics mine) are treated as ethnic outsiders when they are unable to live up to the criteria for group membership that co-ethnics impose (p. 5).

In their school experience, the $3 \mathrm{GAB}$ must also overcome possible "mental withdrawal." Mental withdrawal is a condition illuminated by Carter (1970) and cited by Ogbu (1978), in which Mexican-American (as the USB was labeled in the study) students become bored with the school curriculum and tune-out or shutdown mentally in class. In Ogbu's observations of these USB school children he described the repercussions,

According to all reports gathered in the field, "mental withdrawal," manifests in boredom, failure to work, inattentiveness, and discipline problems, and begins sometime from the third grade to the sixth grade (p. 221).

For the present $3 \mathrm{GAB}$, mental withdrawal could be a result of academic neglect (ChavezReyes, 2010b). Which is caused by: (a) schools prioritizing the linguistic and sociocultural needs of the $1^{\text {st }}$ and $2^{\text {nd }}$ generation first; (b) school officials misidentifying 
the $3 \mathrm{GAB}$ as immigrant and placing them on the wrong academic track; and (c) allowing the $3 \mathrm{GAB}$ to graduate "with little or no direction about how to enter the world of work or higher education (Chavez-Reyes, n.d., p. 4)." The Generatıonal Comparıson Chart (Table 1) illustrates some of the differences from the $1^{\text {st }}$ through $3^{\text {rd }}$ generation and beyond.

Table 1.

Generational Comparison Chart

\begin{tabular}{|c|c|c|}
\hline $1^{\text {st }}$ Generation & $2^{\text {nd }}$ Generation & $3 \mathrm{GAB}$ \\
\hline $\begin{array}{l}\text { Lived Expenence }= \\
\text { Different Worldview }\end{array}$ & $\begin{array}{l}\text { Lived Expenence }= \\
\text { Different Worldview }\end{array}$ & $\begin{array}{l}\text { Lived Experience }= \\
\text { Different Worldview }\end{array}$ \\
\hline $\begin{array}{l}\text { Leaving Homeland } \\
\text { "Immigrant Experience" }\end{array}$ & $\begin{array}{l}\text { Defending Being American }> \\
\text { "Immigrant Perception" }\end{array}$ & $\begin{array}{l}\text { Defending Being American > } \\
\text { "Immigrant Perception" }\end{array}$ \\
\hline $\begin{array}{l}\text { Finding Shelter/ } \\
\text { Source of Income }\end{array}$ & $\begin{array}{l}\text { Possible Home "Culture } \\
\text { Clash" Old vs New }\end{array}$ & $\begin{array}{c}<\text { Defending Being Mexican } \\
\text { "Mexicaness" } \\
\text { (Duarte, 2008, Jimenez, 2008) }\end{array}$ \\
\hline $\begin{array}{l}\text { Language Barriers }> \\
\text { (Spanısh Only) }\end{array}$ & $\begin{array}{c}\text { Possible Language Barriers }> \\
\text { (ESL) }\end{array}$ & $\begin{array}{l}<\text { Possible Language Barriers } \\
\text { (English Only) }\end{array}$ \\
\hline $\begin{array}{l}\text { Adjusting to New Life, } \\
\text { Loneliness, etc. }\end{array}$ & $\begin{array}{c}\text { Feel Comfortable Among } \\
\text { Their Own } \\
\text { (Brown, 2007, Duarte, 2008) }\end{array}$ & $\begin{array}{c}<\text { Pressure to Only Associate } \\
\text { Among Their Own } \\
\text { (Chavez-Reyes, 2010a) }\end{array}$ \\
\hline Acceptance > & Acceptance > & $<$ Acceptance $>$ \\
\hline $\begin{array}{c}\text { Apprehension of ICE/ } \\
\text { Government/Police Officials } \\
\text { (Niemann et al , 1999) }\end{array}$ & $\begin{array}{l}\text { Possible Apprehension of } \\
\text { ICE/Government/Police } \\
\text { Officials }\end{array}$ & $\begin{array}{l}\text { "They All Look Alıke" } \\
\text { Possible Racial Profilıng } \\
\text { (Ochoa, 2000, Chavez-Reyes, } \\
\text { 2010a) }\end{array}$ \\
\hline School Experience & School Experience & School Experience \\
\hline $\begin{array}{l}\text { Navigating School Culture } \\
\text { w/o Parental Assistance Due } \\
\text { to Language Barriers or } \\
\text { Limited Education } \\
\text { (Valenzuela, 1996) } \\
\text { Greater Academic Success } \\
\text { Than USB } \\
\text { (Matute-B1anch, 1986, } \\
\text { Ogbu, 1978, Padilla, 2001) }\end{array}$ & $\begin{array}{l}\text { Navigating School Culture } \\
\text { w/o Parental Assistance Due } \\
\text { to Possible Language } \\
\text { Barmers or Limited } \\
\text { Education } \\
\text { (Valenzuela, 1996) } \\
\text { Greater Academic Success } \\
\text { Than 3GAB } \\
\text { (Chavez-Reyes, 2010b, } \\
\text { Pew, 2009) }\end{array}$ & $\begin{array}{c}<\text { Neglected Students }= \\
\text { Not Prepared For College } \\
\text { Curriculum } \\
\text { (Chavez-Reyes, 2010b, } \\
\text { Valenzuela, 1996) } \\
<\text { Possible } \\
\text { Mental Withdrawal }> \\
\text { (Carter, 1970, Ogbu, 1978) } \\
<\text { Less Academic Success } \\
\text { Than } 1^{\text {st }} \& 2^{\text {nd }} \text { Generation } \\
\text { (Chavez-Reyes, 2010b, Pew, 2009) }\end{array}$ \\
\hline
\end{tabular}


Additionally, Table 1 highlights other challenges faced by the 3GAB Mexican including pressure from $1^{\text {st }}$ and $2^{\text {nd }}$ generation Mexican and Latinos to associate exclusively within their ethnic group, because the $3 \mathrm{GAB}$ has learned to navigate relationships with co-ethnics and Euro Americans in spite "of prejudice, in-group pressure, and racial tensions" through what Kim (2006) as cited in Chavez-Reyes (2010a) has termed "interethnic identity,"

Interethnic identity emerges when individuals encounter members of other cultures, the contact creates stress, which leads to a negotiation of identity to adapt to the new environment (p. 512).

In relation to the pressure of associating only within their own ethnic group, the $3 \mathrm{GAB}$ also seeks acceptance bi-directionally from the 1st - 2nd generation and U.S. mainstream society. And while immigrant and earlier generation Mexican college students maybe apprehensive about Immigration \& Custom Enforcement, or other federal and local government officials (Niemann et al., 1999), the 3GAB Mexican college student may become a victim of racial profiling because of similar ethnic appearance and features among the Mexican-origin populations (Ochoa, 2000; Chavez-Reyes, 2010a).

With such a large number of college students of Mexican heritage in border states, the numbers growing in the Pacific Northwest, and multigenerational USB Mexican enclaves in states such as Utah, Minnesota, Nebraska, Kansas, Michigan, and Illinois placing $4^{\text {th }}$ (only 55,265$)$ behind Arizona for $3^{\text {rd }}$ most populated Mexican-origin state in the country (United States Census, 2011. The Hispanic Population: 2010 Census Briefs), not to mention newer migration patterns throughout the Southeast and along the Eastern Seaboard, few studies have looked at possible differences based on multigenerational 
(beyond 2nd generation) status or other demographic variables such as place of birth, and community of residence.

The continual focus of research on Mexican immigrants and their assimilation process says Chavez-Reyes (2010b) "obscures" viewing and learning about 3GAB Mexicans, "who have rich, long, and affirmative histories as Americans and whose lives and experiences describe an established racial, ethnic, and class identity unique to them (p. 23)." By widening that focus to include the 3GAB-USB Mexican, researchers could not only augment data collection, but also allow for more precision when researching Mexican heritage college students of the United States, addressing some of the structural and methodological concerns illuminated in this chapter.

Lastly, if the intention of studies on ethnic groups is to gain knowledge and arrive at solutions to problems faced by these groups, researchers should consider two questions before embarking on studies involving not only ethnic groups, but all population groups: (1) Is the worldview, belief system, values, and language, similar enough to justify labeling them as one whole sample population in research; and (2) if there are major differences within the studied group, why are they not accounted for in the research? 


\section{CHAPTER 3}

\section{RESEARCH DESIGN AND METHODOLOGY}

Selection of appropriate methods is an act of judgment that may be undertaken privately but must be justified and explained publicly.

Richard M. Jaeger (2005)

This study was designed to focus on the sample participants lived experiences and to listen and understand the reality of those experiences, in order to create a foundation on which to proceed in future research with the $3^{\text {rd }}$ generation and beyond U.S-born (3GAB-USB) Mexican heritage college student and arrive at recommendations, which might be useful for this U.S. multigenerational population in their transition to college. The original intention of this study, was to obtain the sample population of 3GAB-USB Mexican heritage college students from within two predominately Caucasian private universities in the City of San Diego because previous research conducted by Crockett et al. (2007), Gloria et al. (2005), McGinley, Carlo, Crockett, Raffaelli, Torres Stone, \& Iturbide (2010) and others, had illuminated indifferent and sometimes unfriendly university environments at predominately Caucasian institutions were a contributing factor to the psychosocial challenges experienced by Mexican and other Latino heritage college students on those campuses.

However, because of the difficulty obtaining a population sample from universities that matched the exact study criteria, the sample pool was opened to community college participants. As a result, the nine final sample participants consisted of four community college students, and five university students. ${ }^{11}$ An additional benefit

\footnotetext{
${ }^{11}$ While searching for themes during the data analysis process, it was discovered that eight of the nine participants had or were attending Hispanic Serving Institutions (HSI) at the community college level. This
} 
derived from the deviation of the study, was instead of a regional response, the opinions expressed from the participants would be from three regions of California: Los Angeles, the San Francisco Bay Area, and San Diego. Once the parameters of the study were readjusted, the study continued on its course of examining facets such as school experience, social support, discrimination, and self-labeling, the latter illuminating whether or not the self-label helped or hindered their ethnic identity.

Literature reviewed for the present study clearly showed evidence 3GAB-USB students of Mexican descent have different identity perceptions and experiences than immigrant Mexican students (Alvarez, 1973; Holloway-Friesen, 2008; Niemann et al., (1999); Roosa et al., 2008; Umaña-Taylor et al., 2001) In spite of this, very few studies have looked at within-group animosity, differing worldviews, and other possible differences based on multigenerational status, or other demographic variables such as place of birth, and community of residence.

\section{Research Design}

While conducting literature reviews on Mexican heritage individuals, it became apparent my dissertation would not be a quantitative study because of the dearth of accurate information on $3 \mathrm{GAB}-\mathrm{USB}$ Mexican heritage individuals in the academic literature. It is my belief one cannot quantify what one knows nothing about. Filled with

\footnotetext{
discovery posed a major problem for the study, because the responses during the interviews from the participants expressed a very nurturing and welcoming environment contradicting the literature reviewed and the original intention of the study - which was to learn about the 3GAB-USB at institutions that were indifferent to Mexican or Latino students. This dilemma was justified threefold: (1) Although eight of the nine participants had attended schools at the community college level they described as very nurturing, other psychosocial challenges still existed; (2) the fact these students attend or attended an HSI should not be seen as a detriment to the study because unlike Historic Black Colleges and Universities, where some of these institutions have developed solid academic reputations and attract students because of their academic record, many Mexican or Latino students attend college in close proximity to their home as illuminated by Santiago (2007a, p. 3) who declares, "Latino students' college choices create HSI's;" and (3) the sample population presented a unique situation according to the academic literature on Mexican-origin college student experiences - to learn about a disaggregated positive school experience and observe the results.
} 
over a half century of lived experience as a $3^{\text {rd }}$ generation USB Mexican individual, I had no empirical data to address social ills which I knew existed, but had never been resolved among my specific ethnic population. It was with this understanding that my research plan and design would have to begin from the ground up.

When little is known about a topic, a qualitative approach instead of quantitative inquiry is often desirable because it allows the researcher to ask broader questions and then refine them during the interview process as themes begin to emerge (Patten, 2004). Long favored in anthropology, sociology, and clinical psychology, qualitative research has gained prominence and acceptance within the last two-plus decades among researchers as an alternative to the more traditional quantitative method of analysis (Merriam \& Associates, 2002). Reviewing research methods literature, but in particular the works of Creswell (2003); Geertz, (1973); Jaeger (2005); Marshall \& Rossman (1999); Merriam \& Associates (2002); Patten (2004); Spradley (1979); and Van Manen (1990), provided a variety of opinions on the merits of the use of qualitative vs. quantitative research methods.

Creswell (2003) describes the characteristics of qualitative inquiry as the usage of multiple methods that are interactive and humanistic; take place in a natural setting; are emergent rather than tightly configured; are fundamentally interpretive; holistically centered; reflexive, because the researcher constantly reflects on his or her role and how it shapes the study; and the complex reasoning used by the researcher is multifaceted, iterative, and simultaneous (p. 182). Marshall \& Rossman (1999) stipulate qualitative research can be streamlined into three genres: (1) individual lived experiences; (2) society and culture; and (3) language and communication. Once the genre is selected, the unique 
strengths of it can be used to narrow the focus of inquiry, and the strategy to be used in research (p. 60). For example, if a study's focus were on the lived experience of an individual(s), the use of an "in-depth strategy" would be appropriate because it would illuminate the individuals experience in their own words. In Table 2, the author's illustrate how the genre, strategy, and focus of inquiry are linked.

Table 2.

Qualitative Genre and Overall Strategy ${ }^{12}$

\begin{tabular}{ccc}
\hline Genre & Strategy & Focus of Inquiry \\
\hline Individual lived experiences & In-depth interviews & Individuals \\
Society and Culture & Case study & Groups or organizations \\
Language and communication & Microanalysis & Speech events and interaction \\
\hline
\end{tabular}

Merriam \& Associates (2002) explain there are many types of qualitative research, but cite the work of Denzin \& Lincoln (2000) for narrowing the field to a manageable eight strategies in which qualitative research can be conducted: case study, ethnography, phenomenology, grounded theory, biographical, historical, participatory, and clinical. Listed below are explanations of the author's own eight variations:

1. Basic Interpretive Qualitative Study. In conducting this type of study, the researcher wishes to understand how study participants make meaning of their world by acquiring data through interviews and observations, or documented analysis. The data is then "inductively analyzed to identify recurring patterns or themes that cut across the data," resulting in a rich descriptive account by the use of the narratives collected (p. 6).

\footnotetext{
${ }^{12}$ From Designing Qualitative Research $3^{\text {rd }}$ ed. (p. 61), by C. Marshall and G.B. Rossman, 1999, Thousand Oaks, CA: Sage Publications, Inc. Copyright 1999 by Sage Publications, Inc. Reprinted with permission.
} 
2. Phenomenology. The defining characteristic of this type of research is the focus of "describing the 'essence' of a phenomenon from the perspectives of those who have experienced it (p. 93)." Van Manen (1990) defines it as the study of lived experience, or the human scientific study of phenomena, in which, researchers attempt to describe and interpret these meanings to a certain degree of depth and richness, by explicating "the meanings as we live them in our everyday existence, our lifeworld (p. 11)."

3. Grounded Theory. Grounded theory is the discovery of theory from data, where the constant comparison of the data, allows the theory to emerge. It is a systematic approach of data collection, note taking, coding, memoing, sorting, and writing. "Unlike hypotheses in experimental studies, grounded theory hypothesis, are tentative and suggestive rather than tested (p. 8)."

4. Case Study. Citing Stake (1995) and Merriam (1998), a case study is defined as "an intensive description and analysis of a phenomenon or social unit such as an individual, group, institution or community (p. 8)." With the emphasis on just the "case," the exploration of it is more in depth.

5. Ethnographic Study. Originally developed by anthropologists to study human society and culture by collecting data through interviews and observation in the field over a period of time, "for a qualitative study to be an ethnography, it must present a sociocultural interpretation of the data" through the use of the data collected (p. 9).

6. Narrative Analysis. This type of a qualitative strategy uses a first person account of their experience as data to retell their stories. Autobiographies, biographies, and life histories, are some examples of narrative analysis. 
7. Critical Qualitative Research. A critical qualitative approach "uncovers, examines, and critiques the social, cultural, and psychological assumptions that structure and limit our ways of thinking and being in the world," by focusing less on individuals than on context. According to the author, this type of inquiry can raise questions about the influence of race, class, and gender, along with questions associated with power structures and how they may advance one group while oppressing another, the nature of truth, and the construction of knowledge (p. 9).

8. Postmodern Research. This newer qualitative approach challenges the universal norms of truth and morality by assuming "there are many truths, and all generalizations, hierarchies, typologies, and binaries (good/bad, right/wrong, male/female, etc.) are 'contested,' 'troubled,' or 'challenged (p. 10)."

After reviewing and considering three of the eight described qualitative strategies (Phenomenology, Narrative Analysis, Basic Interpretive), the following strategies were ruled out:

Phenomenology - while attempting to learn about the lived experiences of the study participants, the research focus was not about understanding the "essence" of their human experience or "of gaining a deeper understanding of the nature or meaning of everyday experiences (Van Manen, 1990, p. 9)." Grounded Theory - the study was not based on any theory because the purpose was about introducing into the literature, a subsumed population on which future research and development of theories could proceed. Case Study - an intensive deeper analysis of the participants was not the focus of the study, the topic was (Merriam \& Associates, 2002). Ethnography - bounded by time constraints, obtaining and collecting data over a period of time was not feasible. 
Narrative Analysis - the intention of the study was not to gather information and retell in a narrative chronology (Creswell, 2003). Critical Qualitative Research - the study was not about "empowering," the participants toward any action, or a critique of power structures. It was about learning about the participants "life" experiences through college. Postmodern Research - the study was also not about challenging universal norms on truth and morality.

Recalling the Marshall \& Rossman (1999) approach of linking the qualitative genre (individual lived experiences); to the focus of inquiry (individual); then the strategy (in-depth interview); and "rather than approaching the research task with preconceived notions based on published theory and research (Patten, 2004, p. 19)," a basic interpretive and descriptive qualitative research design was selected. Since little was known about the sample population, and the study was to begin at the most basic level, this design presented the best fit for my study. As outlined above in the eight qualitative design variations, when conducting a basic qualitative study, the researcher is seeking "to discover and understand a phenomenon, a process, the perspectives and worldviews of the people involved, or a combination of these" by acquiring data through interviews and observations, or documented analysis. The data is then "inductively analyzed to identify recurring patterns or themes that cut across the data," resulting in a rich descriptive account by the use of the narratives collected (Merriam \& Associates, 2002, p. 6).

Consequently the aim of this study, was to listen to what participants had to say about themselves in relationship to their identity development, their lived experience through the life cycle, and to learn about the reality of their life (not one perceived or conjured by the researcher), without the use of measuring instruments which were 
designed for other populations and then adapted to fit whichever ethnic group is being researched. The basis of the study was designed to answer the principal research question: "What are the unique psychosocial and identity challenges of $3^{\text {rd }}$ generation and beyond U.S.-born (3GAB-USB) college students of Mexican heritage?" Additional answers were elicited for the following sub-questions:

1. How do members of this population identify themselves?

2. How does this self-identification help/hinder their ethnic identity?

3. How does the perception of others influence this self-identification?

4. What specific challenges do 3GAB-USB college students of Mexican heritage experience in their transition to college?

The study was also designed to invite the sample participant's input. Before the interview began, the participants were told the interview would be transcribed and sent to them for review. Whereupon, they had the opportunity to edit their answers by deleting or adding to the content of the interview, make recommendations, and offer suggestions.

\section{Research Participants}

The parameters for the sample population were adjusted four times during the nine-month recruitment phase. The original participants were to be recruited from two private predominately Caucasian universities within the City of San Diego. Having made contact with the Directors of both Multicultural Centers at their respective campuses, one took a "hands on" approach and attempted to recruit from her Center. After two months, she was unable to find participants who met the very specific and limited criteria of the study's original population sample: (1) ten 3GAB-USB individuals of Mexican heritage who were juniors and seniors; (2) individuals had to be USB and of Mexican heritage, (3) 
the parents had to be USB and of Mexican heritage, and (4) the grandparents also had to be of Mexican heritage. At the other campus, having exchanged electronic mail various times with the Multicultural Center Director, I followed the director's suggestions and went to visit the Ethnic Studies office, requesting and receiving permission to post a flyer (Appendix D) on their bulletin board. I also attempted contact with a few Latino/Mexican organizations on campus, and with the exception of one organization, there was no response.

Unable to find any sample participants at these institutions, the sample pool was then opened to all universities in San Diego County. A website search of all student organizations on the campuses was conducted and a recruitment electronic mail letter (Appendix F) was sent to over sixty-four organizations throughout the San Diego campuses. Quite a few had incorrect or non-existent contact links. Eight organizations responded, were positive in their remarks about the study, and agreed to help recruit. Within the week, there were four inquiries from students. Unfortunately, they did not meet the criteria, but wanted to know more about the study, and also agreed to recruit. A few days later, two students contacted me, met all the requirements of the study, and agreed to participate. It took an additional four months to conduct the interviews.

While waiting to conduct the two interviews, the parameters of the study population were changed a third time. The decision was made to recruit universities from Los Angeles and San Bernardino County. Once again, correspondence was sent over electronic mail to student organizations at three universities in those counties. There were three responses out of twenty-three organizations. Two of the respondents had no Mexican heritage individuals in their organizations, but agreed to spread the word among 
their contacts, and the other agreed to post a flyer (Appendix D) at their highly respected Chicano Resource Center on campus. In addition, I made the decision to post online at Latino/Mexican websites frequented by college students and on Craigslist. No one expressed any interest in the study.

Now in the seventh month of the nine month recruitment period, the parameters were changed for the fourth and final time. The recruitment would change from solely university juniors and seniors to inclusion of community college students. I contacted a former colleague who at the beginning of the recruitment period, had suggested including community college students in the study because the criteria was so limited in scope. Given that she was in an administrative position at a community college in Northern California, she could use her office's electronic mailing list to send out a recruitment email. Within the next two weeks, I received inquiries from three campuses; a request to share my findings with another; a recommendation from one school on a potential participant; one professor would forward the study information to his Chicano Studies class; and four possible study participants were recruited by my colleague.

The last minute recruitment resulted in twenty possible participants, out of which ten were chosen. Eight met the exact study criteria. Two participants were initially told they did not meet the criteria. After a revaluation, it was discovered that although one parent was born in Mexico (making them a part of the 2.5 generation) the caveat which made them eligible, was they were $3^{\text {rd }}$ generation by virtue of being raised by the only parent they ever knew, a $3^{\text {rd }}$ generation single parent because the immigrant parent had been absent or deceased throughout their lifetime. The final total of ten sample participants became nine, after the tenth for various reasons (i.e., time constraints, slow in 
responding, no show to interviews) was dropped from the sample pool. There were five university students, and four community college students. Because two of the nine participants helped recruit, seven participants attend or attended the same two Hispanic Serving Institution community colleges in San Mateo and Los Angeles County, while the eighth, attended an HSI in the City of San Diego.

Having never met the participants I was tentative on how receptive they would be in sharing their life experiences with a total stranger. In addition, since some of the sample resided in communities over 500 miles away, the idea of trust was foremost on my mind. A thought was given to flying up to Northern California for two days, but when scheduling conflicts made it impossible to conduct the interviews in that time frame, it was decided to conduct the interviews by telephone. For the four participants who resided in the County of Los Angeles and San Diego, three of the four were conducted in person, while the fourth because of time restrictions was also conducted by telephone. Being trustworthy was never an issue. The study participants were eager to participate and talk about their lives, and answer questions some had never been afforded the chance to answer.

\section{Demographic Profile of Participants}

The nine study participants were from three regions of California: the San Francisco Bay area; the Los Angeles area; and San Diego, approximately 540 miles south of San Francisco, and roughly 18 miles from the United States/Mexico International border. Five were university students, and four were community college students who plan to transfer to a university, once eligible. The study participants were all $3^{\text {rd }}$ generation and beyond U.S.-born (3GAB-USB) of Mexican heritage ranging in age from 
19-31 years of age, and spoke English as their $1^{\text {st }}$ language. Only one had what could be considered a typical Latino first name. Eight of the nine participants were female. All except two participants understood Spanish, and although they wrote in their demographic sheet they could not speak Spanish, four other participants were bilingual (spoke English and Spanish), but chose not to speak Spanish in order to avoid ridicule.

On the following page, Table 3 delineates the basic demographics of the study participants: generational status; age; place of birth; community of residence; grade level, major/minor; gpa; language spoken; if they are bilingual; and if they were raised in a single parent home. The full demographic statistics of the participants can be found in Appendix $\mathrm{C}$ at the end of the study. 
Table 3.

Basic Demographics of Study Participants

\begin{tabular}{|c|c|c|c|c|c|c|c|c|c|}
\hline & Brynn & Mandy & Maria & William & Amber & Lisa & Jessica & Jamey & Samantha \\
\hline Generation & 4th & 8 th & $3 r d$ & $3 \mathrm{rd}$ & 3.5 & 3.5 & $3 \mathrm{rd}$ & $3 r d$ & 3rd \\
\hline Age & 22 & 31 & 24 & 20 & 22 & 21 & 19 & 20 & 19 \\
\hline $\begin{array}{c}\text { Place } \\
\text { of } \\
\text { Birth }\end{array}$ & $\begin{array}{c}\text { Sun } \\
\text { Valley, } \\
\text { CA }\end{array}$ & $\begin{array}{c}\text { El } \\
\text { Cajon, } \\
\text { CA }\end{array}$ & $\begin{array}{c}\text { Redwood } \\
\text { City, } \\
\text { CA }\end{array}$ & $\begin{array}{c}\text { Oceanside, } \\
\text { CA }\end{array}$ & $\begin{array}{c}\text { East Los } \\
\text { Angeles, } \\
\text { CA }\end{array}$ & $\begin{array}{c}\text { West } \\
\text { Covina, } \\
\text { CA }\end{array}$ & $\begin{array}{c}\text { Redwood } \\
\text { City, } \\
\text { CA }\end{array}$ & $\begin{array}{l}\text { Palo Alto, } \\
\text { CA }\end{array}$ & $\begin{array}{l}\text { Palo Alto, } \\
\text { CA }\end{array}$ \\
\hline $\begin{array}{l}\text { Lives in } \\
\text { County of }\end{array}$ & $\begin{array}{c}\text { San } \\
\text { Diego }\end{array}$ & $\begin{array}{c}\text { San } \\
\text { Diego }\end{array}$ & $\begin{array}{c}\text { San } \\
\text { Mateo }\end{array}$ & $\begin{array}{c}\text { San } \\
\text { Mateo }\end{array}$ & $\begin{array}{c}\text { Los } \\
\text { Angeles }\end{array}$ & $\begin{array}{c}\text { Los } \\
\text { Angeles }\end{array}$ & $\begin{array}{c}\text { San } \\
\text { Mateo }\end{array}$ & $\begin{array}{c}\text { San } \\
\text { Mateo }\end{array}$ & $\begin{array}{c}\text { San } \\
\text { Mateo }\end{array}$ \\
\hline $\begin{array}{l}\text { Grade } \\
\text { Level }\end{array}$ & Senior & Senior & Junior & Sophomore & Junior & Junior & Sophomore & Sophomore & Sophomore \\
\hline $\begin{array}{l}\text { Major/ } \\
\text { Minor }\end{array}$ & Mathematics & $\begin{array}{l}\text { PoliSci/ } \\
\text { Criminal } \\
\text { Justice }\end{array}$ & Sociology & Biology & Sociology & $\begin{array}{c}\text { Kinesiology/ } \\
\text { Pedagogy }\end{array}$ & $\begin{array}{c}\text { Fashion/ } \\
\text { Criminal } \\
\text { Justice }\end{array}$ & Psychology & Biology \\
\hline GPA & 3.2 & 3.47 & 3.3 & 3.2 & 3.59 & 3.3 & 3.5 & 3.2 & 3.33 \\
\hline $\begin{array}{l}\text { Language } \\
\text { Spoken }\end{array}$ & English & English & English & English & English & English & English & English & English \\
\hline Bilingual & Yes & No & Yes & Yes & No & No & Yes & Yes & Yes \\
\hline $\begin{array}{l}\text { Single } \\
\text { Parent } \\
\text { Home }\end{array}$ & Yes & Yes & No & Yes & Yes & No & Yes & Yes & Yes \\
\hline
\end{tabular}




\section{Researcher's Role}

The role of the researcher in qualitative research is that of the primary data collection instrument (Merriam \& Associates, 2002). As a result, identifying personal values, assumptions, and biases, beforehand is of the utmost importance (Creswell, 2003). Since the researcher was a $3^{\text {rd }}$ generation USB Mexican from the Chicano Generation, in order to minimize the bias, it was imperative the participants were allowed to tell "their lived" experience without interference from the researcher infusing his. Also, because the researcher was an insider (Venegas-Garcia, 2009; Rosales, 1993) it allowed for inquiry specific to the sample population, rather than a reliance on ethnically glossed (Trimble, 1991) and inaccurate data collection instruments. By virtue of the specificity and the sharing of lived experiences with the sample population, the emergence of new questions and inquiry led to data that may never have been acquired if not for the shared experience between the researcher and the participants of the study.

\section{Reliability and Validity}

Creswell (2003) has written about the concern researchers conducting qualitative studies have guarding against bias, credibility, and authenticity. In order to ensure reliability and validity, a triangulation of strategies were employed (Creswell, 2003; Merriam \& Associates, 2002; Patten, 2004). The first strategy Participant Feedback, allowed the participants to review the data, verify its accuracy, and offer insight. The second Peer Review, allowed peer's to review the research and provide feedback, possible challenges, and their insight. Serving as peer's, were two $3^{\text {rd }}$ generation USB Mexican heritage former doctoral classmates who have obtained their doctorates within the last three years, and a $2^{\text {nd }}$ generation USB Mexican heritage alumni University of San 
Diego undergraduate student. The third strategy employed, was Reflection, which allowed the researcher to be aware and self-reflect on his biases and preconceived notions, which might affect the research process and conclusion by keeping a journal.

\section{Pilot Study}

A pilot study was conducted prior to the start of the actual study in order to assess potential issues with the interview guide (Marshall \& Rossman, 1999). Using the first two qualified participants (a $4^{\text {th }}$ and $8^{\text {th }}$ generation USB), all the questions of the interview guide were given to the participants to determine if there were any ambiguities, whether or not a particular question was necessary, and test if the duration of the interview was within the time frame estimated. Two questions were rephrased, five subquestions were eliminated, and it was determined the interviews could be conducted within the time indicated in the tenets of the study. After transcription, and because they were from different generations than the other participants, I felt it was important to keep them as part of the study because the $4^{\text {th }}$ generation participant was the only one not to attend a community college out of all the sample participants, and the $8^{\text {th }}$ generation could provide two additional perspectives: (a) her family had been in the United States for eight generations, (b) and her family's ancestry could bring a possible New Mexico perspective to the study.

\section{Data Collection}

The University of San Diego Internal Review Board (IRB) approved this study on Feb 25, 2010. The day after receiving approval, the nine-month recruitment process began. The majority of the recruitment was conducted through electronic media (Appendices F \& G). I decided the most efficient and expedient manner in which to reach 
potential participants would be through Latino/Mexican heritage blogs on the internet, as well as reviewing college campus online directories for all organizations and clubs which might have members of the target population. Peer's and others helping me recruit, always suggested I contact the obvious Mexican and Latino students organizations on campus, but it appeared they were the least interested, with only one response from one organization from within my own campus, which appeared to be more of a courtesy than an interest in the study.

As potential candidates for the study began to respond, I prescreened them, answered any questions they had, and sent them by electronic mail a demographic sheet (Appendix B) to document their eligibility. Once the demographic sheet was returned and they were determined eligible, an interview was scheduled. The initial and follow up correspondence was important because it allowed for casual conversation, personalization, confidentiality, and developing a level of trust. The participants were told interviews would be from $60-90$ minutes. The majority of the interviews were conducted in that time frame, with a few lasting from 35-60 minutes. No secondary interviews were required. All interviews were transcribed and coded by me. Every effort was made to protect the identity of the participants by keeping their names and their educational institutions anonymous. All participants were given pseudonyms. I was the only person with access to the data files. All data was stored in a locked file cabinet and will be kept a minimum of five years.

All study participants were provided a consent form (Appendix A) prior to the interview session and given an opportunity to ask questions about the study. For those interviews conducted by telephone, I sent them the consent form electronically as soon as 
they were determined to be eligible for the study. The participant was also reminded they could stop the interview at any time, decline to answer a question, or withdraw from the study at any point if they chose to do so. Interviews were conducted wherever the participants were comfortable. The interviews were always conducted at times convenient for participants, and for those interviews not conducted by telephone, at a location within their community.

An Interview Guide (Appendix E) was used in all interviews to focus the interview conversation. The Pilot Study conducted prior to the study ruled out any ambiguities in the guide, and ensured the interviews could be conducted within the estimated time frame. There were six sections in the guide: Personal; Identity; School Experience; Social Support; Personal Growth, and Recommendations with a total of 34 questions designed to focus the interview conversation. Not all questions were asked in any given interview (with the exception of the Pilot Study), as some questions in the guide were addressed as they became a part of the respondents narrative as they spoke about their lived experiences, and their self-identity. Their responses to the open-ended questions on identity and a self-label led to the "rich and thick" descriptions Geertz (1973), Spradley (1979), Van Manen (1990), and others have described. It also became for some of the participants, the most difficult section of the interview guide to address.

\section{Data Analysis}

A non-digital tape recorder was used because I wanted a hard copy of the interviews and a telephone-recording earpiece for the interviews conducted by telephone was used to record verbatim. It was important at the start of each interview to have participants give a brief biography of themselves and then ask them to recall memorable 
moments from kindergarten through college, their lifespan, or both. Their responses provided highly descriptive and detailed narratives setting up a natural progression to inquiries about their identity, college experience, and social support. Throughout the interview session, the participant's spoke freely without hesitation. It was only during the identity portion of the interview, the majority of the participants began to have difficulty putting into words how they felt about their identity, particularly when probed to discuss their self-label and why they used it. Additional queries allowed for further reflection.

The interviews were transcribed and used as the primary unit of analysis, with the demographic sheet providing additional data (Appendix B). Once reviewed, the transcripted interview was electronically mailed to each corresponding sample participant for their review, input, follow-up questions, and any editing of their answers. Upon return of the reviewed interview transcripts by the participants, I analyzed each transcribed interview to see how it related with my interview guide and the research questions. After the first two interview transcriptions, the same patterns and themes kept recurring throughout the seven remaining transcriptions. Those pattern and themes were constructed based on the data emerging from the participant's perspectives and my interpretation while analyzing it.

Multiple readings of the biographical data in the transcriptions helped me formulate the demographic profile chart (Appendix C) illuminating commonalities and the biographical information of each participant. Thereafter, each transcript was analyzed individually for patterns and themes and compared to the other participant's transcripts in the study (Creswell, 2003). Reviewing the transcripts line-by-line allowed recurring themes to emerge. Coding segmented the data into manageable bits of information into 
which categories were constructed. The first two readings of the transcribed interviews produced twenty-four possible themes. Additional readings and comparisons narrowed the possible themes to fourteen parceled into a possible five categories. A final line-byline analysis resulted in color-coding twelve themes and four categories, later finalized during the writing of Chapter 4 , to nine themes and three categories.

A journal was kept during the data analysis process where I expressed revelations, doubts, fear, concerns about bias, interpretation of the data, and credibility. The journal writing kept me aware, vigilant, grounded, and focused, even though my thoughts had me thinking I was constantly doing something wrong because the data analysis process for me was not like anything that had been described by colleagues or read about. Another of my concerns, was because six of the interviews were conducted by telephone, I could not keep memos on other supplementary sources of data as in personal observations. An attempt was made during the three in-person interviews, but I discarded the idea because I felt it would not help if two-thirds of the sample were not included.

\section{Summary}

This chapter described rationale for the particular design and methods employed in this research study. The choice of the design was of the utmost importance because of the need to listen and attempt to understand the study participant's life experiences, without the investigator entering the study attempting to fit the participants into any predetermined schema, an over reliance on theories, or the use of antiquated instruments and data. This basic approach allowed the investigator to learn through their experiences about the reality of their lives and how it equates to transitioning to college, in an attempt to hasten additional research, which might one day offer solutions to alleviate specific 
challenges never fully resolved for this invisible population and those generations, which preceded it. 


\section{CHAPTER 4}

\section{RESEARCH FINDINGS}

And you know, even at school I have kids my age who are $1^{\text {st }}$ generation or $2^{\text {nd }}$ generation, and there is this disconnection. In the sense that we're both Mexican but...

William, Study Participant

The study was designed to answer the following overarching question: "What are the unique psychosocial and identity challenges of $3^{\text {rd }}$ generation and beyond U.S.-born (3GAB-USB) college students of Mexican heritage?" Additional answers were elicited for these underlying questions:

1. How do members of this population identify themselves?

2. How does this self-identification help/hinder their ethnic identity?

3. How does the perception of others influence this self-identification?

4. What specific challenges do 3 GAB-USB college students of Mexican heritage experience in their transition to college?

This chapter has been constructed to allow the study participants a voice to share their lived experiences. It begins with a brief biography of each participant (See Appendix C, Tables 1-3 for full profile). The following section will discuss commonalities among the sample population, followed by an explanation of how the nine themes that emerged from the transcribed interviews were segmented into these three overarching categories: (1) Identity; (2) Alienation; and (3) Transition to College. Lastly, what the study found will be discussed, and a brief summary will conclude the chapter. 


\section{Biography of Study Participants}

Brynn $-\mathrm{A} 4^{\text {th }}$ generation 22-year-old, university senior who attends a university in San Diego County, is $5^{\prime} 0$ tall, petite, with piercings, dark hair, and blueish-grey colored eyes. She is very light-skinned, almost alabaster, and does not look Mexican and/or Latina. She is a single parent. Articulate, polite, and during our interview, appeared self-assured. She was raised in a single parent home in Los Angeles County and has two other sisters. She is a $1^{\text {st }}$ generation college student.

Mandy - Is an $8^{\text {th }}$ generation 31-year-old, university senior who was born in San Diego County, and attends a university in San Diego County. She is a Hispanic Serving Institution (HSI) community college transfer who is, approximately $5^{\prime} 7$ tall, average in stature, medium brown hair with highlights, medium brown colored eyes, and oliveskinned, looks Mexican and/or Latina. Has gregarious personality, well spoken, and appeared at-ease during our interview. Was raised in a single parent home, but has always spent time with her father, and has two brothers, and one sister. She is not a $1^{\text {st }}$ generation college student.

Maria - Is a $3^{\text {rd }}$ generation 24-year-old, San Francisco Bay area university junior, who transferred from the same HSI community college in San Mateo County, that is being attended by four other study participants. She is 5 ' 4 tall, olive-skinned, average build, dark brown hair, and eyes, looks Mexican and/or Latina. These attributes were self-reported as the interview was conducted by telephone. She is a single parent, $1^{\text {st }}$ generation college student, who comes from a two-parent household, and has 2 brothers. She has pleasant demeanor, is analytical, and a conversationalist. 
William - A $3^{\text {rd }}$ generation 20-year-old from San Diego County is a sophomore at the same San Mateo County HSI community college Maria transferred from. He is 5'7 tall, has an athletic stature, dark brown hair, light brown eye color, and olive-skinned. Looks Mexican and/or Latino. These attributes were self-reported as the interview was conducted by telephone. William was raised in a single parent home and has no siblings. Articulate, forthcoming with information, appears confident in his demeanor, and his goals in life. He also recruited three of the participants, and is a $1^{\text {st }}$ generation college student.

Amber - A 3.5 generation (1 parent is $4^{\text {th }}$ generation) 22-year-old university junior is another HSI community college transfer from Los Angeles County. She is 5'7 tall, average build, dark brown eyes, and hair, with olive-skin. Looks Mexican and/or Latina. She has a pleasant demeanor, funny, articulate, and analytical. Her interview was one of the longest. Recruited four individuals, of which, only one qualified for the study. Has two brothers, and comes from a single parent home although, she has always stayed in contact with her father. Not a $1^{\text {st }}$ generation student.

Lisa - Also from Los Angeles County is a 21-year-old, 3.5 generation university junior, who transferred from the same HSI community college as Amber. She is 5'3 tall, athletic build, dark brown hair and eye color, olive-skinned, and is a member of the school's track team. Looks Mexican and/or Latina. These attributes were self-reported as the interview was conducted by telephone. She was raised in a two parent household, has one brother, one sister, is a $1^{\text {st }}$ generation college student, who was personable, concise, and to the point in our interview which turned out to be the shortest in length, thirty-five minutes. 
Jessica - A 19-year-old, $3^{\text {rd }}$ generation sophomore at the same San Mateo County HSI community college as the others from San Mateo County, is 5'2 tall, with light brown eyes, long light brown/blondish curly hair, and plum-shaped in stature, who looks Mexican and/or Latina. These attributes were self-reported as the interview was conducted by telephone. She was pleasant, very forthcoming, and detailed in answering the interview questions. She was raised by her $1^{\text {st }}$ generation Mexican grandmother, has no siblings, and is a $1^{\text {st }}$ generation college student.

Jamey - A 20-year-old $3^{\text {rd }}$ generation sophomore attends the same HSI community college in San Mateo as the others from San Mateo County. She is 5'4 in height, petite, light-skinned, light blondish hair, and green eyes. She does not look Mexican and/or Latina. These attributes were self-reported as the interview was conducted by telephone. Cordial, appeared to have a great personality, was informative, and detailed in her answers. She was raised in a single parent home, has two sisters, and is not a $1^{\text {st }}$ generation college student.

Samantha - 19-year-old sophomore from the same San Mateo County HSI community college as Jamey, is $5^{\prime} 7$, athletic build, light-skinned, with brown hair, and green eyes. She does not look Mexican and/or Latina. These attributes were self-reported as the interview was conducted by telephone. Pleasant, confident, focused, and detailed in her responses, she is from a single parent household. She has 1 sister, and is not a $1^{\text {st }}$ generation college student. 


\section{Participant Commonality}

While some of the common characteristics can be explained by seven of the nine participants attending or having attended the same community colleges, these other commonalities were discovered during data analysis:

- All nine participants were educated in a public school system.

- All nine participants' core language was English.

- All nine participants are Honor Students.

- Eight of nine participants attended community college.

- Eight of nine participants understood Spanish.

- Eight of nine participants were employed. The ninth participant quit working in December 2010 in order to take additional classes to accelerate her transfer to a university.

- Seven of nine participants received financial aid.

- Seven of nine participants were raised in a single parent home.

- Seven of nine participants had two or more siblings

- Six of nine participants planned to attend graduate school, the seventh was strongly considering it, and the final two, remained undecided.

- While only three of the nine participants stated they were bilingual, an additional four could converse in Spanish.

- Three of nine participants were $1^{\text {st }}$ generation college students.

- Only two of nine participants lived independently. 
Discovered during the data analysis process was the fact, eight of the nine study participants attended or were attending community colleges designated by the federal government as Hispanic Serving Institutions (HSI). This study, was not intended to have HSI students for the simple reason it would portray a very different image in comparison to the sometimes unfriendly and indifferent university environment described in the interview by Brynn, the only one of the participants who did not attend a community college, and studies conducted on Mexican or Latino heritage individuals in college (Crockett et al., 2007; Gloria et al., 2005; McGinley, Carlo, Crockett, Raffaelli, Torres Stone, \& Iturbide, 2010; Yosso, Smith, Ceja, \& Solórzano, 2009).

However, a recurring theme throughout the data analysis, which led to the discovery of the majority of the sample population attending or had attended an HSI, was how highly the HSI students spoke of their experience there. Having read the literature (and at times experienced on my own educational journey) how the college experience was not always a pleasant one for Mexican and Latino heritage individuals, the opportunity presented itself to learn about a positive educational experience in the lives of seven 3GAB-USB Mexican college students. The eighth HSI attendee, now a graduating university senior never spoke about her community college experience during her interview, and the only reference to her attending one, was on her demographic sheet (Appendix B).

In brief, Hispanic Serving Institutions are colleges, universities, or systems/districts where total Hispanic enrollment constitutes a minimum of $25 \%$ of the total enrollment (Hispanic Association of Colleges \& Universities, 2011). This designation by the federal government qualifies an institution of higher education to 
receive federal education grants under the Title $\mathrm{V}$ and Title III of the Higher Education Act of 1965, which are then used to expand educational and academic opportunities for Hispanic students, expand or enhance curriculum, improve the quality of programs offered, and provide institutional stability, in an effort to offer Hispanic and other lowincome students an opportunity to complete postsecondary degrees. An amendment to the original Higher Education Act of 1965, (Higher Education Act of 2008) superceded Section 503(b) and authorized additional monies under the HSI statute to improve programs such as: student support services; establish customize courses (e.g., distance learning) to help retain students, create programs designed to facilitate the transfer from community colleges to universities, and provide additional education on counseling and financial aid in order to increase the knowledge of students and their parents of what resources are available to facilitate entry into postsecondary education (U.S. Department of Education, Developing Hispanic Serving Institutions Program, Title V, 2011).

One other element, which may be a coincidence but nonetheless drew the investigators attention, was three of the participants ( 2 of 3 bilingual participants) who spoke Spanish at an early age were later diagnosed as having a learning disability. The parent of one of the participants, who is a teacher, believes the "disability" was merely the result of her child mispronouncing the letters " $\mathrm{S}, \mathrm{R}$, and $\mathrm{T}$ " in her transition from the Spanish language to English. It is beyond the scope of this study to offer an opinion and any unsubstantiated insight, but it is mentioned here as a possible recommendation for future study. 


\section{The Findings}

In order to address the study's overarching and subsequent questions, the interview guide (Appendix E) was divided into six sections. They are described as follows:

1. Personal - allows for questions pertaining to the participants personal and family background information, and any memorable life experiences.

2. Identity - explores self-labels, identity confusion/diffusion, existing in Hybridity (living in two worlds i.e., bicultural), losing identity, and ethnic pride.

3. School Experience - probes into the participant's college experience.

4. Social Support - asks the participants if they had among family, friends, or institutions any mentors, and/or confidants who they knew would be there for them during hardships.

5. Personal Growth - asked the participants if they had felt they had grown through their college experience.

6. Best Practices Recommendations - asked the participants what was missing in regards to helping future students of the same study population navigate the transition from high school to college.

The responses from these transcribed six sections of the interviews were then segmented into the three main categories: Identity; Alienation; and Transition to College, into which the nine emergent themes were appropriately grouped. Table 4, illustrates the themes within the three categories. 
Table 4.

Emergent Themes and Overarching Categories

\begin{tabular}{ccc}
\hline Identity & Alienation & Transition to College \\
\hline Identity Confusion & Feeling Distant & School Experience \\
Self-Label & Discrimination \& Racism & Support Groups \\
Hybridity & Reverse Assimilation & Recommendations \\
\hline
\end{tabular}

\section{Identity}

College is a time when many students regardless of ethnic background begin to seek answers about their identity. Baxter Magolda (1999) has stated in fact, it is not until after college and additional life experience that all college students begin to feel comfortable about their identity. For individuals of various ethnic groups however, the added component of skin pigmentation, invalid perceptions, and racial stereotypes among other variables, continue to add complexity to their identity challenges. This section will elaborate on some of those identity challenges that became apparent during the participants responses, which at times were contradictory, because some of the participants were answering questions they had not previously thought about.

Theme 1 - Identity Confusion. All the participants to some extent experienced identity confusion. Even Mandy, the $8^{\text {th }}$ generation U.S.-born (USB) university student who stated that she is an "American," had doubts. She does not believe she fits any demographic category by stating:

I guess I feel like I don't belong anywhere. Like, I don't feel like I'm Mexican. I don't feel you know... well obviously, I feel American, I don't know.... 
For Maria, who is a $3^{\text {rd }}$ generation university student, her identity confusion stems from not knowing who is Mexican-American. She understands that a USB qualifies as "American," but is not sure how the "Mexican" part fits in:

We're Mexican-American because we're born here, that makes you the American part, but we are still Mexican, and then we're different, I mean... I don't know... like, it confuses me. I understand that someone from Mexico has/is closer to Mexican, but when does it translate into Mexican-American?

William a $3^{\text {rd }}$ generation USB community college student, questions his identity because of a disconnect between the immigrant and USB Mexican:

And you know, even at school I have kids my age who are $1^{\text {st }}$ generation or $2^{\text {nd }}$ generation, and there is this disconnection. In the sense that we're both Mexican but... they came from Mexico, so it kind of makes them more (with emphasis) Mexican, and me, they kinda consider me American, because I'm from... I was born here, but I grew up in a Mexican home, but I can't speak Spanish. So, I'm American, but with Brown skin.

Amber from the 3.5 generation, and who is a university student, attributes her identity confusion to not being like a "full blown" Mexican:

It's just during college that I started to think, "who am I, what am I," because I mean, I guess when I think of Mexicans, I consider someone who speaks Spanish and full blown (with emphasis) and all about Chicana, and Chicano rights, and I'm completely not like that, I'm the opposite.

For someone like Jessica, a 3rd generation community college student who was raised by her 1 st generation grandmother, and at times her great-grandfather, identity confusion comes from being taught to identify as a Latina in a type of hierarchal selflabel:

I think only just because my grandmother raised me and told me, "Yes, you're Mexican-American, but I want you to know you are Latina and you stand by it, and don't let anybody break you down and say anything different. You stand for your culture, and what 
you are (with emphasis), and how I raised you." My grandmother had a huge impact on raising me with the pride of being Hispanic, Latina, Mexican, whatever she said was my culture.

Identity confusion began in college for Jamey, a $3^{\text {rd }}$ generation USB community college student respondent who is light-skinned, with blondish hair and green eyes says, "It wasn't until I went to college that I had to figure out who I was." Lisa, another $3^{\text {rd }}$ generation USB community college participant simply says, "I just figure Mexican, Hispanic, Latin, are all in the same category." While Brynn, a $4^{\text {th }}$ generation USB university student participant whose white skin pigmentation and bluish/grey eyes add to her identity confusion states:

Well, I can say that it's really, really.... difficult to try to tell people I'm Mexican or Mexican-American and they say, "Oh well, your grandmother was born in Mexico?" No, her mom. Well yes and no, because my family is from the border between Texas and Mexico, so I mean, like my great grandma I think was born before the Revolution so she was Mexican and all of a sudden, she was free to go back and forth, and then I guess, it's the old cliché, the border crossed us (with emphasis). So I can say she was born in Mexico... but it was America at the time... it's really difficult to say. I always have a problem with that, with people saying, "oh well, are you $1^{\text {st }}$ generation?" I don't know because my grandma and great grandma were along the border... so it's a little difficult to figure out now.

Mexicaness. An aspect of identity confusion which became an interesting phenomena and was a part of every interview when discussing various aspects of the participants interactions with other Latinos was how the immigrant, $1^{\text {st }}$ and $2^{\text {nd }}$ generation Mexicans and other Latinos equated speaking Spanish to how "Mexican" a person is. This term will be referred to throughout the remainder of this study as "Mexicaness." Simply defined, from what was garnered through the interviews, one is not considered to really be a Mexican if one does not speak Spanish. The less Spanish one knows appears to be a barometer of how "American" or "White-Washed" one is. 
In previous generations, these "lesser" Mexicans were called many different names. One still used today is "Pocho." The term Pocho is fully defined in Chapter 1 in the Definition of Terms, but the basic term as it is being used here means "half-breed," neither fully Mexican nor American (Madrid-Barela, 1976). This investigator was aware of this lesser Mexican mentality, because of his own life experience, but was not aware how prevalent it still was among this group of students.

Mexicaness has also been played out on a national stage in the sports world. Mark Sanchez of the National Football League (NFL) has become the face of the New York Jets since the day he was drafted in 2009 out of the University of Southern California. While there have been other USB players of Mexican heritage to play in the NFL, Sanchez is the first $3^{\text {rd }}$ generation USB Mexican to play in the league (Arangure Jr., 2008). At USC, where one in seven students is Latino, there were whispers among the Latino population in L.A., that he too was not Mexican enough because of his lack of Spanish-speaking skills (Baxter, 2008).

Having been raised in Orange County, CA away from the inner city, ethnicity was not something, which was foremost on his mind. Attending college in the City of Los Angeles changed that, and realizing the impact his ethnicity would have on his career, Sanchez reconnected with his roots and began taking Spanish language classes to connect with his fans (who would paint themselves the colors of the Mexican flag, wear homemade ¡Viva Sanchez! T-shirts, Mexican wrestling masks, and serapes during games) and the Spanish speaking media during interviews (Arangure, Jr. 2008; Davis, 2008). 
For eight of the nine study participants, their examples of Mexicaness are described differently. Mandy feels she is looked down upon and talked about by other Mexicans,

It's more like I said when I see people and I don't speak Spanish. You know, it's like I'm looked down upon by Mexicans (with emphasis), and I sometimes feel they talk about me.

Brynn does speak Spanish but chooses not to, in order to avoid "getting complaints:"

When I say I'm Mexican-American, I'm told by others "you don't speak Spanish, you can't consider yourself Mexican." Well I speak it, but with an accent, and because of that, I don't sound Mexican (with emphasis). So I choose not to speak it, and get a lot of complaints with people telling me that I'm "White or WhiteWashed."

Whereas Maria does not want to be "too much on the American side" because she does not want to be labeled a White-Washed Mexican:

You don't want to be too much on the American side and then have that whole, "oh she is very White-Washed (with emphasis)." White-Washed where she doesn't even know Spanish. How could she even be Hispanic? When you meet an older Hispanic person there is that one question that you know they will ask you when they find out your Mexican. It is "do you speak Spanish?" For the longest time when I was little, I was asked that question. Then there would be the following question of, "let me hear you speak Spanish."

While William, questions those who accuse him of being a "White Boy" because he does not speak Spanish:

I knew I was Mexican, but I didn't speak Spanish. People like all my friends used to call me "White Boy (with emphasis)," you know they'd call me Gringo (with emphasis), or they'd tell me "you're such a White Boy," and then I'd be like dude, I'm a White Boy (with emphasis), like how? My skin color isn't White. Is it because of the way I act, my attitude, or is it because I can't speak Spanish? I do exactly the same things you guys are doing I just can't speak Spanish. I didn't grow up in Mexico, but how am I, why am I considered a White Boy? 
Amber on the other hand, becomes upset and shifts more to her "American" side when Spanish-speaking Mexicans and other Latinos "dog" her:

What irks me more, what drives me crazy, and to be more American (with emphasis), and kind of... just gives me a bad outlook on Mexicans (with emphasis) because of what they tell me... like when I wanted to get involved at community college I wanted to join "Latinos Unidos," and it is basically a Hispanic or Latino Club, and everyone would be talking in Spanish and I would just tell them that I'm not able to speak Spanish, so I kind of felt people would $d o g$ (with emphasis) me as not being a real (with emphasis) Mexican. Yeah... a lot of people have told me that. "Oh you don't speak Spanish...."

Lisa's example of Mexicaness is whenever she meets someone from a Hispanic background they are "shocked" when she tells them she does not speak Spanish:

When I meet someone who is also from a Hispanic background, they ask you, "oh, do you speak Spanish?" And you say no they're shocked. So they're very surprised (with emphasis) and then they say, "Oh you're Mexican, and you don't speak Spanish?" Stuff like that does happen often.

For Jamey, Mexicaness means being labeled White-Washed by Mexicans, because she does not speak Spanish around them:

I mean basically if I'm around Mexicans, you can say they would label me as... I guess you can say White-Washed. Because if I don't speak Spanish to them, they just label me as White-Washed (with emphasis), you know, American (with emphasis). They don't consider me Mexican.

While Samantha recalls an incident in her classroom a few days prior to the interview when a classmate told her that she was not "Mexican" because she does not speak Spanish:

A few days ago I was in class and someone asked me what ethnicity I was, and I was "oh Mexican," and this guy looks at me and says, you're not Mexican, you don't speak Spanish (with emphasis). I was okay... (with emphasis) like I don't know. Just 
because I don't really speak Spanish, I'm still Mexican. I do get that a lot especially because I'm not fluent in Spanish.

Theme 2 - Self-Label. The importance of what individuals call themselves is not always given serious considerations when studies are conducted among the ethnicities under the Latino category (Phinney \& Alipuria, 1996; Zarate, Bhimji, \& Reese, 2005). If it were, this study would not have had to come up with the term U.S.-born (USB) to distinguish between immigrant Mexicans and the U.S. native. The preceding chapters have elaborated on the importance of unequivocally defining sample populations when doing research on Latinos. Another aspect one must consider, especially since seven of the nine participants of this study are between the ages of 19-22, is the self-label can change over time, in different situations, and regionally (Dowling, 2005).

The following four questions addressing a self-label from the interview guide were at times very difficult to answer for the respondents. Some nervously laughed, some repeatedly would pause and say "I don't know" whenever they were not sure of how to answer, others were given the opportunity to collect their thoughts, and some simply did not know how to answer, because it was the first time they had been asked a particular question. The first question was,

1. How Do You Describe Yourself Ethnically? For six of the nine participants they self-described as Mexican-American, the seventh as Mexican, the eighth as Hispanic, and the remaining participant Mandy, chooses among Mexican, Hispanic, or Latina to self-describe and explains why:

I think it changes, whatever's there. I mean I don't really understand the whole ethnic thing. You know if it say's Mexican, I put Mexican, if it says Latina, I put Latina/Hispanic. I just check whichever one is closest to me. I don't really always fall into that category, so I don't know which one of that category I fall under. 
When she was asked if she really cared about identifying with her indigenous Mexican roots, her reply was, "I don't think I'm Mexican because I'm not from Mexico." There are a few reasons she may not identify with her indigenous roots. The first is being $8^{\text {th }}$ generation in a family that did not have "Mexican" family traditions would allow her to just consider herself as all those around her_- "American," while another reason could be having been born and raised in a Caucasian section of San Diego where she has stated there might have been one or two African-Americans in the schools she attended, there is not much need to identify as anything but the majority, and lastly, because her family's generational roots are from New Mexico.

The discussion on how some individuals from New Mexico do not identify with their indigenous side was illuminated in Chapter 1 in the Definition of Terms section, but will briefly be rekindled here for clarity:

Hispanos were originally the descendants of Spanish settlers who moved into the most northern reaches of New Spain in the $16^{\text {th }}$ century. Even though through intermarriage with Pueblo and nomadic Indian tribes, Mexican heritage and Euro-Americans, this population continues to exhibit clear cultural differences from the Hispanic or Mexican category they have been homogenized under (Nostrand, 1992).

Brynn self-describes as Mexican-American and when asked the reason why she describes herself that way, she responds:

Well, I can't say I'm Mexican because I'm not from Mexico and I don't speak Spanish. I can't say that I know how to cook food or things like that, but then again, I have American qualities too. But I don't consider myself American or White (with emphasis) as some people do, so I say Mexican-American. And I can't call myself "Chicana or Chicano" because I don't associate with that type of culture... (with emphasis). 
Asked for clarification on what she means by "that type of culture," she elaborates on her thoughts:

Like what I think of when I think of Chicana or Chicano (with emphasis), I think more of a dark-skinned (with emphasis) person that you know, their appearance is of Mexico. They still have ties to Mexico, more than I would. They have more a sense of that, Mexican culture.

When she is asked if her self-label changes situationally as has been documented in the literature review section her answer is:

I want to say no, but I think it does. When I go home I'm completely different then when I am in school or in San Diego. When I'm at home, I don't know how to say it, I guess my Mexican-American culture, because I can just say that is my culture of ethnicity, I'm like that. But when I am over here in San Diego, I seem more like, how can I say... White (with emphasis), that type of culture. So I feel like I'm more like that over here because that's what I see how I fit in and I definitely do not act like that when I'm back home.

Maria's response was, "I'm Mexican-American" and she replied with laughter to the question if the label changes situationally, "No, I'm Mexican-American all the time. It doesn't change." For William he identifies, as "Mexican, Mexican-American." But his self-label does change situationally, "Mainly if I use, if I'm around like either Black or White, I identify myself as Hispanic. It does change situationally." Amber responds:

Mexican... Mexican-American. But I don't really consider myself too much Mexican. I feel I'm more Americanized (with emphasis). I do acknowledge my roots, where I came from, and I know what "my people" are about, but I do definitely consider myself like American (with emphasis) and do support that.

Depending on the circumstances, if she is with family, at work, at school, or in places like the barrio of East Los Angeles, Amber's use of her self-label does change situationally:

Yeah, definitely, because when I'm with family, I'm Mexican guaranteed \#1 before anything (with emphasis), and even when I 
go to places like East L.A., all of a sudden, I have like a little accent when I say everything or whatever like that, and when I'm at work or at school, suddenly the accent disappears and I just kind of... Like one thing I always notice is that I don't pronounce like Tamales (with emphasis), I say, 'oh, Tamollies' when I'm at school or when I'm totally in a situation just with people who are not like, Hispanic or Latino or anything like that. It definitely changes.

Lisa self-describes as "Mexican-American," and states it doesn't change situationally, but her response says otherwise: "Nope. No, I just figure Mexican, Hispanic, and Latino are all in the same category, so I just kind of go with it."

For Jessica she calls herself, "Hispanic. On those surveys with the little bubbles, whatever of the three... Hispanic, Latino, Mexican, I'll just fill it in." She does not think her self-label changes situationally, "I don't think it does. I mean, I think me describing myself as a Latina, I don't think it changes situationally." But just as with Lisa, it does change as her answer to the first question was "Hispanic," and then her next answer was "Latina." This seems to validates what Rodriquez (2000) has stated on how ethnically an individual of Latino heritage can be one of three categories depending on the circumstances: a Mexican on a personal level; a Latino(a) on an instrumental level; and a Hispanic to the government.

Jamey describes herself as Mexican-American even though her appearance of blondish hair, green eyes, and light skin pigmentation does not equate to the perception and stereotype of how a person of Mexican heritage should look like. She has had a difficult time answering questions on the identity portion of the interview because she says no one has ever asked her about it, and because of that at times during the interview, she does not feel qualified or feel she has an answer to the question posed. When she was 
asked if her self-label changes situationally, she took some time before answering and then replied:

I'm technically Hispanic, and then Latina. I'm not too sure.... Yeah, regardless, I think I consider myself Mexican-American, mainly because my grandmother spoke in Spanish, and I know the language, and so I can't ignore that. I can't pretend like I don't know anything. So I'd still consider myself Mexican-American.

Samantha, another green-eyed, light-skinned individual who also does not fit the perception or stereotype of how a Mexican should look like, describes herself as Mexican. As to whether she describes herself differently depending on the situation she replies:

No, no, no, no.... I NEVER alter my... I'm full Mexican. I'm American (with emphasis). But I always say Mexican, and it doesn't change. Whether I'm at school, at work, anywhere, because that's who I am and I don't alter anything.

The second question pertaining to the choice of a self-label was asked to see if the label helped them in regards to their ethnic identity or became a hindrance,

2. How Do You Feel This Self-Label Helps Or Hinders Your Ethnic Identity? For three of the respondents, they feel their self-label helps them, while two feel it makes no difference. Another respondent does not understand the question and gives no answer, while one other, believes it hinders her ethnic identity. Samantha believes her self-label is a double-edged sword:

I think being Mexican helps me in terms of like... at times in school, because I do know how schools are trying to get more minorities integrated into their school, so checking the "Hispanic" bubble on the demographic sheet helps. But then also sometimes I feel like when I put Mexican (with emphasis), I don't know... I feel like I'm being stereotyped. You know, like immigrant... I don't know... (with emphasis) that depends on who you're talking to. 
Amber not only believes the self-label hinders her, but has her living constantly in two worlds because some day's she is "Mexican," and other days she is not:

I think it hinders because I feel I'm constantly... like I feel, I'm not a set person. I just change constantly in my ethnic identity. I mean yeah, it does, because I feel I can't represent just being Mexican at one specific time. I have to like sometimes, someday's I'm Mexican, and someday's I'm not Mexican (with emphasis), and so definitely, I think it does hinder it.

For William, he feels his self-label helps in the sense it sets him apart from stereotypes such as gang-related or that of an immigrant, and allows him to present a positive image of a Mexican:

I think it helps me a lot because you know, it helps me like when I start applying for college, I'm basically showing myself as a minority, you know. Disadvantaged, underprivileged person who is really working hard towards obtaining the American Dream (with emphasis), and that really kind of helps me to identify myself as Mexican because you're trying to prove... you're kind of like the outcast, compared to everyone else (with emphasis). I know I'm American, but it's like... Mexican (with emphasis), I can use it as an advantage because there aren't too many Mexicans as public figures or making an impact. When they think of Mexican, it's either gang-related or like immigrants. But they don't see a Mexican-American one, who understands the culture and is really successful academically or professionally. I see it as a good thing (with emphasis).

Maria also believes it represents a positive image, but gets confused on who is MexicanAmerican, because she believes the more one incorporates from Mexican culture, the more a USB Mexican is going to be a "different" American:

It helps in the sense that there isn't many Mexican-Americans who go to college. So I guess to make it more diverse or marketable, the colleges are trying to increase the diversity on their campuses. And hinders because I get kind of confused on who is MexicanAmerican. I mean the longer you are away generationally, you don't have those close ties to Mexico. I still feel like... that I know what it is to be a Mexican and I'm proud (with emphasis), because I'm very close to my grandma who is from Mexico, but I guess the 
more you incorporate, you'll most likely going to consider yourself as a different American.

Mandy remains neutral and believes she does not receive a response either negatively or positively on her self-label:

No, I don't think I get a response either way. Like when I say I'm Mexican, I'm Spanish, Latina, whatever, is when I have to fill out forms. So I would think that would be like the only time I would consider myself one of those categories.

Brynn on the hand, believes the self-label illustrates she can be a part of two cultures without hesitation:

I think it kind of helps. I think it's me calling myself MexicanAmerican shows that I'm like talented (with emphasis). I can deal in both cultures or I can sway back and forth and I'm more flexible in what I can do. I can go ahead and go into a business conference full of "White" people and still go into my neighborhood and go to the Ice Cream man and get some Ice Cream, and still feel comfortable and be okay in both of those worlds....

Lisa does not see her self-label making a difference, "No, I don't really sense any negativity from saying I'm Mexican or Hispanic. I don't see any difference whatsoever." Jessica and Jamey had no responses to this question for two different reasons. Jessica: "I don't think I understand that question, sorry," and Jamey's lack of an answer was because the investigator did not notice until now, he forgot to ask her the question.

The third question asked of the participants about their self-label was to understand if outside influences were a factor in how they chose to self-identify,

3. How Much Did The Perception Of Others Influence Your Self-Label? The perception of others did have an influence on the self-label of five of the respondents, while one respondent's self-label was influenced by family, and the remaining three felt, perception had no influence on their self-label. Maria describes an incident in high school 
when she was told she was "White," instead of being called a Mexican, so her self-label is a reminder of where her roots are and how proud she is because of it:

One time in high school someone thought I was "White," and they're like "oh you're 'White,' da... da... da...." I'm not White! I'm Mexican, and I don't want to be White! I'm happy. I'm proud, proud to be a Mexican (with emphasis). I'm proud to know another language than just English... I'm proud to know that my grandfather came to this country in order to have a better life and to make something of himself. It's a reminder to me that I am here today because of my grandparents wanting a better a life. It would be disrespectful if I would deny my heritage.

William believes his self-label was not a result of anyone's perception other than his own. He feels he is whom he is:

It didn't. I am who I am, so it's like, I'm Mexican (with emphasis). I can't change it, where I grew up... I remember hearing somebody say, "I wanna be Mexican" and I was like why? You are who you are. If you're Black, stay Black. It's who you are, how you grew up. Like me, I grew up Mexican, and I see my grandparent's culture in me.

Where Amber believes the perception of others did influence her self-label. It was all about standards she perceived:

Completely I think. It really did... "Perception of others, hmm..." I think it really did affect me because you know, to see how they were "I need to be like that too." Or, I need to change my ways in order to kind of fit those requirements, not those requirements, but standards of what other people see too.

Perception was not a factor for Samantha who is proud of whom she is, and feels her selflabel reflects it. She always states that she is Mexican rather "Hispanic," because that is how she was raised:

I do feel that and sometimes... no, I never alter, I always say I'm "Mexican" as opposed to "Hispanic." Just because that's how I've been raised to say it, or the way I've always thought of myself. I do feel that sometimes people would change their answers because of what people are going to think about them, but no not me. I don't 
know... I'm proud of who I am and won't change it for anybody (with emphasis).

Lisa also feels perception has nothing to do with her self-label, what she calls herself reflects who she is, an American of Mexican heritage:

I guess if somebody were to ask me what ethnicity I am, I automatically say Mexican-American because my heritage or background is Mexican. But, I live in America. So I just say Mexican-American. So as far as like it was influencing my answer, no.

Mandy does believe her self-label has been influenced by perception ever since she was growing up, and laughs when she reveals how her Latina sorority is trying to influence her choice of a self-label:

I think it's been since I was growing up and how I felt. I think it did have an influence. You know what I think, well being from my Latina sorority and stuff, a lot of the girls have influenced me more with Latina culture, but yes, I would say perception has been an influence.

Jessica's self-label did not come from the perception of others, but by the influences of her grandmother and great-grandfather:

Yeah, my grandmother and my great-grandfather actually, he always had stories and always told us don't let anybody tell you that you're different (with emphasis) because I not only look Latina, but because of my complexion, people who hear me talk Spanish ask me if I learned it or if I'm Latina.

Whereas Brynn believes, the name-calling of "White and White-Washed" has not only contributed to her self-label, but has her questioning at times, if she really is Mexican according to the definition of the Spanish-speaking:

I get a lot of complaints and people telling me that I'm White or White-Washed (with emphasis) and things like that, because I don't speak Spanish. So I think that kind of makes me question if I'm Mexican, which I can't deny. So I just lie somewhere in between as in Mexican-American. 
Jamey did not know how to answer. She began to say her self-label was a result of where she lived, but then:

It's because of the fact of where I live. When I had to move, grown up, I never really thought about it as much. I guess you can say, a lot of people, always ask me... and I... I'm not sure how exactly how to answer. I mean, I've never been asked that as much, I mean, I might have been asked ... I think it's always been I get asked after I get to know a person, and I start giving them a little feedback, not before. I don't know... I don't know how to answer (with emphasis).

The last question in the identity category was asked because of persons in society, government, and the media, who question why some ethnic groups use a self-label. Past generations had their particular reasons, but not much is known about the present generations reason(s) especially among this USB sample population. The question,

4. There Are Those That Say, Why Use A Self-Label, It Only Creates Further Separation/Alienation. Why Not Be Just “American?" The responses to this question varied from bridging two cultures, to maintaining their heritage. Only one felt a self-label causes separation. Jamey believes her use of a self-label is for better understanding of who she is:

Sometimes somebody might have a better understanding of where you're coming from. I know I'm American, but I keep thinking, I'm American, but I feel sometimes there is more for us to say. We have to have some sort of cultural... cultural part to define you.

For Amber, it's about acknowledging her ancestral roots even though she is American and born in the United States:

Because I am American yes, I was born here, but I mean my roots... I feel like there is more. It's not just like my blood is American (with emphasis), it isn't. I have to acknowledge that, but I can't discard that completely. Being Mexican I have to like, learn at least a little bit. 
When asked why she "feels" she has to do this, she replies and laughs at the thought of being "disowned or something," if she forgets her ancestral roots:

I think my family. Like, definitely my family and then just seeing others, but first my family definitely, because I see how my grandmas always speak in Spanish, and I'm not really like that. But, I'm not too far from that. I mean it's not like she's my great, great, great, grandma from thousands of whatever years ago. This is someone who is only two generations ahead of me, and we have lived together for only within the last twenty-two years. When I look at her and I see how she is, in a way it forces me like okay, I guess you can say, that's what I could have been not too long ago. It's kind of hard to explain, but basically seeing her, it's like I have to do it and it's my family. Like, I have to do it because if I completely desert that idea then... I get disowned or something...

William feels it is because of his skin-color and had trouble trying to articulate,

but the words do not appear to express his thoughts and he nervously laughs while stating:

Well, because it's not. American is not like when I see myself, I don't see myself. I kind of see American as more like the "White" person. I'm Mexican (with emphasis), so it's like I'm not fully American because I'm not White. I'm Mexican... I just consider myself Mexican (with emphasis). It's the way I grew up with the family and everything. I highly identify as a Mexican and I go to a public school. So I know where I grew up and know I'm Mexican, but I'm still an American (with emphasis) because I grew up in America.

The question for Maria produced laughter, and at times exasperation, as she appeared offended by the questions inference of causing separation:

You're taking the label of who I am? Like, it just isn't right... it does not make sense to me. I mean we're, you... I wouldn't be an American (with emphasis)! I'm not... I don't even know how to answer this question. Like it's kind of mind-boggling... to think that I'm just an American...(with emphasis). I mean, you just took part of who I am and just threw it out the window, and now, I'm an American (with emphasis) and they're like, well I'm not just an American (with emphasis) and how can that even be possible? I have been living as a Mexican-American (with emphasis), and now 
you guys are like, you're an American (with emphasis). It's like, when did I just become an American (with emphasis)? I've known all my life to be Mexican-American (with emphasis). I know that in my family we have some of the Mexican ideology and I couldn't just be an American because of the "welcome to the melting pot" mentality and being all mixed up into a new generation because I still have ties to Mexico, so I just wouldn't feel that it's right, or a better way to include us because now that you're saying everyone is an American (with emphasis), you wouldn't have a concept of what America is. Which standard is American? I don't know... that just isn't right (with emphasis).

Brynn's response to the question was she is not just an American, she is more than that, and it is the "Mexican-American" who serves as the bridge to bring those two cultures together, not separate them:

Because I am not just American (with emphasis), I am more than that. I am an American because I was born in America. I have learned social norms that are acceptable in American culture, but I still maintain some Mexican culture and even "Chicano" culture, hence, Mexican-American. How can people say it is alienation (with emphasis)? Doesn't having a hyphenated label mean you belong to both? If anything, we, Mexican-American (with emphasis), are part of the bridge that meshes these two cultures into one.

Defining who you are is what Jessica feels her self-label does, not create separation. She believes it better defines people:

I don't think it creates separation. I figure it defines who you are. It goes with who you are. Your name could be the heading and below, the little bullet points could have one for Latina, and the other would be whatever else I needed to define who I am as a person. I don't think it creates any type of separation it better helps define people.

Lisa also believes the self-label better defines who you are, "For me it's like further identifying yourself, giving more description of what you are personally. If you live in America, you are pretty much always going to be part of America, so as a Mexican, you 
pretty much add more definition." Although Mandy does agree, the self-label can create a separation and/or alienation since according to her, everybody's "roots" are elsewhere:

I feel like, I tend to agree. I know I feel like we're American (with emphasis). We're born here, and your roots are somewhere else. Everyone's roots are somewhere else, you know, so we're all Americans (with emphasis). So yeah, I agree.

While Samantha believes the self-label is a way to maintain your heritage, not cause separation:

I would say because in America especially with so many different races, cultures, and ethnicities that come together, just saying American would just be... I don't know... I think you like have to say what you are... Mexican (with emphasis), and it's not alienation. It's not creating a separation, I don't think, it's just keeping a separate identity as your heritage. That's something I think you should hold on to, and if you just start saying American (with emphasis), you're going to lose that, and that's kind of losing like part of who you are and stuff.

Theme 3 - Hybridity. Properly defined as being bicultural, the term hybridity is used in this study because of the treatise by Alvarez (1973) highlighted in Chapter 2, and the sample participants resonating with Alvarez's use of "two worlds" to describe what he termed living in the United States as a USB person of Mexican heritage. The first of two questions proffered to the participants was:

1. In 1973, Professor Rodolfo Alvarez from UCLA Wrote About Hybridity Meaning, the U.S.-born Mexican Lives in Two Worlds Because of His Mexican Ethnicity and Being Born in the United States, and Because of This, He/She Must Learn to Navigate Both of These Worlds to be Successful. What Do You think? All but one of the participants agreed with Alvarez's assessment, with the lone dissenter Lisa expressing:

I think it would be good to know why or where you're from. So with me being Mexican-American, I should for sure know. Where as an American, since I do live here, it would be a better aspect to 
also know what my background is as far as Mexican culture and stuff.

While Samantha believes Alvarez is correct, especially among the $3^{\text {rd }}$ generation like herself:

Yeah, I think there is definitely some truth to that. With myself being Mexican-American, and especially $3^{\text {rd }}$ generation, I feel a little more "Americanized" than like my mom or my grandma. I do definitely feel obligated to know how to speak Spanish, and also be able to speak English. You definitely have to like, play both sides. I feel it's an obligation.

Mandy agrees with Alvarez's sentiments, but speaking for herself, she does not live in two worlds:

I can totally see where he is coming from and I agree. I feel like if you are $2^{\text {nd }}$ generation to Mexico, I think it would be difficult because you do have those traditions and you do have that culture. Where like with me, my parents are so far back, it does not affect me. We don't have the culture. Like I said, when I was brought up, we spoke English only, and it wasn't like I had to struggle with two different cultures and stuff. But I would think, the closer the generations to Mexico would be more difficult to do that, so I would agree.

Whilst Jessica feels, she does not know anything about living in two worlds even though her grandmother has taught her to "always be a Latina," and she has lived in a primary Asian community since the $6^{\text {th }}$ grade:

I think it's true. I would have to agree with that. I mean, even if I don't know anything about that, but as far as what you told me, I think it would be good to navigate both.

Brynn's thoughts on living in two worlds are, one has to learn to navigate them because of different norms that sometimes do not agree:

I do believe that one would have to learn to navigate both these worlds. In each, they have certain norms and sometimes they do not agree. I grew up around Mexicans, spoke slang, and mixed in. Now at school, I try not to speak the way I would back home. 
Imagine if I go see my college counselor and say, "Wats crackin? I need 4 units. You think you could help me?" This would be acceptable back home but would be kind of silly, and in some cases, rude in another setting. Rather, I would say, "Hello, how are you? I was looking at my transcripts and I noticed I was lacking 4 units. Could you assist me in finding the right class to complete the units?" Sometimes back at home people think you are weird if you are too polite. It is different and I need to be different in each setting.

Whereas Maria agrees, and feels it is especially true for those who have closer ties to their Mexican heritage:

I agree. I'm finding that we do kind of live in two worlds. We, as the ones with closer ties to our heritage, we want to know where we kind of come from and yes, I feel I need to know how to navigate where your legend lies and the "American Dream" too. It's like living you know, the American Dream...get rich, there is so many opportunities, and then we're "Mexican... (with emphasis)." Yeah, I say we live in both worlds. But you don't want to be too much on the American side and then have that whole "she is White-Washed, and she does not even speak Spanish." The ability of speaking Spanish is important in Mexican cultural identity. You need to know how to navigate both cultures at the same time.

Living in two worlds has William agreeing whole-heartedly. He navigates both

worlds and tries to be bilingual in order to communicate with those who speak Spanish:

I agree! Because when you're around other Mexicans and you don't speak Spanish well, you're obviously seen as "White." It's all right, cool. But when you hang around with White (with emphasis) people, you're automatically seen as Mexican, who aren't "Americans" automatically... "oh, the Mexican guy." And so when I'm around Hispanics or Mexicans, I try to see, I try to understand them and fool around and speak Spanish. I kind of feel like I'm a part of them, I can communicate with them. So I'd say a lot has to do with being able to communicate with both of them well, you really need to. You know its two worlds, its two worlds (with emphasis) you live in, and so you need to learn two languages to be able to know them. 
As Amber concurs, and is more succinct in her response, "Agree completely. You have to navigate it. I have to know when to be 'Mexican,' and I have to know when to be 'American.' So that definitely sounds right on." Lastly, Jamey agrees even though she states she had never really thought about it until the question was posed to her:

I'd have to agree. It is trying to navigate two worlds. I mean, I never really thought about it till now, but I mean definitely you try and remember because you're trying not to forget your traditional past, and try to maintain your culture. But then you have to focus on real stuff that is happening in the world. So maintaining the two worlds is kind of tough. Having both of them is a positive thing. I mean I believe having both of them is a benefit because it gives you an insight of two different worlds, and you're not just accepting one worldview. I guess you can say... you can see the world in different ways. I'm not sure how else to answer...

The second question posed to the participants was because the investigator wanted to determine if the study participants believed what Professor Alvarez foretold 38 years before held true,

2. Alvarez Wrote That if the U.S.-Born Were Not Careful, "Outsiders" Would Write Them Out of Their "Existence" Meaning, They Would be Lumped in with Other Groups and Lose Their Voice/Identity/History. What Are Your Thoughts? Some respondents were confused by the question, two agreed with Alvarez, one lost his train of thought and gives a non-answer, and Jamey is not sure how to answer the question but gives it a try:

Hmm... I'm not sure how to answer that question... I believe everyone has a voice... I'm not sure how to answer that question. I think it is why I am having difficulty answering these questions because I don't know much about my past, and I'm not being taught a lot of it. I'm not privy to that culture anymore. Slowly I'm starting to figure out some of this stuff, and while I'm in my community, I'm reminded of my culture and ethnicity and stuff like that. When I'm around people from my culture they teach me 
a little bit, but I'm not into the culture anymore, so I don't know much about my culture anymore.

Brynn believes at some point all ethnicities of the United States will become one, but for now, if they do not distinguish themselves they will end up as Alvarez states:

If U.S.-born Mexicans do not distinguish themselves, of course they will end up blending in. But Hispanics have attempted to make their distinctions between themselves: Mexican; MexicanAmerica; Chicano/a; Puerto Rican, so that now, there are options in surveys regarding ethnicity, race, etc. I think eventually, we will all combine races and ethnicities, and there will be only one common ethnicity.

Samantha agrees there is a little truth to what Alvarez states and the U.S.-born Mexican is at times being "lumped" into one group:

There is a little truth to it just because like when we fill out an application or something, it says "Hispanic." So they're kind of lumping us Mexicans, Salvadorians, and all the other ethnicities that come from different countries, not just Mexico. We're all kind of grouped into one big group. So I think Mexicans are kind of losing their heritage.

While William chuckles at the question, agrees with its sentiments, and then loses

his train of thought and his answer does not address the question:

I agree. You know, I kind of feel like, just hearing stories about my mom and stuff, when she would go down to Mexico she's really a "light-skinned" Mexican, like she looks White (with emphasis). But she is Mexican and when she is down there and she speaks Spanish really well, unless she is with a native like my great grandmother, they try to "rip her off," or they look at her like a "rich White girl" with money compared to a Mexican-American who can speak English and Spanish... I forgot the question.

Maria on the other hand, does answer the question and agrees the U.S.-born could all be lumped together and lose their existence:

Yeah, that's true. We could be lumped into a different group or, category, which may not have the same concerns as someone like a Mexican-American. Even if they have the same ideas or thoughts, 
we're not going to have the same heritage as why our ancestors came to this country, or in some cases, some of us were already here and the border "crossed." So it wouldn't give a clear picture and we wouldn't have the right to expand our thoughts on how we fit into things. I know it would be a mistake if that were to happen.

As Amber concurs with Alvarez and Maria's sentiments, and gives an example of lumping when she fills out demographic surveys at the DMV, or other government documents:

I agree with Alvarez in his belief. When I fill in the little bubble at the DMV or on government documents, I have to fill in "Hispanic/Latino" because I feel as though I am just thrown in with everybody else.... Salvadorians, Hondurans, Puerto Ricans etc., and I am not that at all... I am not that at all. I am MexicanAmerican.

Lisa appears confused by the question and answers, "With being kind of put under the mat? Like if I have a voice to be heard? I'd like to think I survived that." Then answers, "Yes, the fact that we are placed in the "minority' category." Mandy understands the question, but feels she has no knowledge of whether it's happening or not. She replies, "I could see how it can happen, and I don't think I have the knowledge of if it's happening or not. But I can see where it can" Jessica's answer completes the questions asked in the Identity Category:

I think that could be true. Because here at my community college, we have different Clubs and Groups, and we have AB540, which is undocumented students and they in particular, don't really have a voice here on campus. This was part of the meeting we had today as in, how could we help them have a voice here at the community college.

As I listened to the interviews, reviewed the transcripts, and wrote what has been chronicled in this identity section, there was one factor apart from the themes and categories which kept coming to the forefront at all times, "Ethnic Pride" (with the exception of one). Over and over as they discussed their lives and expressed their 
thoughts, they were proud to be who they were. Yes, they felt alienated from "their own," contradicted themselves at times, and dealt with discrimination, reverse racism, and resorted to what I will call "Reverse Assimilation" (all concepts which will be discussed in the next category), but despite this, "never backed down" from who they are and let it be known they are Americans, but of Mexican descent. Period. Others may label them something else, but if one allows them to self-describe, this is who they are and want to be, and they will not apologize for it.

\section{Alienation}

There is an abundance of literature on students of all colors feeling alienated as they navigate the educational pipeline (Acuña, 1986; Castillo et al., 2006; Harper, 2009; Lewis, Chesler, \& Forman, 2000; Matute-Bianchi, 1986; Museus, Nichols, \& Lambert 2008; Ogbu, 1983; 1992; 2003; Solórzano, 1992). However, the focus here is on the sample population of these 3GAB-USB Mexican college students, and their alienation issues are not necessarily those which have been perceived for many years. This alienation category has been divided into three themes, which emerged from the transcribed interviews: Feeling Distant, Discrimination, and Reverse Assimilation.

Theme 4 - Feeling Distant. This theme emerged because of the question from the interview guide, which specifically asked if the respondents felt they were losing their identity or becoming distant from family and friends due to them becoming educated (Ousley, 2006; Rodriguez, 1982; Vielma, n.d.). The origin of the question was the result of conversations the investigator had with faculty, peers, and other Mexican and Latino individuals who successfully navigated the education pipeline because of Tinto's (1987; 1993) assertion that detachment from the home community, along with incorporating new 
behaviors, memberships, campus resources and networks, were a necessary condition of a successful college transition (Munoz \& Maldonado, 2011).

The question asked was, "Educated Latina/o(s) have spoken about feeling distant from family and friends as they navigate academia and achieve their goals. It is a problem for them because they do not want to lose who they are (Identity). Do you feel the same ambivalence?" Four of the nine participants felt they were distancing themselves, while two did not, one felt they were "evolving," and one did not care because of wanting to experience "new things." One of the respondents, Jessica at first did not understand the question as stated. When it was restated, her response was:

Now that you further elaborated on the question, yeah, I do. Because I mean, how I said earlier, I'm the first to graduate from high school and go to college in my family. So far as I know, my parents did not graduate or go to college, and my grandmother you know, just raised her kids. Once I graduated and I came to college, I was kind of just in "culture shock" like, whoa... I'm not distant from my family, I'm just a couple of minutes away, but I feel distant, like when I was telling my grandmother "this and this" happened at school, she would just look at me like "I have no idea what you're talking about." I do feel I'm losing this culture and once I graduate and transfer down South to the Los Angeles area, I feel like I'm going to be distant from my family, and at an educational level feel like I'm higher than I already am, and I do see myself distancing myself even further.

Maria also felt she was distancing herself especially from her mother and has disagreements with her because of different points of view. She explains:

I do feel distant in my family with my mom at times because of some ideas my mom has at times, that I kind of disagree on. It's not the way she says and I kind of look at her with a different viewpoint, and then she's kind of like no, and then you look at the older mentality where this is the right way, and I just let it go. I guess the more you move up, the more it becomes different in seeing things around us. 
As does Jamey, who feels, she's growing distant because of time commitments at school or work:

Yeah, actually I do. Right now I'm not too close with my family, and I feel different... I mean, the majority of the time, I'm at school or work. I'm not as much with my family and that's the thing my mother kind of nags at me about, because I'm not at home as much anymore, she feels I'm growing distant. Cultural wise, I'm not as close as I was when I was a kid. I would be with a majority of Hispanic people, but not now. I mean, I guess in a way, I am kind of furthering away from my family and my culture. Yeah, that's the way I can describe it.

For Lisa and Amber, their response is no, they do not feel they are growing distant or losing their identity. Brynn says, "I do not feel distant. I am MexicanAmerican, and I can dabble in both worlds and still maintain my identity." Mandy feels, "I feel like I have to get a degree, go to college because that is something that was always imbedded in me... you have to go to college, you have to do something. I don't feel distant at all." William and Samantha, also do not feel they are losing their identity and both at this time are okay with becoming distant. Samantha calls it evolving:

For me personally, I don't feel like that, because I have a very small family and we're not very close with our extended family because we have issues and stuff. So, it's just basically my mom and my sister that I consider like family. I don't feel like I would be leaving people behind. Even if it were to happen, I don't think I'd care, because I want to succeed and "evolve" so I won't really leave people that I care about... just like my mom. I don't think I'll lose who I am. I'll just evolve; it will be like we've grown... like we grow as people so... it would be part of me that has grown.

And William wants to experience new things. He does not want to be living or working at the same thing till he's " 50 ":

Not really. What I mean is, how do I live in Oceanside, CA all my life? With family and friends who grew up in the same neighborhood. I love them, but I don't want to be working a crappy job working 40 hours a week, 8-5. I need to do something. I need to grasp this world and accomplish what I want to do. I don't want 
live in Oceanside till I'm " 50 " and never move out of the city, or even the state. I want to experience life, and part of that journey is going to college.

Theme 5 - Discrimination and Racism. Throughout the interviews incidents of discrimination and racism were exposed from the personal recounting of the participants life, their school experience, or the reason they chose their self-label. Some of the participants had become so immune to the microinequities, that when they were asked if they had ever been discriminated against, or been a victim of racism they responded no, even though in other portions of the interviews they had recounted specific instances of it, and some claimed they were not offended by it.

Additionally, some may notice (because many studies on Mexican or Latinos do not discuss it because the focus is on other variables), most of the discrimination, and racism came from within the Latino category, with the majority of it, from fellow Mexicans. Ono (2002) has referred to this, as Ethnic Competition meaning in the hierarchy of ethnic individuals fighting for whatever resources are available to them, someone ultimately have to be lower than the other. The two questions addressing discrimination and racism were intended to illustrate the internal and external perspectives. The first question was directed at external discrimination and racism, while the second question dealt with internal or within-group discrimination and racism,

1. Have You Ever Felt Discriminated Against or Been the Victim of Racial Comments? For five participants the answer was a definitive yes. For the other four, it was more complicated. Mandy states she does not remember any instances of discrimination, "I don't know of a certain situation. I don't have something that's happened that I could think of but I realize it happens." When she is asked about 
comments directed at her Latina sorority, or the Multicultural Council she is president of, her answer changes:

Yeah, people have said comments about like the sorority, or talk about the multicultural council and organizations, you know, offcolor things.

Lisa also says, "Not that I can think of." Then in the next instant, gives an example of cultural discrimination:

All I can think of, is one time at my first job, I worked at a Hispanic clothing store not knowing Spanish, and I would be criticized by some customers who would say, "You work in a Hispanic store and you don't speak Spanish?" Stuff like that, so in that case yeah, other than that no.

Maria on the other hand, says yes many times, and elaborates on one incident during an Individual Education Plan (IEP) meeting in high school with her parents, school counselor, and teacher:

In my senior year I was being evaluated and in the meeting my teacher asked "What is going to happen next," and it seemed what was on their mind was "oh, I guess the best thing for her is just to find a job." You know, it just bothered me, that they were going to cast me off (with emphasis), as if I wasn't able to do anything, that the best thing in my life was just to go work and not get an education, with the counselor saying, "maybe you won't excel in college."

And gives another example of what she perceives to be an incident of discrimination at her local shopping center:

So, I don't know about this shopping center. I really don't like going there because it's mostly wealthy, with a wealthy AngloAmerican population, and going into the boutiques, I just don't get a welcoming feeling. It really comes off as you're watching me. It's just uncomfortable. I feel like my skin color and hair color let them know that I don't fit in this shopping center. 
William recalls racial jokes and an incident with someone he was working with the previous summer, and feels there is not much he can do, but to blame it on ignorance:

I remember I was working this summer with a guy from Church, and he was helping us out. Ironically he is married to a Mexican and he says, "Well all the immigrants and stuff, they should go back... they're taking all the jobs, yada, yada, yada..." And then he goes on... He tells me he learns stuff from me with me being the only Mexican around, but I get the racial jokes "here and there..." being called "Beaner" and stuff, but I feel like I don't take it as offensive, I mean, I do, but I just think it is people who are ignorant. It's not like I can identify with being Mexican much, I don't have a strong identity as "Mexican," as in totally brought up and stuff. So it's like not even offensive to me like I'm sensitized, it's cool. I mean there's nothing I can do....

While Jessica recalls her attending a predominately Asian/Filipino high school where a classroom may have had only one or two Latinos in it, and elaborates on her experience:

Actually, yeah I have. The high school I went to was primary Asian, and Filipinos, and maybe 1 or 2 at the most were Hispanics in class, and the teachers were also of primary Asian/Filipino ethnicity. I felt they always had snide comments, and you'd kind of be like, is that towards me, or even joking around with friends, it's not hard to hear snide comments... oh you know, "Border Hopper" whatever. Even though it wasn't specifically toward that person, it was kind of like you haven't earned the right to be here. But definitely in high school, I feel I was the victim of that, the snide comments from teachers or students around me because of being one of three Hispanic students in class.

Samantha feels it happens sometimes with her friends or when she hears people referring to Mexican-origin individuals:

Sometimes, like when I'm with my friends and stuff, I hear like people kind of referring to Mexicans... kind of like a joke. Especially because I don't look Mexican, people will say a joke, and I do take it personal because I am Mexican (with emphasis). 
Where for Brynn, who states that she has not been a victim directly, gives an example of an incident at school:

I was with a friend and he had some "White" friends and I asked them to walk me towards the light when I was leaving, and one of the White guys said, "oh, what do you have to worry about" White (with emphasis) people only rape White (with emphasis) people, and ... I didn't know if he was trying to be offensive or he was just trying to make me not worry. But either way, it still didn't seem like the right thing to say. Suttle things like that I have.

Whereas Jamey's response appears very conflicted as she starts to say no, she has not been a victim of discrimination or racial comments, and then says she has, around Mexican individuals:

Not really. I mean, sometimes I do really... I mean, basically if I'm around Mexicans you can say they would label me as... I guess you can say, "White-Washed." I guess you can say sometimes... because if I don't speak Spanish to them sometimes, they just label me as White-Washed (with emphasis) you know, "American." And other people, I guess with my skin color consider me American, they don't consider me "Mexican." I don't know... I mean, it isn't till I tell them I'm Mexican, that they... I really haven't experienced it.

Amber feels, "Yeah, definitely have." The example she gives is of cultural discrimination and laughs as she talks about it:

Yeah a lot of people have told me, "oh you don't speak Spanish," and I definitely get it all from my family. It's not only me, but my two brothers, and my cousins... we're all completely just considered like "White" coconuts. Now that I think about it, they always say, "what a waste of color."

Then follows up with a comment about teachers, "And some teachers too...but I mean just talking out of their butts. They don't know anything!" Asked if she excuses teachers because of their ignorance she responds, "I guess I do to them what they do to me, I'm just like, "oh, they're 'White,' they don't know" and laughs. 
The second question posed to the participants regarding discrimination or racial comments was to ascertain how much within-group conflict the participants encountered,

2. What About Discrimination, or Racial Comments From Fellow Mexicans or Other Latino Subgroups (e.g., Puerto Rican; Central Americans; South Americans; Spain, etc.)? All the participants agreed they have been victims of discrimination or racial comments from within their own ethnic group, some more than others. Amber feels tension with Mexican, and other Latino groups because she does not always do the same things they do and she has already been told numerous times that she is not "really" a Mexican because she does not speak Spanish:

No comments, but kind of get the impression especially like at my university, we have a Cesar Chavez Foundation Center, just when they're telling me about it, "oh, we did all these marches and we did these things for Chicano Rights and stuff," and I'm not really into that. So I definitely feel that, and I feel the tension with other Latino groups, and it definitely pisses me off. What does it matter if I speak Spanish or not? It's what's in my veins that define whether I'm Mexican or not. And then when they speak to me in Spanish and I answer in English and they just walk away... I guess if they're going to be that ignorant well...

Jamey as recounted throughout her interview and because of her blondish hair, light skin, and green eyes has constantly been "picked on" throughout her life because of how she spoke Spanish as a child, and stopped speaking it, until after high school, and contributed to making her "a very quiet and shy person" around Mexicans and other Latinos because of the constant bashing and labeling from them of being White-Washed. The first five questions of her interview took up over five transcribed pages of her discussing how she is treated with indifference and contempt from Mexicans and Latinos, just because she did not in her opinion, speak Spanish well enough to appease peers and adults. She 
appeared to be at peace when her mother moved the family (Jamey, and her 2 sisters), to an "all Caucasian" place and spent her four years at a high school where:

I mean, they cared more about academics, and the students were much friendlier and they didn't really speak Spanish or anything, so it was just very different from where I was coming from where I was speaking Spanish all the time, and it didn't really matter as far as school work and stuff like that...

And now at community college, Jamey is attempting to reconnect with her ethnicity as well as taking up speaking Spanish again because she feels, "like my college taught me well, and I got to think more for myself and tried to figure out who I was because in high school and middle school, I was basically all towards trying to figure out my education."

Brynn responds to the question, "I guess just like, 'oh, you're White?' I have some people call me White (with emphasis), and I don't really like that. I don't like that stuff, 'White-Wash...' they did call me a 'Pocha."' When she is asked if this is recently or throughout her lifetime, she replies:

Throughout my lifetime. Yeah I mean, when it comes from friends it's just like, "ah, you're a Pocha" whatever. But there are some friends that would really get upset like that, where they'd say "you're a Pocha," and you really can't have a say in it kind of thing. So it's just different because I'm the person that always gets told that kind of thing.

Samantha states that she hears it a lot, and believes a reason for it is because like Jamey, she does not look Mexican because of her 5'7 athletic, light-skinned, green-eyed, and brown hair appearance:

Yeah, yeah, that's one where I hear it a lot. I'm good friends with a Salvadorian, and he like, always gets really frustrated when people say he Mexican, and he like takes I and starts cracking jokes like, "I'm not Mexican (with emphasis), I don't eat frijoles...I eat Pupusas" and stuff like that. And I do hear... even among my Mexican friends, I will constantly hear "she's Mexican," like they don't believe I'm Mexican. It' more like they're joking about it, 
but I think there is some truth to it. Definitely I used to get like, "oh you're White-Washed (with emphasis)," and this and that.

As does Jessica, who has light-brown colored eyes, long curly light-brown/blondish hair and also hears "snide" remarks from friends:

I think a lot of my friends say snide comments, or just little things kind of like whoa... where did that come from? Like I thought you and I were different, but then we have the same background like we're both Hispanic. So where'd that come from? It kind of tends to shock people, when people of your own race do that.

Mandy who does have a Mexican and/or Latin appearance, believes the comments are more directed towards her because she does not speak Spanish, and laughs when she states that even her sorority sisters make fun of her for not knowing how to speak Spanish:

I would say yes. It's more like I said when I see people like I don't speak Spanish, you know, its like I'm looked down upon by Mexicans and I sometimes feel they talk about me and whatever. That would be it. You know even my sorority sisters make fun of me for not speaking Spanish.

While Lisa, who is a 5'3 member of the track team with olive-skin color, dark brown colored hair, and eyes, laughs and says it happens often:

When I meet someone who is also from a Hispanic background, they ask you, "Do you speak Spanish?" and you I say no, and they're shocked. So they're very surprised and then they say, "oh your Mexican, and you don't speak Spanish?" Stuff like that, so that does happen often.

Maria, who has spoken of various within-group discrimination and racist remarks throughout her interview replies, "Well, like the comment, "What kind of Mexican are you?'You don't really have the full traits of what it is to be Hispanic/Mexican." William who also recounted various incidents throughout his interview states, "Yeah, I'm usually 
called 'White' and stuff like that." But then recalls frustrating instances in school while on the Basketball team and wanting to be in the Honors program:

In high school I kind of felt discriminated against when I was playing Basketball because I was short and Mexican. But yeah, I could "Ball." I could handle the ball. But you know, most of the kids were "White," and I felt like there was a racial barrier as far as sports wise at the school. Then in freshman year I was excited because of my grades, and I believe in my overall potential when I really work hard. I brought this up to my English and History teachers that I want to be in "Honors," and they kind of said, "well, you know Honors (with emphasis) is kind of hard and you should really think about it" and stuff like that, and I'm like, what... wait... Rather than encourage me they kind of said, "you can't really do that." I did it anyway, even though I was the one Mexican and the rest were "White." I went to an all "White" public school.

Theme 6 - Reverse Assimilation. The literature on ethnic groups explains the process of assimilation into mainstream society. In Chapter 2, the literature review questioned if the USB multi-generational Mexican whether a student or not, did in fact assimilate according to the definition of assimilation which is basically an immersion into the host society. The argument being, that if one is born and is a part of that host society, how then does one "assimilate," if it inherits the norms and practices of said society? There is no doubt arguments can be made against this premise, but for participants of this study population, their process of assimilation went retrograde. They did not assimilate toward the U.S. society, as has always been the perception, they tried to assimilate to "Mexican" society, in order to "fit," and in some cases be accepted among their own ethnic group. This process which I will call "Reverse Assimilation," is described below by the study's participants:

Amber throughout her interview made it a point to elaborate how fellow Mexicans and other Latinos continually drew her towards being "American" even at the 
consequence of continual ridicule from her family for being "a waste of color," and feels she has to "be like that too" or "I need to change my ways in order to kind of fit those requirements." She elaborates further:

That's what influences my... "Well I'm not going to be Mexican" idea. Why am I going to be that? I'd rather be "American." I am American (with emphasis), because apparently, I don't fit the requirements of being Mexican (with emphasis). I wasn't born and raised in East L.A., I didn't grow up in the "hood," I didn't grow up anything like that.

But then, she feels remorse and exclaims, "That's when I kind of feel bad and ask myself, what kind of Mexican are you? You don't want to be with your people or defending them. What's wrong with you." When she is given a chance at the end of the interview to add or have the last word (as all participants were encouraged to do so) she ends the interview with:

Just one thing that $I$ think is interesting is that either we are completely stereotyped by society as being an immigrant because I say I am Mexican-American, or we are completely ostracized from our own people. I think that is one thing I truly want to emphasize is just that, you know, I guess you can say because of "my people," I'm not Mexican (with emphasis) enough, and that just bugs me and I know it bugs my friends as well that I've grown up with. We're not Mexican enough because we don't speak Spanish? I guess that's what irritates me. That's what causes me to think, well who am I, what am I? What should I do? Do I shift and consider myself "Hispanic?" Do I all of a sudden, turn on "that accent" when all of a sudden someone is around me? I know I had already mentioned this, but it really bugs and irritates me. It's like I have to turn on a light on and off. It's like who am I, what makes me, ME? It's kind of sad when you think about it. I need to change myself in order to fit the surroundings around me. I think that is the big issue I have.

Jamey acknowledged after years of being ridiculed because of her Spanishspeaking skills and being labeled White-Washed because of it, she had to reverse assimilate to her ethnic group in community college: 
I mean, once I started college is when I started identifying myself, as who I was, and what I wanted and stuff. So it wasn't until I got here at community college that I started to pick up the language again because I had a lot of students and friends who spoke the language, and they always asked me, "How come your not speaking the language? Why don't you speak Spanish?"

William has already stated previously how he tries to reconnect with Spanish-speaking Mexicans and other Latinos by speaking to them in Spanish and trying to "live in their world." He adds:

So I'm American, I wasn't taught my culture, I basically have to go back and integrate myself in the Mexican culture in order to actually understand them in a much richer sense, rather than you, learning it from the $1^{\text {st }}$ generation and kind of just watching them enjoy the food. No one teaches you about what it means to be Mexican, working hard, or values. You just sort of already know.

Whereas Brynn, who firmly believes she can "dabble" in both a Mexican and Caucasian environment, because she can speak Spanish, but "chooses not to," will engage herself in order to "fit in" with Mexicans and other Latinos:

"You don't speak Spanish, you can't consider yourself Mexican." Well I can speak it, but have an accent when I do so, and because of that, I don't sound "Mexican." So I choose not to speak it. But I understand it and we can have a conversation and I always respond in English. I do think about though. I am Mexican (with emphasis), and I can't deny it.

Nevertheless, she says that if there were cultural boundaries, she would not want to know these individuals and maintains a group of close-knit of about five or six friends who are Hispanic:

I have kept a close-knit group of about five or six friends that I met in freshman year and are surprisingly Hispanic. Two are from Guatemala and one is from Brazil, I think. I think, I still have... if I don't relate to someone, I won't see them again. If there are these cultural boundaries, I won't, I wouldn't want to get to know them. 
For the only three who claimed on the demographic sheet they were bilingual in Spanish and English language proficiency, they were fully aware it allowed for acceptance into the "Mexican/Latino" Spanish-speaking group. Jessica states that when she speaks Spanish, "the people who hear me talk Spanish, they'll be like, 'oh, did you learn it, or are you Latina," which gives her an opportunity to have more fruitful conversations with Mexicans and/or Latino Spanish speakers. Samantha feels it is an obligation, "I do definitely feel obligated to know how to speak Spanish... and also speak English. You definitely have to like play both sides, to be accepted." For Maria, it's about finding the right fit and feeling comfortable:

A lot of it is where you fit in. Because you know your Hispanic, and there is a group of $1^{\text {st }}$ generation Hispanics, and because I'm Mexican-American, I ask myself, do I try to meet them and hang out with them because they're Hispanic, and I'm Hispanic? Do I need to hang out with them, although we're not the same because you speak Spanish at home and you are very comfortable speaking Spanish as your $1^{\text {st }}$ language and I am not? And then it's like, so how... okay, how does, I don't fit in that category. But then you have to find the medium that you really fit comfortable in.

The last two participants Lisa and Mandy understand they would have to go through the process of reverse assimilation in order to connect with Spanish-speaking Mexican or other Latinos. But at this point in their lives, Mandy being comfortable as an "American," and Lisa being an athlete, it is something they did not address in the interview because it was not important to them.

There were other variables which I recognize were prevalent within this portion of the interviews, but because of time, and the framework of the study (i.e., to only introduce the very basic issues associated with the sample population), there was no effort to delve deeper into within-group differences and/or fighting; racial and ethnic 
discrimination; ethnic differences; racism; reverse racism; phenotype, or how skinpigmentation determines acceptance within the Mexican and Latino communities. These factors are for another day and time.

\section{Transition to College}

How Mexican/Latinos gain access to the higher education pipeline has been assessed and reassessed a multitude of times again, with the understanding that the results achieved, may or may not have a true bearing on the 3GAB-USB cohort. Eight of the nine participants have attended community college. All eight attended, or are still attending, Hispanic Serving Institutions (HSI) in very nurturing settings, which is not always the case for $3 \mathrm{GAB}-\mathrm{USB}$ Mexican and Latino students throughout the country. There were four sections from the interview guide (Appendix E), which focused on their educational experience and led to the following three emerged themes: School Experience; Support Groups; and Recommendations, for a successful transition to college.

Theme 7 - School Experience. The questions asked were to gain an understanding of what the participants experienced while attending college. The first of four questions was,

1. All College Students in the Beginning Feel a Sense of "Not Belonging or Alienation." How Much Does Your Ethnicity Enhance or Alleviate Those Feelings? Five of the respondents do not feel their ethnicity has been detrimental in their school experience. Three do believe it has at times, contributed to their sense of not belonging, while the remaining participant appears indifferent to the question. Maria, who is a transfer commuter student from a San Mateo County Hispanic Serving Institution (HSI) 
community college in the San Francisco Bay area and now attends a university there, feels:

At times, I feel that my ethnicity has made me feel like I don't belong when there is not a large population of the same ethnicity as me. I feel like there is something wrong with me. I am I doing the right thing in being here in college? After some time, you get used to the new environment of what college life is. I now know what it takes to graduate because I transferred, I got myself halfway, and I kind of know what it takes to finish here.

But Jessica, who is still at the same Hispanic Serving Institution community college Maria transferred from, is not sure her ethnicity has anything to do with it:

I don't know if it enhances me. I just know that when I started college, I just felt so lost. I didn't know what I was doing. I didn't know what building... classrooms, nothing. I don't think my ethnicity helped pave the road with my feeling alienated my first year in college. I don't think my ancestry had anything to do with my first semester in college.

Brynn, the only sample participant who went directly to a university from high school experienced "culture shock," and then laughs when she recalls her first encounter with the university's Asian population:

I felt alienated my first year of college after my summer Bridge Program because of my ethnicity and my background. Here at my university it was a big "culture shock" for me since I went to a high school with about a $99 \%$ Hispanic population. Since I had not been exposed to other cultures, I did not know how to associate with other students. I mean as silly as it sounds, I saw Asian people smoking, and I would say to myself, “Asian people smoke?" Wow, they're normal and it's kind of ridiculous, there just like regular people.

She then elaborates on her first few months attempting to establish friendships on campus:

When I first came to school, I was trying real hard to mingle and people would tell me, "you have an inflection" and I would tell them what do you mean by that? I speak English and people would 
say, "oh well, you sound different," you say things differently, and I'm like okay... and I thought maybe I have an accent and I don't even know it. But then I figured out that they just thought I was different. I don't have the same manners that people have, like based on my family and Hispanic background. It is okay back home, but now it's like people think I'm different, and they can't relate to me, so I'll just rather go with that.

In the investigators observation of Brynn, she was polite, well mannered, and spoke perfectly. There was no accent, or difficulty in her speech or pronunciations, of both English and Spanish words. In fact, she was one of the most eloquent interviews in her choice of words and expressiveness.

Amber believes at her Los Angeles County HSI community college her ethnicity helped her not feel alienated, but when she transferred to a nearby university, it changed and she laughs at how she no longer see's Mexican food delicacies like at her HSI community college:

I think it actually enhances it because when I look at my past growing up all the students were well, Hispanic, Mexican as well or Latinos. So I guess going to school, I thought, "Oh, there all like me." I didn't feel like, "I'm the only Mexican here." It was never that all. We were always the majority. When I look at them, they kind of look like me, "the coconut Mexican." They're not wearing a big old "Chicano" shirt. Now that I transferred to my university, for the first time I feel "ethnically" inferior, because everyone at the school is Asian, and so I see that and I crack up because it is racist I guess, but there are no Bake Sales with "pan dulce," just Asian food on sale.

Even though Samantha, who attends the same nurturing HSI in San Mateo County as William, Jamey, and Jessica, feels the question does not apply to her:

Definitely does not apply to me because I am very social, and like, I don't let myself feel uncomfortable. I feel it depends on how you take the situation... that's just the experience I've had. I'm just the type of person that initiates conversations and stuff, so I never feel alienated, and I don't think my ethnicity has affected me either in situations like that, just because I'm so "Americanized." 
As does Lisa, who attends the same Los Angeles County university as her good friend Amber and responds, "I'd have to say neither. Being in school like I'm part of the track team, and like everyone gets along. I don't think it has anything to do with my environment in school." Likewise with Mandy, who expresses similar sentiments to those of Samantha and Lisa by stating, "I don't think it does. I don't feel, yeah... I don't think it does at all," and William, who agrees with all three:

Oh, I don't think it does at all. You know, it's about getting involved, being open to... meeting with people and breaking the ice, you know? Just breaking the ice with people.

Lastly, Jamey does not know if her ethnicity helps or alleviates a sense of not belonging by declaring, "I don't know, I can't really think that far back."

The second of the four questions describing the sample participants' school experience was,

2. Describe Your Overall Experience at This School. With the exception of two participants, the experience at school has been great for the respondents. Jamey really enjoys attending her HSI because of everything it offers, from the small class enrollment to all the support she receives:

I have to say it's really good. I really enjoy it because the classrooms are really small and the teachers are really good. Just the fact that the classes are small and the professors are accessible in addition to the many different clubs on campus allows the students to be active. I've really enjoyed my college experience because of all the support I have at my school.

Whereas Mandy has had great experiences at her San Diego County university because of the contacts she has made:

Fun... I met so many... I've met so many great people, people that I will be a friend with forever. A lot of staff yeah... a great experience. 
While William has taken advantage of the support programs available and wants to totally "soak" it all in before he transfers:

I love it a lot. There are so many resources available for lowincome $1^{\text {st }}$ generation college students. I'm totally taking advantage of everything, like filling out my FAFSA, the TRIO Program, and all the grant and scholarship money available because I'm a minority. I'm just totally soaking it in before I transfer.

Lisa a recent community college transfer, has loved both her community college and university experience:

At community college, I absolutely loved my entire experience, as far as being part of the athletic side of the campus. Academically, as far as teachers, they were very helpful. However, now at my university, I love the atmosphere. Like those in my major... students, teachers, professors, like everyone is very comfortable with one another. Like they help you out with everything, again like my track athletic body, everything is wonderful.

Although Lisa's friend Amber, has had a different university experience because

she is no longer the majority ethnic population as she was at her HSI community college:

Here, the majority is all Asian, and so it's like... I don't know, it just throws me off... I feel like everyone's looking at me because I'm Mexican, and I don't know... I guess for the first time in my life, I actually feel like I'm being singled out. Being Mexican and being brought up and kind of getting thrown back at my face in a way because I'm not like everyone else. That's what has really caused me to think from the first day on campus. It has caused me to really ask myself, "Are you Mexican, or what are you?" I think that's what really has got my juices flowing. So it's like, okay, I got to find out who I am... I can always be Mexican you know, except when I'm here...

Samantha has also had a good time at her community college, and has participated in student government, and is a member of Phi Beta Kappa:

It's been good. I've gotten to really know a lot of the professors and staff, and a lot of key people even those in my class. It's really been enjoyable for me and I'm in student government. I'm a 
Senator for our student government, and I also joined Phi Beta Kappa, which is an Honor Society. I am very involved. I do like my school very much.

From the same college as Samantha, Jessica as well, has enjoyed her stay and loves the campus, the people, and the support groups:

I love it here. It's just a beautiful campus. The people here are incredible. The teachers here are great. They really help us. The support groups are just phenomenal here, like EOPS and TRIO, the Latina Horizon Group we have here, it's just great.

Maria, who transferred from the above community college to a university nearby, explains, "I think it's good. I'm a commuter student, so I don't stay on campus that often. The atmosphere and population is different then what I would see at home. It's more diverse. It's interesting." While Brynn's response seems a little contradictory, considering the statements throughout the interview of culture shock, discriminatory and racist incidents, no really help from the support services on campus etc.:

My overall experience, it's been good. I think my social life hasn't been like really crazy yet, because of my close-knit group of five or six friends and I have not really gone outside of that.

The third question pertaining to the participant's school experience, which was asked, was to learn about where the source of encouragement to attend college emanated from:

3. Who Encouraged You To Attend College? Three respondents were selfmotivated and stated no one encouraged them, five were encouraged by family members and for Brynn, it was her $10^{\text {th }}$ grade Mathematics teacher:

My $10^{\text {th }}$ grade math teacher. She actually thought I was going to do really well in math and encouraged me to take a $2^{\text {nd }}$ year of Calculus in high school. I was not sure I could pass both tests, but I said okay anyway. Then at the last minute, I began to fill out 
college applications, and I ended up passing and she was really proud of me.

Family, self-motivation, and not wanting to be a "statistic" is what got Jessica to complete high school and enroll in college:

My family. Like my grandmother, and most of my family, and I didn't want to be another "statistic." I've overcome a lot of statistics. I graduated high school. My parents didn't graduate high school. My mother got pregnant when she was very young. I have not gotten pregnant. I've graduated with a good GPA, I've just overcome statistics. People have tracked me, and I don't want to be a statistic...I aspire to be a young Latina who done this and that, I'm going to college, and though I haven't graduated yet, that is another statistic that I can be. That also helps... encourages me to go to college and go as far as I can in terms of being a Latina.

With Amber, it was her parents who encouraged her and recalls her mother telling her about her college experience before dropping out because she got married and began to raise a family:

Definitely, my parents encouraged me to go to college. My mom had gone to college for a couple of semesters, but she got married young and wasn't able to finish. She used to tell me about it and I guess, her best times in her life were when she was in school. She learned more and loves to learn. My dad had gone to Trade Tech, so my parents definitely encouraged me and were excited for me to go to college.

While Samantha credits her mother and herself because she has goals she wants to achieve in education:

My mom and myself. It's something that I personally strive for, and I want to get my degrees and stuff. So it's definitely like I'm personally driven. I don't need someone to tell me to go to school. But my mom has this big rule about education because she went back to college when she was older. 
Jamey already knew in middle school and was further encouraged by her high school Biology teacher mother and grandmother:

My mother is an educator, a high school Biology teacher, and she has always been in my ear. My grandmother would tell me, 'I don't care what you're gonna do, but you're going to get some kind of education."

William encouraged himself because he remembers his Aunt attending UCLA, and so he wanted to attend UCLA too. Lisa stated the she encouraged herself. Maria laughed and said, no one encouraged her to go to college because it was just something she wanted to do, while Mandy responded that it was "basically my family, my mom and dad."

The last question was asked to understand and gauge, how much the respondents had matured or learned through this point of their lives,

4. In What Ways Do You Feel You Have Grown While Attending College? The respondents cited factors such as becoming more organized, responsible, and maturing, whereas Maria believes she has grown because of acquiring critical thinking skills:

I guess critical thinking. You can really question a lot of thoughts, a lot of different viewpoints. Public speaking, just know that every class has some type of presentation. To know that you can conversate, I guess in an enlightenment type of conversation in general... to know, that if you ever need to conversate with someone you don't know, you can always go back to something you learned in class.

William believes he has grown to be more responsible, organized, and confident, because he feels his time in college has set up that foundation:

I've grown in the sense of being responsible. Going to school has allowed me to be more effective, how to be more organized, and prioritize in putting some things first, before all others. I feel like I'm more, how should I put it... I feel more confident just as a person, academically as well as personally. Its like going to college, has allowed me not to worry about what some people 
think. A lot of people may not like you or whatever, but I gained a lot of confidence because college really set up that foundation.

While Brynn like William, believes she has become more responsible, in addition to becoming more disciplined:

I've become very responsible. Like I said before, you know I did have my responsibilities and independence before, but when I came here, I learned to discipline myself more... it was more like feeling like an adult and it was probably the biggest growth.

Lisa also feels she has grown by prioritizing, like staying home on Friday instead of going out:

I find myself studying hard. As far as like attending or utilizing my free time to study, making my priorities to where they should be, like staying home on a Friday night studying and doing homework rather than going out. I see myself more grounded and understanding of what's more important.

Whereas Samantha has gained knowledge, laughing while she reiterates that is the point of attending school, but also feels real "growth" for her has not happened yet:

I definitely have gained knowledge. I've taken classes that I've actually come out like, knowing things. Obviously that is the point of going to school. Socially, I've met a lot of people. I don't know about the growth, because the growth hasn't really started yet, because it's pretty much like high school. It's pretty much a routine. I'm kind of stagnant now.

Mandy feels her growth is measured by how much she has matured while at her university, Jessica concurs with Mandy's assessment of maturity, while adding, "I learned how to use my time. I never used a planner, but I do now, and it has helped learn how to manage my time." Amber measures her growth by, "definitely got my priorities straight and I really just figured out, who I am, and what I stand against." And Jamey believes "I think I have more confidence within myself. So I've grown up in the sense that I'm more active, more talkative, and I am a more poised person." 
Theme 8 - Social Support. Support in this section meant who helped the students navigate obstacles they faced while becoming educated. Some studies in the literature have described the lack of social support as one of the causes Mexican and Latino students do not complete their educational journey (Andalón, 2005; Castillo et al., 2006; Gloria, Castellanos, Lopez, \& Rosales, 2005; Moilanen \& Raffaelli, 2010; Rodriguez, Mira, Myers, Morris, \& Cardoza, 2003; Schneider \& Ward, 2003; Tinto, 1993). This in turn, becomes another psychosocial challenge the 3GAB-USB Mexican college student must navigate. Three questions from the interview guide (Appendix E) are highlighted here. Beginning with,

1. Who Is Your Support Group? Support for this sample come from a variety of sources: including school programs; friends; family; and for William, support comes from his faith, and his college administrator Aunt, who obtained her Ph.D. approximately three years before:

God. When I feel really overwhelmed by things, I just pray and communicate with God. It's like when I don't know what's going on, on a really deep and intimate level, I just ask for strength and comfort, and it's always the first thing I do, first person I run to. Secondly when it comes to education or it's academic, I go to my Aunt, she understands, she lets me know. But as far as direction in life and how far I want to go in life, and how I learned about relationships, I've learned it just by observation. It has given me wisdom about life and how important it is.

Jamey's support group comes from the TRIO program on campus, which are federally funded student support programs such as Upward Bound:

The TRIO Program. They listen to you. If you're having a bad day, they care. They ask you how you are doing and actually listen to what you have to say. And also, the program offers tutoring, counseling support, different trips to go see other campuses. There are so many academic benefits that they offer, like the TRIO Jr. Advisory Council which I'm on, which helps create on/off campus 
activities like, volunteering, fund raisers for scholarships, mentorship, or having students from the Youth Center come to the community college and get informed on how to afford college and stuff. The program has really benefited me a lot.

Amber's support group comes from friends and the people she met at her HSI community college before she transferred to her university:

Definitely from a certain extent, my friends from elementary school, and a lot of people I met at community college, the school counselors. They are the ones who saw potential inside of me that I never saw. They kind of just lit that little fire and inspired me to really change my mindset and become focused on what I really needed to do in life.

As it does for Maria, Lisa, and Samantha, who rely on their friends as their support group. Lisa elaborates:

I would say definitely my friends. If anything, when I have to talk with someone, and I don't feel comfortable talking with my sister or parents about it, I definitely go to a friend. Yeah, I basically feel more comfortable sharing my personal information with an outside member of the family, kind of like the same age because we're going through the same thing as far as school and personal situation where I'm at.

Followed by Samantha, who does not know what she would do without her very good friends:

I have very good friends. I don't know what I would do without my friends. My family yeah, but like, I don't know... any normal family argues a lot and especially like me, who shares a bedroom with my 20-year-old sister, makes it kind of hard sometimes. I may want to go to sleep and she's still up, so I can always go to my friends. I have a best friend. He's like my brother. We've been best friends since my freshman year in high school.

For Brynn, Mandy, and Jessica, their support group is their family. Jessica does add, "My grandmother, my family, and myself. My support groups in school are EOPS and TRIO, they are really great." Mandy specifically says it her mom: 
With everything, it's my mom. I mean, I can go to her and go to dinner and be like "ahhhhhh...." you know, and we would meet twice a week for dinner, and I needed that, just to kind of vent, I guess, and she has always been my support system.

The second question from the interview guide addressing the sample participant's social support was:

2. Do You Feel That Your Family Members And Friends Understand Your Needs (Frustrations, Anxieties, Doubts)? Three respondents felt the friends understood, but family did not. Three believed both family and friends understood their needs, two others did not believe family and friends understood, and one felt she had discussed the question previously. Brynn believes both her family and friends understand her needs especially her mother:

Yeah, I think they do. Recently, when I had my daughter I've gotten really, really, close to my mother. I ask her what she would do, how she would make "this" for the baby and just different other things. I usually tell them what's going on with my boyfriend when I talk to my mother, sisters, and friends.

Mandy as stated in the previous question, relies on her mother because the others do not always understand:

No obviously. I may go to my family, but my mom is always the one. My dad doesn't... like he's more like, "you're losing sight of the big picture." Get out of school and start working. My dad doesn't really understand, my mom always, my sisters and brothers...

Although William, does not always believe his family understands his needs and the demands of attending school as he presents an example:

Not always. Like last semester, I had to move and I had like two or three tests to do, so that weekend we had to move and I'm at the library studying and they're like, "well you're being lazy and selfish because you are not helping us move," and I'm like dude, if I don't pass these classes, I'll just have to retake them over and 
that's another semester... scholarships are taken away... no, not always, do they understand.

As for Jamey, who has stated previously that her mother feels at time she is growing distant, responds that her family does understand her needs:

They actually do, because my mom is a high school teacher. So she knows what it is to go through the educational system. She knows it's hard. My mom had gotten her Bachelors' degree and then took some time off to get her Masters' degree because she had my sister and I, and then she went back to college when I was in middle school to get her Masters.' My friends have been a great support system... and we all understand with all the school activities and classes, but sometimes, it gets frustrating and it's hard, so I feel I have somebody out there who can help me.

While Maria responds that her friends understand, but her family does not, but tries not to be rude to her mother:

I would say my friends because I have a friend who goes to this university, so it's kind of easier to relate to them, like if we're having midterms. So it's not like I'm trying to alienate you, I'm not trying to be a bad friend or anything, it's just that we both know we're busy, the common ground. If I haven't heard from you in a while, it's because you know we're studying, unlike family. My mom likes to see me often, and I don't have the time. It would be horrible to not pass the class after putting in the time because in finals you don't give them your all, just because I have to spend time with my mom, it just... it just doesn't work out. I can't be rude to my mom, but then I'm... can't talk, can't talk... Maybe it's kind of hard for her because it's important for her to see me, and to conversate and make sure that everything's fine, but at other times, you really don't have that luxury... that extra five minutes to talk and have chocolate or whatever.

Lisa does not have the problem Maria has, because she says her parents do understand her needs:

Yes, being in school I have been stuck at my computer and stuck at my desk doing my homework all day and they understand. They tell my other family members, "Leave her alone, leave her be, she's at the computer, let her have it." They understand that if I'm 
under pressure, they give me my space. If I'm frustrated about something as well, they are there for me.

There is no answer to the question from Jessica because she believes, "I think I covered it pretty much already," and Samantha feels her family and friends understand her needs because her mother also went to college:

Yeah, I think my family and friends do understand my needs because my mom went to school and my friends also go to school. I would say they have a great understanding.

Amber does not believe her family understands because her parents question why she is away from home most of the day, although she says they try:

No, I think they try to understand it as much as possible, but I think, they just don't really understand just how important it is to me, or how stressful it is. Like as an example my mom, she doesn't understand why I have to be at school all day studying, or why I have to be in charge of fundraisers and things like that. I kind of get "dogged" for that, and even my dad will be like, "I haven't seen you in two weeks," he understands, but he kind of still feels bad and says, "I would like to see you." But, I have no time. And then my friends somewhat understand, but definitely, not fully.

The last question addressing the participant's social support while attending college was:

3. Tell Me About Mentors Or Individuals On Campus You Have Had? Only the one sample participant, who went straight from high school to a university, was without mentors or campus support. The others like William, have mentors or someone on campus. "I have one mentor. She is the Dean of Science and Technology. When it comes to education, I'll go and ask her for advice, or just let her know what I'm considering." Jamey as she previously responded, has the staff from the TRIO program. Maria now at a university as well lists the TRIO program with providing mentorship: 
This program, TRIO. The Director there kind of made me open my eyes. "It's getting time to transfer you need to move on. You've done a lot of wonderful things here on this campus, but its time to take your next big step." I just feel that program has a lot of getting me to where I am today.

Amber and Samantha credit professors from their classes who provided mentorship.

Amber now at her university states:

Now at my university, my Native American professor. She's really cool. I mean the Native American class. I loved it, but I think one really cool thing is she's kind of bringing it to light. They struggled too. But I haven't really been able to keep in contact that much, but she is someone I really connected with at my university.

While Samantha adds that it was the professor from her Economics class who took an interest in her and wrote Letters of Recommendation on her behalf:

I took a class last semester in Economics and I didn't even like Econ, but I had to take it because it is required. It turned out he is the Advisor for Phi Beta Kappa and we got pretty close, and he's written letters of Letters of Recommendations, and we just talk, and like... I never really confided in him, but he's definitely someone I appreciate. I have like this other Math Advisor who is always there to help me with schoolwork. I honestly feel she wants me to succeed.

Mentorship for Jessica comes in the form of her campus EOPS office and it's

Director:

My EOPS thing, which houses my academic counselor, my Clubs, and the Head of EOPS. I always go talk to them about anything. If it's problems with personal things, school, teachers, or whatever, even if their door is closed, I'll just knock on their door and they'll open it and they see me. I talk to them everyday, even if I'm just passing by.

Where for Mandy, who states she has had many, describes the relationship she has had with her sorority advisor:

So many. My Sorority Advisor, I go in and see her several times a month... sometimes several times a week, and she always like, 
"you got to get out of here. You need to graduate, you're supposed to graduate, and you're doing this and that." She is always telling me how go in this direction, or that direction, she's always there and kind of kicks my butt...

Lisa relies on a variety of people to help her navigate school: classmates, professors, athletic trainer:

I would have to say my classmates. They have been very helpful as in we meet together to help one another. My professor's as well. If I need a question answered, I can email them and they get back to me. Also, my Athletic Trainer, he's there to help me physically, but if I have a question regarding a class, he will answer the question as well.

As for the last respondent Brynn, the only student from the study sample who did not attend a community college and went straight to a university after she graduated from high school replies, "I have not had any mentors, no... nobody."

Theme 9 - Recommendations. The two questions in this theme were asked to gain first hand insight from these students who traversed the educational system and made it to college, despite obstacles that could have derailed them. The first of the two questions,

1. What Do You Feel Would Help Students Such As Yourself In The Transition To College? The sample participants all felt more support and guidance was needed for a successful transition. William also believes the process begins with awareness, being aware about resources available:

I remember last semester TRIO and other programs went to the Boys \& Girls Club and did like an "Icebreaker," to let people know about colleges. All these kids are smart, but they don't always see... are not really concerned about the future. So I'm just like dude, you can party, have a girlfriend, do all the crap you want to, and still (with emphasis) go to college at the same time. Anybody can get money to go to school, if you're poor, you can totally take advantage of resources available. 
Maria concurs with William, by suggesting that students should become aware and get involved with the support programs on campus because there are many people in those programs who want their students to succeed:

I would say to get involved in the support programs. Everyone has this hype, "oh college is so different than high school. College is much harder, oh, college is so different, it's so different." I think they have to include yes its different (with emphasis), but there are many people that are willing to help you and want you to succeed. Like there is help out there if you know how to ask for it. It is important to know where to ask. It's not to scare everyone off. As long as you motivate yourself and have the desire to really work hard, then you can succeed in college. Maybe it takes you a longer to finish, but it's possible.

Jessica also believes more support groups are the key to transitioning to college because for the $1^{\text {st }}$ generation college student, they can become overwhelmed:

A lot of students are coming from being $1^{\text {st }}$ generation, and just being totally lost, like I was. I think schools in general should just have more support groups even if there just there to supply things for school, or even if there just here to talk. You need to figure out how to get whatever you need for school, like we could talk and figure it out.

As for Samantha, she feels while support is needed, guidance is the key, because the student needs someone to talk to:

Probably guidance. You also have to have someone you can talk to definitely, because it's so overwhelming when you're trying to fill out your applications and this and that. You definitely need a support system.

Jamey believes it's about support staff and also getting involved in your community, which she feels is beneficial:

I guess you can say, having those kinds of people around you, supporting you. Telling you that you can do it, instead of those who are negative, it's great. Getting involved in the community within the school, I guess you can say... I feel if you can help yourself and try to help others, is beneficial because you can make 
a difference in somebody's life. Yeah, I think getting involved is beneficial.

Whereas Brynn feels programs like the summer "Bridge" program she attended is

helpful because it creates a network on campus before the actual school year begins:

I think the summer Bridge Program that I had would be a big help, because it helps you establish friends before you get onto the big campus and that way, you kind of get the feel of the campus before everyone gets there, and then you don't have to worry about meeting people and things like that. That program establishes relationships between... a network between some faculty members that participated in that program and you. So that way during the year, you have people you can go to if you have problem, you know where to go. I think something like a step program like that would definitely be helpful. I know it did help me and all my other friends there.

"Introductory" classes for Lisa are the key, "Probably offer Intro classes like in your major. To get the basics to what you will be learning and will be taught. So I think those classes would help any student who is just entering college." Mandy feels mentoring is the answer:

Mentoring. I mean, having people that ask you like what do you want to be, and how do you get there. We have a program called "College Bound" that brings students from the community on to campus, and a lot of them are excited to go to college and say things like, "I never thought I could, I'll never get in, I don't have the grades, etc.," and I'm like, are you kidding me? There's financial aid, and they're like. "I can really come here?" I'm like you can do this, like we were exactly where you were, you know. Mentoring is one of the most rewarding things. So I think, just the opportunity to mentor and keep in contact, like, "hey applications are coming up and what are you doing to get ready for that," you know, just keep in contact.

And Amber believes getting the word out to the high schools about college is the key to a successful transition to college:

I think as simple as it is, is having people go to your high school and speak to you because never do I once remember back at my 
high school, my counselor ever saying we're having a workshop with a college counselor. He's going to be here, or we're having a "College Friday." I never remember that all, so I mean as little as that, it should be about getting the word out. I remember my interactions with my counselor were more like, he would call me in, and I had no choice... he'd be like here is your class now get out of my office. It would be like a five-minute meeting, I hated it.

The second and last question of the recommendation section and of the overall study was:

2. At What Grade Level Should These Programs Be Implemented? The sample participant's response varied from elementary through high school. Mandy replies, "Ideally, like freshman year of high school;" Lisa does not know, "I'm not too sure. I don't know;" and for Amber in increments, "It should definitely start in elementary school in small increments and gradually expand through the higher grades." Jamey's thoughts are:

I think they need to be offered way before high school, because I feel if you're getting notified in advance exactly how it is, and you start learning about it in high school... like there is this program at my community college called "Upward Bound," where you have high school students 9-12 grade come to college classes, I feel like if I had done that, I would have been given a head start. Because it's giving you a little more responsibility than the stuff in high school, and getting you ahead of the game, it teaches you a little bit more of what's going on. I also think they should be more informative in high school and teach you how to get there.

Samantha and Jessica also believe the programs should be implemented sometime in high school, Jessica comments:

I think, like the junior year in high school. Because I know for TRIO, you have that in most high schools as a junior or senior. You're able to enroll in that program and it rolls over to college, if the college offers it. 
Samantha's thoughts are they should be implemented at the beginning of high school because of grades that could affect GPA and entrance to college:

Definitely high school, you mean what grade level? I would say high school, at the beginning of high school. So they don't do what I did. In my freshman year, I didn't realize you need good grades. It wasn't until my junior and senior years that I looked at my GPA and found it was not good enough for college. It could also begin in middle school, but definitely in high school.

Whilst Brynn, Maria, and William believe implementation of programs should begin in middle school. William:

Definitely middle school and high school, like freshman year in high school as well, and senior year, every year. My father used to tell me the same stories over and over again, and like I tried to remember the value in the stories. It's the same way with a student, you teach them, teach them, and let them know, and then they shouldn't know about it. And then there are the seniors in high school, that college is all about "Party, Party, Party," and it's really the need to know about studying. Studying in college is different than studying in high school.

Maria believes middle school is best because elementary is too young of an age, and high school may be too late:

I would say about middle school. Elementary is kind of young, you're still playing outside, looking towards recess, and in high school... you know what college is, you know after high school that there is college... I would say that at that age, or even younger, you start talking in middle school to your students, that there is a possibility after high school to continue your education, not just work.

Brynn's response completes the overall questions of the findings section and of the study by stating:

I think it should start in middle school. I think it should definitely start in middle school. High school you know you have to get those grades to go to college, that's if you want to go straight into college instead of a junior college. But in middle school, things are already making an impact that affect high school and your college 
career. I remember I didn't even know about college in middle school and that is "crazy" to some people, so I think it should start definitely in middle school, or even better in elementary, but I think it should be mandatory it start in middle school.

\section{Summary}

These findings may be atypical from what $3^{\text {rd }}$ generation and beyond U.S.-born (3GAB-USB) Mexican college students experience in less nurturing environments, or in different regions of the country. The one participant in this study who did not attend a community college has discussed her "hostile," and "indifferent" environment on her campus, and the studies by Crockett et al. (2007); Gloria et al. (2005); McGinley et al. (2010); Yosso et al. (2009) on how the college environment can be difficult on Latinos quantify her experience. But this study's main purpose was not about that. It was about introducing an invisible population, which has been ignored leaving in its wake, an abundant gap of empirical data in the academic literature.

In the subsequent and final chapter of the study, the adaption of the Generational Comparison Chart from Chapter 2 to include the sample participants (Table 5); a summary of the findings; the assumptions and limitations of the study; and the implications for future research will be addressed. 


\section{CHAPTER 5}

\section{CONCLUSION}

The objective is to confront the reality of Mexican-American society as we have experienced it and from that basis generate hypotheses for future multidisciplinary research in this area.

Rodolfo Alvarez (1973)

The research study was designed to allow the nine 3rd generation and beyond U.S.-born (3GAB-USB) Mexican heritage participants the opportunity to share their lived experiences and learn about the reality of identity and psychosocial challenges they may have experienced while transitioning to college. The research on Mexicans and Latinos in the U.S. has become immigrant-centric and continues to mask within-group differences between the USB and the immigrant. With this in mind, the study was purposely simplistic and limited, because the intention was to introduce and develop a foundational base on which to build momentum on future research that could then look at a multitude of variables and factors associated with the USB Mexican heritage college student.

Having reviewed the academic literature throughout the dissertation process and more recently, articles on Mexican and Latino-origin individuals describing concepts such as interethnic identity (Kim, 2006); spatial landscape (Duarte, 2008); racial and ethnic socialization (Chavez-Reyes, 2010a); and cultural mismatch/cultural difference theory (Chavez-Reyes, 2010b); only reaffirmed the commitment to stay the course, and continue to focus only on the introduction of the 3GAB-USB Mexican population into the literature, because the research on a multitude of theories has already been formulated. This theory formulation is so abundant their appearance in a comprehensive 
study on Mexican or Latino-origin individuals could appear web like. Therefore, this study by only introducing the subsumed $3^{\text {rd }}$ generation and beyond U.S.-born Mexican, and disaggregating between the immigrant and the USB: (a) allowed for the illumination of differences from the $1^{\text {st }}$ through the $3^{\text {rd }}$ generation and beyond; (b) allowed for established theories to be applied in a disaggregated manner; (c) allowed for further research into the intricacies of the $3 \mathrm{GAB}$; and (d) allowed the introduction of new data to augment what is known about Mexican-origin individuals in the United States.

On the following page, Table 5 is the Generational Comparison Chart found in Chapter 2, adapted to include the sample participants. The chart now compares the $1^{\text {st }}$ through the $3 \mathrm{GAB}$, in addition to what was found among the $3^{\text {rd }}$ generation and beyond U.S.-born sample participants. The results reveal as with all generations, the participants lived experience translated to a different worldview. The immigrant perception prevalent from the $2^{\text {nd }}$ generation onward, and defending their Mexicaness became such microinequities, the participants chose when to "pick their battles" and voice their displeasure. For four of the nine participants, the inability to speak Spanish to Spanishspeaking individuals "standards," had the sample participants choosing not to speak it, even though they could. Therefore, there was less pressure from immigrant or earlier generation co-ethnics to associate only with them. Eight of the nine participants would like to be accepted by both their own ethnic group, while the ninth does not care or seek acceptance from her ethnic group. The atypical of the literature school experience will be discussed in the summary of findings. 
Table 5.

Generational Comparison Chart vs. Sample Participant Findings

\begin{tabular}{|c|c|c|c|}
\hline $1^{\text {st }}$ Generation & $2^{\text {nd }}$ Generation & $3 \mathrm{GAB}$ & $\begin{array}{c}3 \mathrm{GAB} \\
\text { From Study }\end{array}$ \\
\hline $\begin{array}{l}\text { Lived Experience = } \\
\text { Different Worldview }\end{array}$ & $\begin{array}{l}\text { Lived Experience = } \\
\text { Different Worldview }\end{array}$ & $\begin{array}{c}\text { L1ved Expenence }= \\
\text { Different Worldview }\end{array}$ & $\begin{array}{c}\text { Yes }= \\
\text { Not Raised in Barrios }\end{array}$ \\
\hline $\begin{array}{c}\text { Leaving Homeland } \\
\text { "Immigrant } \\
\text { Experience" }\end{array}$ & $\begin{array}{c}\text { Defending Being } \\
\text { American }> \\
\text { "Immigrant Perception" }\end{array}$ & $\begin{array}{c}\text { Defending Being } \\
\text { American }> \\
\text { "Immigrant Perception" }\end{array}$ & $\begin{array}{c}\text { Yes }= \\
\text { Microinequities } \\
\text { "Picked Their Battles" }\end{array}$ \\
\hline $\begin{array}{l}\text { Finding Shelter/ } \\
\text { Source of Income }\end{array}$ & $\begin{array}{c}\text { Possible Home } \\
\text { "Culture Clash" Old vs } \\
\text { New }\end{array}$ & $\begin{array}{c}\text { < Defending Being } \\
\text { Mexican } \\
\text { "Mexicaness" } \\
\text { (Duarte, 2008, Jumenez, 2008) }\end{array}$ & $\begin{array}{c}\text { Yes }= \\
\text { More So For The } \\
\text { 3 Non-Latıno Looking } \\
\text { Students }\end{array}$ \\
\hline $\begin{array}{c}\text { Language Barriers }> \\
\text { (Spanish Only) }\end{array}$ & $\begin{array}{c}\text { Possible Language } \\
\text { Barners }> \\
\text { (ESL) }\end{array}$ & $\begin{array}{c}<\text { Possible Language } \\
\text { Barriers } \\
\text { (English Only) }\end{array}$ & $\begin{array}{c}2=\text { English Only } \\
4=\text { Select1ve (Spanish) } \\
3=\text { Bilingual } \\
\text { All English } 1^{\text {st }} \text { Lang }\end{array}$ \\
\hline $\begin{array}{l}\text { Adjustıng to New } \\
\text { Life, Loneliness, etc }\end{array}$ & $\begin{array}{c}\text { Feel Comfortable } \\
\text { Among } \\
\text { Their Own } \\
\text { (Brown, 2007, Duarte, 2008) }\end{array}$ & $\begin{array}{c}\text { < Pressure to Only } \\
\text { Associate Among Their } \\
\text { Own } \\
\text { (Chavez-Reyes, 2010a) }\end{array}$ & $\begin{array}{c}\text { No }= \\
\text { Less Pressure If } \\
\text { Associate With } \\
\text { English Speaking }\end{array}$ \\
\hline Acceptance > & Acceptance $>$ & $<$ Acceptance $>$ & Yes $=8$ of 9 \\
\hline $\begin{array}{l}\text { Apprehension of } \\
\text { ICE/ Government/ } \\
\text { Police Officials } \\
\text { (Niemann et al , 1999) }\end{array}$ & $\begin{array}{l}\text { Possible Apprehension } \\
\text { of ICE/Government/ } \\
\text { Police Officials }\end{array}$ & $\begin{array}{c}\text { "They All Look Alike" } \\
\text { Possible Racial Profilıng } \\
\text { (Ochoa, 2000, Chavez-Reyes, } \\
\text { 2010a) }\end{array}$ & $\begin{array}{c}3 \text { Do Not Look } \\
\text { Latıno(a) } \\
\text { 6 Look Latıno(a) } \\
\text { Possible Racial Profile }\end{array}$ \\
\hline School Experience: & School Experience & School Experience. & School Experience. \\
\hline $\begin{array}{l}\text { Navigatıng School } \\
\text { Culture w/o Parental } \\
\text { Assistance Due to } \\
\text { Language Barniers or } \\
\text { Limited Education } \\
\text { (Valenzuela, 1996) } \\
\\
\text { Greater Academic } \\
\text { Success Than USB } \\
\text { (Matute-Bianch, 1986, } \\
\text { Ogbu, 1978, Padilla, 2001) }\end{array}$ & $\begin{array}{l}\text { Navigating School } \\
\text { Culture w/o Parental } \\
\text { Assistance Due to } \\
\text { Possible Language } \\
\text { Barners or Limited } \\
\text { Education } \\
\text { (Valenzuela, 1996) } \\
\text { Greater Academic } \\
\text { Success Than 3GAB } \\
\text { (Chavez-Reyes, 2010b, } \\
\text { Pew, 2009) }\end{array}$ & $\begin{array}{c}\text { Neglected Students }= \\
\text { Not Prepared For } \\
\text { College Curriculum } \\
\text { (Chavez-Reyes, 2010b, } \\
\text { Valenzuela, 1996) } \\
<\text { Possible } \\
\text { Mental Withdrawal > } \\
\text { (Carter, 1970, Ogbu, 1978) } \\
<\text { Less Academic } \\
\text { Success Than } 1^{\text {st }} \& \\
2^{\text {nd }} \text { Generation } \\
\text { (Chavez-Reyes, 2010b, Pew, } \\
\text { 2009) }\end{array}$ & $\begin{array}{l}\text { Not Neglected }= \\
\text { Prepared For College } \\
\text { Curriculum } \\
\text { *8 of } 9 \text { Have/Had } \\
\text { Nurturing School } \\
\text { Culture } \\
\text { No Mental Withdrawal } \\
\text { All } 3.2 \text { or Above GPA } \\
\text { *Attend/ed Hispanic Serving } \\
\text { Institution }\end{array}$ \\
\hline
\end{tabular}


The remainder of this chapter will summarize the findings discussed in Chapter 4 not included in Table 5; discuss the assumptions and limitations of the study; the implications for future research; and conclude, with a summation of the study.

\section{Summary of Findings}

Apart from the findings already illustrated in Table 5, a total of nine themes emerged from the data: identity confusion; self-label; hybridity; feeling distant; discrimination/racism; reverse assimilation; school experience; support groups; and recommendations. They will be summarized below:

\section{Identity Confusion}

Identity confusion during college is not limited to individuals of color. It can affect anyone. With individuals from ethnic groups, an additional component apart from questioning who one is, is not just an understanding of who one is, but also of how one "fits" in society, and within their own ethnic group. For the study's participants, it was clear they were questioning their identity, because of the comments of individuals from within their own ethnic and sub-group, and were having difficulty in finding a comfortable fit within those groups. Most telling were the participants being told since childhood they were White-Washed or not Mexican enough from co-ethnics, their peers, or their own family, which lead them to question if indeed they were Mexican because they did not seem to have the "requirements" to be Mexican. On the other end of the spectrum, was the risk of being "othered" by Euro Americans because of their surname, phenotype, and their English speaking, which may include Mexican colloquial terms (Chavez-Reyes, 2010b; Duarte, 2008; Jimenez, 2008). 
Another aspect of ethnic identity which was identified and found among the findings of this study and should be considered in future research, is the differences in worldview between immigrants and the USB, especially the 3GAB-USB. The results of the study have clearly shown it is affecting and causing psychosocial challenges for these U.S.-born individuals. Padilla (2006) Phinney (1990; 1996; 2005), Umaña-Taylor \& Fine (2001; 2004), and others, who have written extensively about ethnic identity, realize identity has a psychosocial impact on ethnic individuals. However, because of the complex multidimensionality of ethnicity, little is known on exactly how much of an impact it has. Phinney (1996) has suggested that in order to understand the psychosocial impact, research must first identify and find the aspects of ethnicity, which may be affecting ethnic individuals.

\section{Self-Label}

In this study, asking rather than labeling the participants, provided an insight into what the self-label meant to these individuals by allowing them to explain their choice of self-label, what influenced their choice of a self-label, if their self-label changed situationally, and if they felt their choice of a self-label was divisive, as claimed by critics who believe describing oneself as anything other than American, causes alienation and separation among the mainstream society of the United States.

The decision to ask the participants what they called themselves instead of the investigator labeling them, was a direct result of reviewing the research literature on Mexican heritage college students and realizing the identifying label given by researchers to this group was not always accurate, and led to questions about the validity and reliability of the research. Buriel (1987) has stated the diverse labels used by Mexican 
heritage individuals have different psychological meanings. Waters (1990) concurs and feels individuals may use various labels in particular situations because of circumstance. Phinney (1996) concludes,

Labels are not consistent indicators of group membership; rather, they vary over time and situations, carry different connotations among individuals and groups, and gloss over within-group variation. To get beyond simplistic ethnic categories, we need to examine the meanings associated with ethnicity, specifically culture, identity, and minority status (p. 920).

Therefore, labels such as Mexican American, Mexican-American, and Chicano, because of the generational, historical, or regional context, can have different meanings to a variety of people. The importance of understanding what individuals call themselves cannot be understated. Among this heterogeneous group, it is equally important to understand the variety of names used by the USB may or may not always acknowledge their indigenous lineage such as Texas (Tejanos), New Mexico (Hispanos), and that the immigrant Mexican (Mexicano), self-identifies by their country of birth, not as an American.

Although there are not many options to consider, it appears the USB Mexican is in need of a new name to self-describe. The use of the term Mexican-American has lost its salience for those who truly are Mexican and American, because as the literature review has shown, the dilution of the term "Mexican-American" by researchers labeling anyone of Mexican heritage in their study "American" whether they are or not, has corrupted its true meaning which the "Mexican-American Generation (late 1930's 1950's)," used to distinguish themselves from the immigrant Mexican. Likewise with the term Chicano, which in its inception in the 1960's was not used by immigrant, $1^{\text {st }}$ 
generation, or most $2^{\text {nd }}$ generation Mexican heritage individuals, which according to these participants, is no longer the case.

The consequence of these actions at least for this sample population, leave them with one more doubt regarding their identity because they do not fit exactly among the labels coined by the government, researchers, or society. Risking more ostracizing, they go with what they feel is politically correct, Lisa: "I just figure Mexican, Hispanic, Latina are all in the same category, so I just kinda go with it." Or as stated by Mandy, "I guess, I feel like I don't belong in any category."

\section{Hybridity}

Whichever term one favors, living in two worlds was not always a positive for the participants. Many expressed doubts at times when ostracized by their own ethnic group for being too "White," or not knowing when to "flip the switch" from one world to the other. While other participants felt, they had "mastered" the nuances associated with changing cultures instantaneously. The overall responses from the participants nonetheless, revealed hybridity was another psychosocial challenge they had to learn to navigate.

In the Pew Hispanic Center study on Latinos (2009), while it was inclusive of all Latino sub-groups, certain trends on $3 \mathrm{GAB}$ individuals applied to this sample. The notion of USB Mexicans living in "two worlds" was brought to the forefront in the treatise written by Alvarez (1973) in which he described it as hybridity. In contemporary times the concept is now known as being Bicultural (Padilla, 2006), even though some researchers are beginning to question if the $3 \mathrm{GAB}$ are truly bicultural, since there is no 
demarcation as to how much of each culture is needed to merit this designation (ChavezReyes, 2010b).

\section{Feeling Distant}

Five of the nine participants did not feel they were distancing themselves from friends, family, and their culture. Two of the five felt it was the price they had to pay in exchange for the opportunities begat by education, while a third felt, the distancing only meant they were evolving into another realm. In my discussions with Latino or Mexican heritage colleagues and faculty, the discussion of "feeling distant" has come up numerous times. The premise of the discussions was the more educated one became, the further distance was created between friends, family, and their ethnic and/or cultural identity. At the beginning of the interviews it was felt the question might not resonate because the participants were still relatively young, but it was decided the question should be included in hope of having a barometer for future studies with graduate students.

\section{Discrimination and Racism}

Biculturalism according to Padilla (2006) is a positive attribute that can offset the psychosocial and emotional harm caused by discrimination because of the positive connection between identity and ethnic loyalty. However, what becomes of this positive association when the discrimination is from within the same group? For the participants of the study, the accumulation of microinequities they received from their own ethnic group because they did not speak Spanish, or were not proficient enough in speaking the language, definitely offset the positive gain between identity and ethnic loyalty. Throughout their interviews the participants recalled incidents of discrimination and racism, with an overwhelming majority coming from within. Niemann et al. (1999), 
Ochoa (2000; 2004), Shorris (1992), and Valenzuela (1999) have discussed this conflict between immigrant and USB Mexicans in their work, while Ono (2002) labels this within-group animosity as Ethnic Competition.

\section{Reverse Assimilation}

As estrangement and critical comments permeated throughout their lifetimes, the majority of the study's participants found it necessary to try to fit in with their ethnic or sub-group by a process of reverse assimilation. These participants having been born and raised among the U.S. mainstream never felt they had to assimilate in order to fit into American society. The harassment and comments directed at them of being White, or White-Washed, by immigrant or earlier U.S. generation Latinos/Mexicans was a testament of that fact. Thus for this study sample, the assimilation process was in reverse, and took place when they were among their own ethnic or sub-group. Reverse assimilation is defined in this study as assimilating towards their ethnic group or subgroup by attempting to speak the Spanish language, and reintroducing themselves to the culture, its history, and vernacular, in order to be in solidarity with the group(s), rather than what is considered in research, the normal process for immigrant or USB Mexican and Latinos of assimilating to the host/mainstream society.

\section{School Experience}

The school experience and its consequences, the dropout rate for Mexican heritage and other Latinos, have been well chronicled in studies (Aloise-Young, \& Chavez, 2002; Gandara, Larson, Rumberger, \& Mehan, 1998; Lopez, Ehly, GarciaVazquez, 2002; Pena, 1997; Rumberger, 1993; Wayman, 2002). While eight of the nine participants experienced some negativity in K-12, most of those educational experiences 
were remedied for seven of the students once they arrived at their nurturing Hispanic Serving Institutions (HSI). Each of the seven students is well versed in the programs available among student services, counseling, financial aid, and the transfer process. Three of the seven have matriculated to universities. The eighth HSI attendee (who had no bad educational experiences she could recall throughout her education) graduated from her university May 22, 2011. All are Honor Students. Three of the four remaining at the HSI's are involved in student government, the fourth is considering running for Student Body President. While this may not be the case at all HSI's, these students are thriving in the academic culture created on their campus. For the three now at universities, they admit there has been a culture change from their community college experience. Yet, they all feel they have been prepared to handle the change.

\section{Support Groups}

Social support has been considered a coping mechanism, which helps alleviate psychosocial challenges the Mexican or Latino college student maybe facing in their educational journey (Arbona \& Nora, 2007; Castillo et al., 2008). Crockett et al. (2007) believe the studies conducted have resulted in mixed results, and feel further research is needed because social support comes from different sources, and those sources may provide different levels and types of support. It is with this understanding the participating students were asked the questions pertaining to mentors, programs, or individuals who have helped them navigate the education process. Once again, the responses that reflect the academic literature on Mexican and Latino students, and not the atypical narratives from the majority of the study sample, came from the non-transfer participant who is at a Tier 1 (nationally recognized for excellence in academics and 
research) research university, and not an HSI. Which begs the question, do HSI's really make that much of a difference? In the study's implication for future research section, this question will be addressed.

\section{Recommendations}

Having understood through my own educational experiences and the review of the literature the challenges faced by Mexican heritage, Latino, and other groups of color in gaining access and navigating the educational pipeline, I concluded the interviews with questions pertaining to what the study participants would recommend for other $3 \mathrm{GAB}$ USB Mexican heritage students attempting the transition to college. They all overwhelmingly recommended access to more information about attending college. Recalling instances in high school where the counselors/advisers did nothing more than hand them a completed class schedule without addressing their concerns, the participants felt guidance and access to college information was vital for a student's successful transition to college. ${ }^{13}$

Asked how best to disseminate this information, the participants recommended workshops, college fairs, and onsite visits to college campuses. While some acknowledged the federal Extended Opportunity Programs and Services (EOPS) and TRIO programs (programs designed to identify and provide services for individuals from disadvantaged backgrounds) offered these opportunities, others claimed those programs were either not offered at their high school, or were never mentioned to them by the

\footnotetext{
${ }^{13}$ It is understood counselors and administrators maybe overwhelmed by the number of students enrolled on their campuses, and that effect, is not limited to just Mexican or Latino-origin individuals. But research has shown racial profiling by counselors in schools (Castillo, Conoley, King, Rollins, Rovera, \& Verve, 2006; Holcomb-McCoy, 2004; Pizarro, 2005) and working-class status (Lee \& Ekstrom, 1987; Lutz, 2007; Oakes, 2005) are contributing factors in the lack of college preparation for USB Mexicans, Latinos, and other groups of color. Chavez (2010b) has also cited the work of Krei \& Rosenbaum (2001) in which they present the "ethical role" of counselors who feel college may be an unrealistic goal of students they are advising because the students are not academically prepared.
} 
school's administrative body. As for what grade levels the information would be appropriate, some suggested as early as elementary school, while most responded in middle school. One of the participants felt an incremental approach was best. She felt, as the age warranted, so should the increments of college information and guidance.

\section{Assumptions and Limitations}

\section{Limitations}

There were several limitations in the study: (1) Time and financial constraints; (2) utilizing a combined sample of community college and university students, instead of measuring both separately in particular, because university environments have been shown in other studies to be detrimental to Mexican, Latino, and other groups of color; (3) the majority of the students from Hispanic Serving Institutions may be atypical of what other 3GAB-USB Mexican heritage students have experienced at their institutions; (4) the inclusion of only one male perspective, rather than an equitable balance of male and female perspectives; (5) the results of the study cannot be generalized to all $3 \mathrm{GAB}-$ USB college students of Mexican heritage because of regional differences, such as place of birth in the U.S., where an individual was raised in the U.S., and community of residence; and (6) the data obtained was solely based on the experiences and reported perceptions of the participants. Their unique beliefs, experiences, values, and the time of the study, limited the range of topics generated and examined because of the length (4590 minutes) of the interviews.

The study was also limited in scope to other factors which could be associated with the sample group, namely USB biracial/multiracial Mexican heritage individuals, socio-economic status, or those whose immediate family members include both USB and 
immigrant Mexican individuals. The rationale for the severely limited sample was because the academic literature on Mexican heritage and Latinos is so homogenized and heterogeneous, a precise delineation had to be made in order to introduce, and allow a voiceless population to be heard. Listening instead of attempting to interpret and "force fit" the information into the researchers preconceived schema, afforded the researcher an opportunity to understand, become aware, and illuminate challenges that may or may not be unique to this USB sample population. While it is entirely possible for others to interpret the findings of this study differently, the interpretations expressed throughout the findings and conclusions apply solely to the sample participants at this particular time of their lives. Placed in a historical context, previous research has shown perspectives and perceptions change over time.

\section{Assumptions}

I assumed my fifty-five years living and experiencing life as a $3^{\text {rd }}$ generation U.S.born Mexican heritage individual qualified me as an "insider" of this population, and being a student myself, gave me license to explore the $3 \mathrm{GAB}$ student population in ways someone from outside the population could not. This belief also led me to assume as an insider with the 3GAB-USB Mexican populations, obtaining a study sample of 3GABUSB Mexican heritage college students would be the least of my worries and never considered the possibility there would be a problem obtaining a sample of 10 participants.

After reflection, while I may have been an insider with the 3GAB-USB Mexican sample populations, I had been four-years removed from any contact with a 3GAB-USB Mexican undergraduate student population. Additionally, having been an insider by ethnicity, I had now become an "outsider" by virtue of my formal education, no longer 
living in the Barrio, and not residing in a predominately Mexican community. VenegasGarcia (2010) uses the term "Insider-Outsider" to describe this existence and concurs with Rosaldo (1993), that insider-outsider perspectives both have their advantages and disadvantages because they can be used to analyze sample participant's narratives in a number of ways.

In my role as researcher, the outsider perspective helped balance my bias. While I listened to the participant's narratives, and understood their experiences, not having been a part of their community, their generation, and at times, their region, I could detach myself and consider the data I was obtaining was specific to them and them only, because of the juncture of their lives and the historical context. Historically speaking, these conversations were bereft of sentiments expressing beliefs of wanting to "take back Aztlán" and other similar notions, which would be more in line with the youth of my generation, and might have had me include my thoughts on such matters.

The insider perspective, allowed me to guide the interview conversations and probe in ways I knew our shared experiences as $3 \mathrm{GAB}-\mathrm{USB}$ Mexicans, would elicit a richly thick and descriptive account of their experiences, while simultaneously enhancing the trust between the sample participants and myself, because of those shared experiences.

Another assumption was the non-response of Latino and Mexican heritage student organizations. I assumed their involvement might be minimal, but did not anticipate a total disregard for the study. I understand all-encompassing Latino student organizations might not have any Mexican heritage among their rank and file meeting the criteria of the study, but what about Mexican heritage student organizations? A possible explanation 
may have come from reviewing literature published in 2010-2011 and discovering the work of Dr. Chavez-Reyes (2007; 2010a; 2010b) from California State Polytechnic University in Pomona, CA who has also written about multigenerational USB Mexicans whom she calls "Later Generation Mexican Americans (LGMA)," and Latinos. ChavezReyes (2010b) posits:

Research on public education has focused almost exclusively on immigrants and their children to the detriment of the needs and success of later generation Latinos. The unwarranted assumption is that later-generation Latinos (third generation or more), of which Mexican Americans are the largest group, have successfully integrated into the U.S. social, economic, and political spheres. However, later generations suffer from academic neglect and low rates of college completion.

Citing the study conducted by Fry (2002) who wrote the 3GAB-USB Mexican student is also a part of the large numbers of Latinos who attempt to extend their education but fail to earn their degree, she states:

Despite their American citizenship and English monolingualism, later generation Latinos have college attendance and completion rates nearly equal to immigrant and second-generation Mexican Americans, making unlikely the ascension of greater numbers of Latinos into the middle and professional classes.

If this premise is correct, could the lack of a response from the Mexican heritage student organizations from the campuses contacted for the study be an indicator of a lack of membership of $3 \mathrm{GAB}-\mathrm{USB}$ students? Much to my chagrin, this is a question, which cannot be definitively answered at this time, and will have to be left for future research. 


\section{Implications for the Future}

\section{Questions for Further Research}

The study's narratives raised a variety of questions that could not be answered within the study's parameters. Three questions come to mind,

Do Hispanic Serving Institutions really make that much of a difference as was shown in this study? The students who attended or are attending HSI's spoke in glowing terms of the programs and everyday support they received. In my review of the literature for this study, I did not consider looking into any HSI material because it was outside the foci of the study. However, having listened in this study to example after example of faculty and staff providing guidance, support, and genuine friendship, not to mention the programs specifically designed for these campus' renders a much more detailed look at HSI's.

Why were Mexican heritage student organizations or faculty not interested in this study? Having considered the possibility these students did not want to be a part of the study because they did not like the study, is too simplistic. At the beginning of the recruitment phase, it was the Mexican heritage students who did not qualify (outside of these organizations) who really wanted to be a part of the study and tried to help me recruit students, and encouraged me to continue contacting these student organizations. Is it as Chavez-Reyes claims, 3GAB-USB Mexican enrollment, and graduation rates are not growing at the rates of the immigrant, $1,1.5$, and $2^{\text {nd }}$ generation? In other words, have the immigrant and earlier generation Mexican college students become the majority within the Mexican-origin population on college campuses? As for department chair, faculty of Ethnic/Chicano Study departments (with the exception of my own university's 
Ethnic Studies Department of which the department chair served on my dissertation committee), and Chicano Resource Centers personally contacted for assistance, why not the courtesy of a reply?

In fairness, there were three responses: (1) an Archivist/Librarian from a Chicano Resource Center at a university posted a recruitment flyer and offered assistance; (2) one community college Chicano Studies professor disseminated the study information to his students (130); and (3) the following paraphrased exchange by electronic mail between a university Chicano Studies professor and myself summed up the experience soliciting assistance from my own ethnic group:

Professor: Why are you contacting me with this study? Myself: Because you teach Chicano Studies and would appear to know something about my sample population. Professor: I really don't know how I can help.

Why do research studies continue to label individuals from Mexico living in the U.S. who self-identify as Mexicano(a), Mexican Americans? The literature has clearly shown they do not self-identify as American (Niemann et al., 1999; Roosa et al., 2008; Zarate et al., 2005). Throughout the literature review of this study, there was not one instance of an individual from Mexico self-describing as "American, MexicanAmerican, or Mexican American." There is already too much confusion in the literature on whom or what is the difference between a Hispanic, Latino, \& Chicano, without corrupting a label which in simplicity, would describe an American of Mexican descent born or naturalized in the United States. 


\section{Recommendations for Future Research}

Mexican and Latino individuals in the U.S. are too multidimensional and complex for across the board generalizations. When discussing issues related to Mexican heritage and other Latino groups of the United States, it is of the utmost importance for researchers to consider the heterogeneous nature of the Latino ethnic group as a whole, look beyond the obvious, and continue to peel off the additional layers necessary to uncover what lies at the core. If one's interest is beyond simply fulfilling academic publishing requirements and truly desires to find solutions, then one has to go beyond the paradigm of regurgitating the same perspectives, outdated data, and the incorrect labeling of some ethnic sub-groups.

\section{Be Precise and Consider Generalizations a Red Flag}

To avoid confusion, a starting point could begin with greater precision concerning the population to be studied, and an understanding of the importance of their self-label. If a different label is used in the study, then define or explain the parameters of why it was used instead of the self-label. This study illustrated the sample population had difficulty in self-identifying because of their confusion over labels that do not fully describe or represent who they feel they are. The participants continue to use them because they feel it is politically expedient to do so. As one participant stated in her narrative, "I know I'm Mexican-American because I was born here, then it was we're different, that confuses me. I understand that someone from Mexico is closer to Mexican, but when does it translate to Mexican-American?"

In Zarate et al. (2005) part of the high school sample participants composed of immigrant and USB Mexicans had different rationale for using labels such as "Chicano," 
because some felt it reflected their parents were from Mexico (p. 105). While there is no exact definition for the term, USB Mexicans from the Chicano Generation, as well as the literature review conducted for this study, would say they are in incorrect. A Chicano according to these sources would not be from Mexico, unless the parents were raised in the U.S. in their formative years such as the 1.5-generation (born in Mexico, but arriving in the U.S. at or before the age of 12), which was not the case for the parents of these sample participants (p. 99).

The above scenario illustrates how inaccurate information can be perpetuated from one generation to the next. The scenario also demonstrates how constant mimicking from one study to the next of incorrect or generalized labels describing the Mexican and Mexican college student population of the United States adds one more dimension to the psychosocial challenges experienced by these individuals, and further complicates matters for researchers conducting reviews of the academic literature on Mexican heritage individuals or other Latino sub-groups.

\section{Consider a Worldview Different Than Eurocentric}

Gallagher (2001) believes a fundamental problem of working with different cultures is the basic differences in worldview. Arredondo and Vasquez (1999) feel respecting the worldview, as well as viewing Mexican heritage and Latino individuals from a position of strength, rather than from a deficit, and having a willingness to suspend judgment and premature interpretations about their issues is key for successful interactions with them. Since most theory and training is done from a Euro American perspective, researchers need to look inward at their own stereotypical tendencies, and come to the realization that not all people respond to the same protocol. The reason why 
is quite simple- the challenges facing both immigrant and USB Mexican heritage college students can be uniquely different than those facing researchers, educators, and administrators.

In understanding the concept of worldview, anthropologists Kluckhohn and Strodtbeck (1961) developed a worldview model based on five universal problems that are encountered by all cultures: (1) The character of human nature; (2) the relation of man to nature; (3) the temporary focus of life; (4) the modality of human activity; and (5) the modality of man's relationship to other men. They believed it was possible to distinguish cultures by these human concerns. In the Euro American worldview, of which many teaching tools, research instrumentation, and books are based on, anyone who differs from their view is considered abnormal and has a problem. Conducting research from this perspective does not bode well in studies of USB Mexican and Latino college student populations.

Therefore, consideration must be given to a perspective, which differs from the Eurocentric thought, and understand Mexican and Latinos view the world differently. While also understanding, there is another worldview that differs between the USB and immigrant Mexican heritage individual. As stated previously, there are many complexities involved, and is the very reason generalizations about this population should raise a red flag when conducting research on them. The following two questions are offered for future studies on Mexican, Latino, and other ethnic populations: (1) Are the worldview, belief system, values, and language, similar enough to justify labeling them as one whole sample population in research; and (2) if there are major differences within the studied group, why should they not be accounted for in the research? 


\section{Recommendations for Transitioning the 3GAB-USB Mexican Student to College}

The consensus from the sample's participants was more information on college was needed, especially in lower-socioeconomic communities. They all felt not everyone had access or knowledge of federal programs such as TRIO, which a program like Upward Bound, is a part of. All the participants also felt the dissemination of college information should start earlier then the $11^{\text {th }}$ grade, preferably in middle school, because by high school, the grades earned in middle school, would have a detrimental effect on college aspirants. In addition, all the participants believed, the majority of students as well as their parents do not have enough knowledge (if any) about the financial aid process, or what it can do for them.

How best to distribute this information? The sample felt it could effectively be conducted by workshops, visiting college and university campuses, mandatory classes/lectures not exceeding an hour, and even "College Days." Some researchers have suggested a series of outreach efforts targeting students of color at colleges and universities to make them aware of what is available to them on campus (Mosby, 2009). Three of these efforts could be implemented at the high school level to help transition 3GAB-USB Mexican and other students of color students to college: (1) An orientation session at the beginning of the $10^{\text {th }}$ or $11^{\text {th }}$ grade could be conducted for all students introducing them to student service programs such as EOPS, Financial Aid, the TRIO programs, and the schools counseling staff; (2) another session later in the semester on financial aid could be conducted for students and interested parents defining and explaining what it is, what is offered, and the process of applying for it; and (3) a 
partnership between colleges and universities with their feeder high schools could be established to find creative ways to connect with diverse student populations.

But not all suggestions are targeted at students. Faculty and supporting staff should be made aware of challenges faced by the students who attend their schools, by developing workshops to help them renew their knowledge of the diverse populations of their campuses (Mosby, 2009). In addition, Rumberger and Larson (1992) have suggested developing methods which could bridge three cultural boundaries: school culture, student culture, and Mexican culture, at schools that have a negative and damaging school culture in order to "mitigate and remediate" their effects on USB Mexican and immigrants student learning and attitudes (p. 17).

\section{For 3GAB-USB Mexican Students Already at College}

Mosby (2009) has suggested colleges and universities should create a welcoming atmosphere for students of color by having top college and university officials hold an orientation in which all new incoming students would attend, and the schools commitment to their success could be discussed. The use of focus groups with the students by the financial aid office and other student service offices to hear their needs first-hand was another suggestion. In my opinion, his most important suggestion however, was the implementation of mandatory workshops, seminars, and training sessions for all faculty, staff, and administrators. Everyone should know and understand the nuances associated with their ethnic student body, but refresher courses to offset incorrect perceptions, myths, and stereotypes should be embraced, especially for this USB sample population more times than not, thought to be immigrant and hence, not American. 
And lastly, another important consideration is the understanding, multicultural centers at higher education institutions may not be viewed positively by the 3GAB-USB Mexican contingent. In this study, and in conversations throughout my education with 3GAB-USB Mexican college students, their thoughts on why they do not frequent multicultural centers were two-fold: they were too cliquish, and they felt if they were to discuss their true feelings about conflict with their own sub or ethnic group, to persons at a multicultural center, what would those implications say about them? Rather than risk further alienation or ostracization, they kept their thoughts to themselves.

\section{In Culmination}

The findings reveal at least for this sample population, they are not like those from the investigator's Chicano Movement Generation. They have, as one study participant stated, "Evolved." They are not as society, educators, or government officials have perceived or the media has portrayed. They also are not like their immigrant compatriots, because of their different worldview and lack of an "immigrant" experience. They do not share the same dreams, thoughts, and a possible return to Mexico one day. For these United States born individuals, they are home.

Additionally, these findings are not to implicate the beliefs of their immigrant counterparts are without merit, there is a "wrong way" to be Mexican, or one is better than the other. It is not about creating division. On the contrary, what the findings revealed was these individuals were very proud of being of Mexican heritage and were not "White-Washed." Rather, they had what was discussed at the beginning of the study - a different worldview because of different life experiences, and since they spoke the native language of the United States... English, their Spanish-speaking (if they knew 
Spanish) would not be on par with individuals whose $1^{\text {st }}$ language is Spanish. Because this was the reality, the sample population had to overcome discrimination, racism, being ostracized, and ridiculed, in order to fit in with their ethnic group.

Furthermore, if a 2 liter bottle of regular Coke was marketed, but then in reality, the contents were 5\% Diet Coke, 5\% Pepsi, 2\% Generic Brand Cola, 2\% Dr. Pepper, and $1 \%$ miscellaneous, would those ingredients still make it a Coke? Would the Coca-Cola Corporation not only be guilty of deception, but face litigation because of false advertising? If the premise presented here is agreed upon, that the above described ingredients in the 2 liter bottle are not Coke, then why are studies which are introduced into the academic literature utilizing mixed samples of immigrant and USB Mexican, or other Latino sub-groups accepted as studies on "Mexican-Americans?"

Which elicits the following questions: Why are the standards different in research academic literature? Should there not be a higher standard of efficiency? Moreover, when studies such as these arrive with incorrect, inconclusive, or minimal results, and are then replicated or used to educate, create school or government policy, establish laws, develop medical research protocol and disease control, is it prudent to continue the status quo?

If accepted by researchers, the discrepancies and disconnect found in this limited study between the perception and reality of the studies sample population might offer opportunities for new unlimited research among not only Mexican heritage and other Latino sub-groups, but those of all other sub-groups regardless of color in the U.S. and globally. Previous studies with a variety of variables, which had been conducted with mixed sample populations, could be duplicated using a disaggregated approach to 
produce new and precise data, in an effort to limit inconclusive, modest, or no difference findings found in ethnic identity, or other types of ethnic group research.

The responsibility for remediation on the other hand, does not fall exclusively on outside forces, the $3^{\text {rd }}$ generation and beyond U.S.-born Mexican also has a responsibility as slain Los Angeles Times reporter Ruben Salazar wrote in his column on February 24, 1963:

A very practical teaching of mental hygiene is that one cannot run away from himself, or what he is. To do so is to invite disaster. Somewhere along the way the MexicanAmerican (italics mine) must make a stand and recognize the fact that if there is to be progress against those barriers which prevent and obstruct a more functional citizenship, he must above all retrieve his dignity and work as a person with a specific ethnic antecedent, having a positive contribution to make to civilization. No man can find a true expression for living who is ashamed of himself or his people.

In conclusion, there are no easy solutions to the multitude of variables affecting 3GAB-USB Mexicans and other Latino sub-groups. No one practice can be the answer for all. McNeil (2001) says it best, one size does not and should not fit all. But a beginning could be disaggregating between the immigrant and USB, affording the opportunity to focus in on psychosocial and identity challenges unique to each group. 


\section{REFERENCES}

Acuña, R. (1986). Anything but Mexican: Chicanos in contemporary Los Angeles. New York: Verson.

Adams, G. R., \& Marshall, S. (1996). A developmental social psychology of identity: Understanding the person in context. In S. A. Hardy, \& J. W. Kisling (Eds.), Identity statuses and prosocial behaviors in young adulthood: A brief report. Identity: An International Journal of Theory and Research, 6(4), 363-369.

Aguirre, J. (2009). Increasing Latino(a) representation in math and science: An insider's look. Harvard Educational Review, 79(4), 697-703.

Alcoff, L. M. (2005). Latino vs. Hispanic: The politics of ethnic names. Philosophy \& Social Criticism, 31(4), 395-407. doi: 10.1177/0191453705052972

Alipuria, L. (2002). Ethnic, racial, and cultural identity/self: An integrated theory of identity/self in relation to large scale social cleavages. In J.S. Phinney (Ed.), When we talk about American ethnic groups, what do we mean? American Psychologist, 51(9), 918-927.

Aloise-Young, P. A., Chavez, E. L. (2002). Not all school dropouts are the same: ethnic differences in the relation between reason for leaving school and adolescent substance use. Psychology in the Schools, 39(5) 539-547. doi: 10.1002/pits.10054

Alvarez, R. (1973). The psycho-historical and socioeconomic development of the Chicano community in the United States. Social Science Quarterly, 53(4), 920942.

Ambrecht, B. C. S., \& Pachon, H. P. (1974). Ethnic political mobilization in a Mexican American community an exploratory study of East Los Angeles 1965-1972. The Western Political Quarterly, 27(3), 500-519.

Andalón, R. (2005). Beacons of hope and success provide college access lessons: Portraits of Mexican American students' university preparation and life histories. Unpublished doctoral dissertation, University of California Los Angeles, Los Angeles, CA

Arangure, J. Jr. (2008, August) ¡Viva Sanchez! ESPN, The Magazine. From http://sports.espn.go.com/espnmag/story?id $=3511275$

Arbona, C., \& Nora, A. (2007). The influence of academic and environmental factors on Hispanic college degree attainment. Review of Higher Education: Journal of the Association for the Study of Higher Education, 30(3), 247-269.

doi: 10.1353/rhe.2007.0001 
Arredondo, P., and Vasquez, L. (1999). Empowerment strategies from Latino/Latina perspectives. Chapter 5 in Advocacy in counseling: Counselors, clients, \& community. ERIC database (ED435909). Retrieved from http://www.eric.ed.gov/ PDFS/ED435909.pdf

Banks, J.A. (2006). Cultural diversity and education ( $5^{\text {th }}$ ed.). Boston: Allyn \& Bacon.

Baxter, K. (2008, April 29). More than pads on his shoulders. Los Angeles Times. Retrieved from http://articles.latimes.com/2008/dec/29/sports/sp-sanchez29/3

Baxter Magolda, M. B. (1999). Constructing adult identities. Journal of College Student Development, 40, 629-644.

Bell, J. D., \& Bautsch, B. (2011). Improving Latino college completion: What state legislators should know. Legislative Policy Brief (2011, February). Retrieved from National Conference of State Legislators website: http://www.ncsl.org/documents/educ/LatinoCollegeCompletion.pdf

Bensimon, E. M., \& Dowd, A. (2009). Dimensions of the transfer choice gap: Experiences of Latina and Latino students who navigated transfer pathways. Harvard Educational Review, 79(4), 632-658.

Bogardus, E S. (1934). The Mexican in the United States. Los Angeles: University of California Press.

Brown, S. K. (2007). Delayed spatial assimilation: Multigenerational incorporation of the Mexican-origin population in Los Angeles. City \& Community, 6(3), 193-209. doi: $10.1111 / \mathrm{j} .1540-6040.2007 .00213 . x$

Buriel, R. (1987). Ethnic labeling and identity among Mexican Americans, In J. Phinney \&. M. Rotheram (Eds.), Children's ethnic socialization: Pluralism and development, 134-152. Newbury Park, CA: Sage.

Canul, G. D., \& Cross, H. J. (1994). The influence of acculturation and racial identity attitudes on Mexican-Americans' MMPI-2 performance. Journal of Clinical Psychology, 50(5), 736-745.

Carter, T. P. (1970). Mexican Americans in school: A history of educational neglect. In J. U. Ogbu (Ed.), Minority education and caste: The American system in crosscultural perspective. New York: Academic Press.

Carter, P. L. (2006). Straddling boundaries: Identity, culture, and school. Sociology of Education, 79(4), 304-328. doi: 10.1177/003804070607900402 
Carter, R.T., Yeh, C. J., \& Mazzula, S. J. (2008). Cultural values and racial identity statuses among Latino students. Hispanic Journal of Behavioral Sciences, 30(1), 5-23. doi: 10.1177/0739986307310505

Castillo, L. G., Cano, M. A., Chen, S. W., Blucker, R. T., \& Olds, T. S. (2008). Family conflict and intragroup marginalization as predictors of acculturative stress in Latino college students. International Journal of Stress Management, 15(1), 4352.

Castillo, L. G., Conoley, C. W., Choi-Person, C., Archuleta, D. J., Phoummarath, M. J., \& Landingham, A. V. (2006). University environment as a mediator of Latino ethnic identity and persistence attitudes. Journal of Counseling Psychology, 53(2), 267-271. doi: 10.1037/0022-0167.53.2.267

Castillo, L.G., Conoley, C. W., King, J., Rollins, D., Rovera, S., \& Verve, M. (2006). Predictors of racial profiling in white American counseling students. Journal of Multicultural Counseling and Development, 34(1), 15-26.

Chavez, M. R., Rudolph, B. A. (2007). Border bicultural personality traits: Surprising gender findings among Mexican American undergraduates. Journal of Hispanic Higher Education, 6(1), 19-33. doi: 10.1177/1538192706294754

Chávez, C. (2007). Five generations of a Mexican American family in Los Angeles. Lanham, MD: Rowman \& Littlefield.

Chavez-Reyes, C. (n.d.). Identifying and improving later generation Mexican-American students' academic trajectory toward higher education: A conceptual model. Unpublished manuscript. Retrieved from http://www.calsa.org/modules/groups/ homepagefiles/cms/1411120/File/UCLA\%20Conclave/Christina\%20ChavezReyes\%20Later_Generations_Mexican_Americans_Draft.doc

Chávez-Reyes, C. (2010a). Racial and ethnic socialization in a later-generation Mexican American family. Hispanic Journal of Behavioral Sciences, 32(4), 495-518. doi: $10.1177 / 0739986310383151$

Chávez-Reyes, C. (2010b). "Starting at the top": Identifying and understanding latergeneration Chicano students in school. Journal of Latinos and Education, 9(1), 22-40. doi: $10.1080 / 15348430903252037$

Coker, A. L., Sanderson, M., Cantu, E., Huerta, D., \& Fadden, M. K. (2008). Frequency and types of partner violence among Mexican American college women. Journal Of American College Health, 56(6), 665-673. 
Cooley, C. H. (1902). Human nature and the social order. In S. J. Schwartz (Ed.), In search of mechanisms of change: Integrating the constructivist and discovery perspectives on identity. Identity: An International Journal of Theory and Research, 2(4), 317-339. doi:10.1177/0272431607308662

Cornelius-White, J. H. D., Garza, A. C., Hoey, A.T. (2004). Personality, family, satisfaction, and demographic factors that help Mexican American students succeed academically. Journal of Hispanic Higher Learning, 3(3), 270-283. doi: $10.1177 / 1538192704265600$

Creswell, J. W. (2003). Research design: Qualitative, quantitative, and mixed method approaches $\left(2^{\text {nd }}\right.$ ed.). Thousand Oaks, CA: Sage Publications.

Crockett, L. J., Iturbide, M. I., Torres Stone, R. A., McGinley, M., Raffaelli, M., \& Carlo, G. (2007). Acculturative stress, social support, and coping: Relations to psychological adjustment among Mexican American college students. Cultural Diversity and Ethnic Minority Psychology, 13(4), 347-355.

Cross, W. E. (1971). The Negro-to-Black conversion experience. Black World, 20(9), 13-27.

Davis, D. (2008, August). Why do people have a problem with OC-raised USC QB Mark Sanchez being proud of his Mexican heritage? OC Weekly. Retrieved from http://www.ocweekly.com/2008-08-21/news/oc-raised-usc-qb-mark-sanchez-isproud-of-his-heritage-but-some-people-have-a-problem-with-that/4/

Delgado-Romero, E. A., Galván, N., Maschino, P. \& Rowland, M. (2005). Race and ethnicity in empirical counseling and counseling psychology research, a 10-year review. The Counseling Psychologist, 33(4), 419-448. doi: $10.1177 / 0011000004268637$

Denzin, N. K., \& Lincoln, Y. S. (2000). Introduction: The discipline and practice of qualitative research. In N. K. Denzin \& Y. K. Lincoln (Eds.), Handbook of qualitative research (pp. 1-28). Thousand Oaks, CA: Sage Publications, Inc.

Devos, T. (2006). Implicit bicultural identity among Mexican American and Asian American college students. Cultural Diversity and Ethnic Minority Psychology 12(3), 381-402. doi: 10.1037/1099-9809.12.3.381

Díaz-Guerrero, R. (1994). Psicología del mexicano. In K. B. Matheny, B. E. RoqueTovar, \& W. L. Curlette (Eds.), Perceived stress, coping resources, and life satisfaction among U. S. and Mexican college students: A cross-cultural study. Anales de Psicología, 24(1), 49-57.

Diaz, C. F., Pelletier, C. M., \& Provenzo, E. F. (2006). Touch the future ...teach! Boston, MA: Pearson Education, Inc. 
Duarte, C. V. (2008). Negotiating 3rd+ generation Mexican American ethnicity in Los Angeles, California. (Doctoral Dissertation). Retrieved from ProQuest Dissertations and Theses database. (ATT3290511)

Duncan-Andrade, J. M. R. (2005). An examination of the sociopolitical history of Chicanos and its relationship to school performance. Urban Education, 40(6), 576-605. doi: 10.1177/0042085905281391

Erikson, E. (1950). Childhood and society. New York: Norton.

Erikson, E. H. (1968). Identity: Youth and crisis. New York: W.W. Norton.

Freud, S. (1965). New introductory lectures on psychoanalysis. In S. J. Schwartz (Ed.), In search of mechanisms of change: Integrating the constructivist and discovery perspectives on identity. Identity: An International Journal of Theory and Research, 2(4), 317-339.

Fry, R. (2002). Latinos in higher education: Many enroll, too few graduate. Philadelphia, Pew Hispanic Center, Pew Charitable Trusts. Retrieved from http://www.pewtrusts.com/pdf/vfpew_hispanic_latino_students

Fry, R. (2010). Minorities and the recession-era college enrollment boom. Pew Hispanic Center, Washington, DC. Retrieved from http://pewsocialtrends.org /2010/06/16/minorities-and-the-recession-era-college-enrollment-boom/2/

Fuligni, A. J., Witkow, M., \& Garcia, C. (2005). Ethnic identity and the academic adjustment of adolescents from Mexican, Chinese, and European backgrounds. Development Psychology, 41(5), 799-811. doi: 10.1037/0012-1649.41.5.799

Galarza, E. (1929). Life in the United States for Mexican people: Out of the experience of a Mexican. Proceedings of the National Conference of Social Work. Chicago: University of Chicago Press.

Gallagher, T. (2001). The values orientation method: A tool to help understand cultural differences. Journal of Extension, 39(6). Retrieved from http://www.joe.org/joe/2001december/index.php

Gamio, M. (1930). Mexican immigration to the United States: A study of human immigration and adjustment. Chicago: University of Chicago Press.

Gamst, G., Dana, R. H., Der-Karabetian, A., Aragon, M., Arellano, L. M., \& Kramer, T. (2002). Effects of Latino acculturation and ethnic identity on mental health outcomes. Hispanic Journal of Behavioral Sciences, 24(4), 479-504. doi: $10.1177 / 0739986302238216$ 
Gandara, P., Larson, K., Rumberger, R., \& Mehan, H. (1998). Capturing Latino Students in the academic pipeline. California Policy Seminar Brief Series 10(3). Berkeley, CA: University of California, California Policy Research Center.

Garcia M. T. (1995). Ruben Salazar, border correspondent: Selected writings, 19551970. Berkeley: University of California Press.

Geertz, C. (1973). The interpretation of cultures. NY: Basic Books.

Gibson, M. A., \& Bachau, P. K. (1991). The dynamics of educational decision making: A comparative study of Sikhs in Britain and the United States. In A. J. Fuligni, M. Witkow, \& C. Garcia (Eds.), Ethnic identity and the academic adjustment of adolescents from Mexican, Chinese, and European backgrounds. Developmental Psychology, 41(5), 799-811.

Gilligan, C. (1982). In a different voice. Cambridge: Harvard University Press.

Gloria, A. M., Castellanos, M. J., \& Orozco, V. (2005). Perceived educational barriers, cultural fit, coping responses, and psychological well-being of Latina undergraduates. Hispanic Journal of Behavioral Sciences, 27(2), 161-183.

Gloria, A. M., Castellanos, J., Lopez, A. G., \& Rosales, R. (2005). An examination of academic nonpersistence decisions of Latino undergraduates. Hispanic Journal of Behavioral Sciences, 27, 202-223.

Gonyea, N. E. (2010). The impact of acculturation on Hispanic students' learning styles. Journal of Hispanic Higher Education, 9(1), 73-81. doi: $10.1177 / 1538192709352228$

Gould, B. (1932). Methods of teaching Mexicans. Unpublished master's thesis, University of Southern California, Los Angeles, CA

Guzman, M. R., Santiago-Rivera, A. L., \& Haase, R. F. (2005). Understanding academic attitudes and achievement in Mexican-origin youths: Ethnic identity, other-group orientation, and fatalism. Cultural Diversity and Ethnic Minority Psychology, $11(1), 3-15$.

Hardy, S. A., \& Kisling, J. W. (2006). Identity statuses and prosocial behaviors in young adulthood: A brief report. Identity: An International Journal of Theory and Research, 6(4), 363-369.

Harper, S. R. (2009). Race-conscious student and the equitable distribution. Liberal Education, 38-45. Retrieved from http://www.aacu.org/liberaleducation /lefa09/documents/LEFall09_Harper.pdf 
Harris, A., \& Tienda, M. (2010). Minority higher education pipeline: Consequences of changes in college admissions policy in Texas. Annals of the American Academy of Political \& Social Science, 627(1), 60-82. doi: 10.1177/0002716209348740

Hispanic Association of Colleges \& Universities website. Hispanic Serving Institutions. Retrieved from http://www.hacu.net/hacu/HSI_Definition.asp?SnID=760214772

Hitlin, S., Brown, J. S., \& Elder, G. H., Jr. (2007). Measuring Latinos: Racial vs. ethnic classification and self-understandings. Social Forces, 86(2), 587-611.

Holcomb-McCoy, C. (2004). Assessing the multicultural competence of school counselors: A check-list. Professional School Counseling, 73(7), 178-186.

Holleran, L. K. (2003). Mexican American youth of the southwest borderlands: Perceptions of ethnicity, acculturation, and race. Hispanic Journal of Behavioral Sciences, 25(3), 352-369. doi: 10.1177/0739986303256913

Holloway-Friesen, H. (2008). The invisible immigrants: Revealing 1.5 generation Latino immigrants and their bicultural identities. Higher Education in Review, 5, 37-66.

Hurtado, A., \& Gurin, P. (2004). Chicana/o identity in a changing U.S. society. Tucson: University of Arizona Press.

Jaeger, R. M. (2005). Contemporary methods for research in education $\left(2^{\text {nd }}\right.$ ed. $)$. Washington, DC: American Educational Research Association.

James, W. (1892). Psychology: The briefer course. In S. J. Schwartz (Ed.), In search of mechanisms of change: Integrating the constructivist and discovery perspectives on identity. Identity: An International Journal of Theory and Research, 2(4), 317339.

Jimenez, T. R. (2007). Weighing the costs and benefits of Mexican immigration: The Mexican American perspective. Social Science Quarterly, 88(3), 599-618. doi: $10.1111 / \mathrm{j} .1540-6237.2007 .00474 . \mathrm{x}$

Jimenez, T. R. (2008). Mexican-immigrant replenishment and the continuing significance of ethnicity and race. American Journal of Sociology, 113(6), 1527-1567.

Johnson, H. D. (2004). Grade, gender, and relationship differences in emotional closeness within adolescent friendships. Adolescence, 39, 243-256.

Keefe, S. E. (1992). Ethnic identity: The domain of perceptions of and attachment to ethnic groups and cultures. In Y. Flores-Neimann, A. J. Romero, J. Arredondo, \& V. Rodriguez (Eds.), What does it mean to be "Mexican"? Social construction of an ethnic identity. Hispanic Journal of Behavioral Sciences, 21(1), 47-60. 
Kim, Y.Y. (2006). From ethnic to interethnic: The case of identity adaption and transformation. In Christina Chávez-Reyes (Ed.), Racial and ethnic socialization in later generations of a Mexican American family. Hispanic Journal of Behavioral Sciences, 32(4), 495-518. DOI: 10.1177/0739986310383151

Kluckhohn, F. R., \& Strodtbeck, F. L. (1961). Variations in value orientations. Evanston, IL: Row, Peterson.

Kohlberg, L. (1984). Essays in moral development: Vol. 2. The psychology of moral development. New York: Harper \& Row.

Kosmitzki, C. (1996). The reaffirmation of Cultural identity in cross-cultural encounters. Personality and Social Psychology Bulletin, 22(3), 238-248.

doi: 10.1177/0146167296223002

Krei, M. S., \& Rosenbaum, J. E. (2001). Career and college advice to the forgotten half: What do counselors and vocational teachers advise? Teachers College Record, $103,823-842$.

Kunnen, E. S., Bosma, H. A. (2003). Fischer's skill theory applied to identity development: A response to Kroger. Identity: An International Journal of Theory and Research, 3(3), 247-270.

Lee, V. E., \& Ekstrom, R. B. (1987). Student access to guidance counseling in high school. American Educational Research Journal, 24(2), 287-310.

Lewis, A. E., Chesler, M., \& Forman, T.A. (2000). The impact of "colorblind" ideologies on students of color: Intergroup relations at a predominately White university. The Journal of Negro Education, 69(1/2), 74-91.

Lopez, E. J., Ehly, S., Garcia-Vazquez, E. (2002). Acculturation, social support and academic achievement of Mexican and Mexican-American high school students: An exploratory study. Psychology in the Schools, Vol. 39(3), 245-257. Wiley Periodicals, Inc. doi: 10.1002/pits.10009

Love, A. S., Yin, Z., Codina, E., \& Zapata, J. T. (2006). Ethnic identity and risky health behaviors in school-age Mexican American children. Psychological Reports, 98(3), 735-744.

Lyon, L. L. (1933). Investigation of the program for the adjustment of Mexican girls to the high schools of the San Fernando Valley. Unpublished master's thesis, University of Southern California, Los Angeles, CA

Luedtke, L. S. (1977). Pocho and the American dream. Minority Voices: 1, 1-16. 
Lutz, A. (2007). Barriers in high school completion among immigrants and latergeneration Latinos in the USA: Language, ethnicity, and socioeconomic status. Ethnicities, 7(3), 323-342. doi: 10.1177/1468796807080232

Markus, H. R. \& Kitayama, S. (1991). Culture and the self: Implications for cognition, emotion, and motivation. Psychological Review, 98, 224-253. doi: 10.1037/0033-295X.98.2.224

Madrid-Barela, A. (1976). Pochos: The different Mexicans, An interpretive essay, part 1. Aztlán: A Journal of Chicano Studies, 7(1), 51-64.

Marcia, J. E. (1980). Identity in adolescence. In A. J. Umaña-Taylor \& M. A. Fine (Eds.), Examining ethnic identity among Mexican-Origin adolescents living in the United States. Hispanic Journal of Behavioral Sciences, 26(1), 36-59. doi: $10.1177 / 0739986303262143$

Markstrom, C. A., \& Kalmanir, H. M. (2001). Linkages between the psychosocial states of identity and intimacy and the ego strengths of fidelity and love. Identity, I, 179-296.

Marshall, C. \& Rossman, G. B. (1999). Designing qualitative research ( $3^{\text {rd }}$ ed.). Thousand Oaks, CA: Sage Publications.

Martin, Phillip (2006, July). The Bracero Program: Was It A Failure? History News Network. From http://hnn.us/articles/27336.html

Matheny, K. B., Roque-Tovar, B. E., \& Curlette, W. L. (2008). Perceived stress, coping resources, and life satisfaction among U. S. And Mexican college students: A cross-cultural study. Anales de Psicología, 24(1), 49-57.

Matute-Bianchi, M. E. (1986). Ethnic identities and patterns of school success and failure among Mexican-Descent and Japanese-American students in a California high school: An ethnographic analysis. American Journal of Education, 95(1), 233255 .

McGinley, M., Carlo, G., Crockett, L. J., Raffaelli, M., Torres Stone, R. A., \& Iturbide, M . I. (2010). Stressed and helping: The relations among acculturative stress, gender, and prosocial tendencies in Mexican Americans. The Journal of Social Psychology, 150(1), 34-56.

McNeill, B. W., Prieto, L. R., Niemann, Y. F., Pizarro, M., Vera, E. M., \& Gomez, S. P. (2001). Current directions in Chicana/o psychology. The Counseling Psychologist 29(1), 5-17. 
McNeil, L. M. (2001). A report of best practices from the Rice research team, Linda McNeil, principal investigator. Houston Annenberg Challenge Evaluation Research. Retrieved from http://www.utexas.edu/projects/annenberg/Exemplary_ Practices_Report.html

Mead, G. H. (1934). Mind, self, and society from the standpoint of a social behaviorist. In S. J. Schwartz (Ed.), In search of mechanisms of change: Integrating the constructivist and discovery perspectives on identity. Identity: An International Journal of Theory and Research, 2(4), 317-339.

Merriam, S. B. (1998). Qualitative research and case study applications in education. In S. B. Merriam (Ed). (2002). Qualitative research in practice: Examples for discussion and analysis. San Francisco, CA: Jossey-Bass.

Merriam, S.B., (Ed). (2002). Qualitative research in practice: Examples for discussion and analysis. San Francisco, CA: Jossey-Bass.

Miller, D. T. (1996). On our own. Belmont, CA: Wadsworth Publishing.

Ministry of Social Development, Government of New Zealand. Cultural Identity: The Social Report 2008. NZ: Author. Retrieved from http:/www.socialreport.msd. govt.nz/cultural-identity/

Miville, M. L., \& Constantine, M. G. (2006). Sociocultural predictors of psychological help-seeking attitudes and behavior among Mexican American college students. Cultural Diversity and Ethnic Minority Psychology, 12(3), 420-432.

Miville, M. L., Koonce, D., Darlington, P., \& Whitlock, B. (2000). Exploring the relationships between racial/cultural identity and ego among African Americans and Mexican Americans. Journal of Multicultural Counseling \& Development, 28(4), 208-224.

Moilanen, K. L., \& Raffaelli, M. (2010). Support and conflict in ethnically diverse young adults' relationships with parents and friends. International Journal of Behavioral Development, 34 (1), 46-52. doi:10.1177/0165025409348553

Mosby, J. R. (2009). From strain to success: A phenomenological study of the personal and academic pressures on African American male community college students. Unpublished doctoral dissertation. University of San Diego, San Diego, CA.

Muñoz, S. M. \& Maldonado, M. M. (2011) Counterstories of college persistence by undocumented Mexicana students: Navigating race, class, gender, and legal status. International Journal of Qualitative Studies in Education. First published on 04, February 2011(iFirst), 1-24. doi: 10.1080/09518398.2010.529850 
Museus, S. D., Nichols, A. H., \& Lambert, A.D. (2008). Racial differences in the effects of campus racial climate on degree completion: A structural equation model. The Review of Higher Education, 32(1), 107-134.

National Center for Education Statistics. (2010). Status and trends in the education of racial and ethnic minorities, Table 2b. (NCES 2010-015). Washington, DC: U.S. Department of Education, Office of Educational Research and Improvement. Retrieved from http://nces.ed.gov/pubs2010/2010015/tables/table_2b.asp

National Center for Education Statistics. (2010). Status and trends in the education of racial and ethnic minorities, Table 2c. (NCES 2010-015). Washington, DC: U.S. Department of Education, Office of Educational Research and Improvement. Retrieved from http://nces.ed.gov/pubs2010/2010015/tables/table_2c.asp

Niemann Y. F., Romero, A. J., Arredondo, J. \& Rodríguez, V. (1999). What does it mean to be "Mexican?" Social construction of an ethnic identity. Hispanic Journal of Behavioral Sciences, 21(1), 47-60.

Nostrand, R. L. (1992). The Hispano homeland. Norman: University of Oklahoma Press.

Oakes, J. (2005). Keeping track: How schools structure inequality. New Haven, CT: Yale University Press.

Ochoa, G.L. (2000). Mexican Americans attitudes toward and interactions with Mexican immigrants: A qualitative analysis of conflict and cooperation. Social Science Quarterly, 81(1),84-105.

Ochoa, G. L. (2004). Becoming neighbors in a Mexican American community: Power, conflict, and solidarity. Austin: University of Texas Press.

Ogbu, J. U. (1978). Minority education and caste: The American system in cross-cultural perspective. New York: Academic Press.

Ogbu, J. U. (1992). Adaption to minority status and impact on school success. Theory into Practice, 31(4), 287-295.

Ogbu, J. U. (2003). Black American students in an affluent suburb: A study of academic disengagement. Mahwah, NJ: Lawrence Erlbaum Associates.

Olguín, B. V. (2005). Reassessing pocho poetics: Américo Paredes's poetry and the (trans)national question. Aztlán: 30(1), 87-121.

Ono, H. (2002). Assimilation, ethnic competition, and ethnic identities of U.S. - born persons of Mexican origin. International Migration Review, 36(3), 726-745. doi: $10.1111 / \mathrm{j} .1747-7379.2002 . t b 00102 . x$ 
Ortmeyer, P. (1997). Let them drink milk: Iodine-131 doses from nuclear weapons testing. Science for Democratic Action, 6(2). Publication of the Institute for Energy and Environmental Research. Retrieved from http://www.ieer.org/ sdafiles/vol_6/v6n2_1.html

Osei-Kofi, N., Richards, S.L., \& Smith, D.G. (2004). Creating inclusive classrooms: Politics of knowledge, reflection, and engagement. In L.I. Rendón, M. Garcia, \& D. Person (Eds.), Transforming the first-year experience for students of color (Monograph No. 38, pp. 55-66). Columbia: University of South Carolina: National Resource Center for The First-Year Experience and Students in Transition.

Ousley, M. D. (2006). Hope for a more equitable society: Student values and perspectives on race, ethnicity, and gender. Journal of College and Character 7(4). 1-10.

Padilla, A. M. (2006). Bicultural social development. Hispanic Journal of Behavioral Sciences, 28(4), 467-497. doi: 10.1177/0739986306294255

Park, H. S., Guan, X. (2007). Cultural differences in self versus others' self-construals: Data from China and the United States. Communication Research Reports 24(1), 21-28. doi: 10.1080/08824090601128059

Patten, M. L. (2004). Understanding research methods: An overview of the essentials $\left(^{\text {th }}\right.$ ed.). Glendale, CA: Pyrczak Publishing.

Pena, R. A. (1997). Cultural differences and the construction of meaning: implications for the leadership and organizational context of schools. Education Policy Analysis Archives, 5(10),

Pew Research Center (2008). U.S. population projections: 2005-2050. Report. J. S. Passel, D'Vera Cohn. Retrieved from http://pewhispanic.org/files/reports/85.pdf

Pew Hispanic Center. (2009). Between Two Worlds: How Young Latinos Come of Age in America. Millennials: A Portrait of Generation Next. Pew Research Center: Washington, DC. Retrieved from http://pewhispanic.org/reports/ report.php?ReportID $=117$

Phinney, J. S. (1990). Ethnic identity in adolescents and adults: Review of research. Psychological Bulletin, 108(3), 499-514. doi:10.1037/0033-2909.108

Phinney, J. S. (1996). When we talk about American ethnic groups, what do we mean? American Psychologist, 51(9), 918-927. doi:10.1037/0003-066X.51.9.918

Phinney, J. S. (2005). Ethnic identity in late modern times: A response to Rattansi and Phoenix. Identity: An International Journal of Theory and Research 5(2), 187194. 
Phinney, J. S., \& Alipuria, L. (1990). Ethnic identity in college students from four ethnic groups. Journal of Adolescents, 13(2), 171-183.

doi: 10.1016/0140-1971990090006-S

Phinney, J. S., \& Alipuria, L. L. (1996). At the interface of cultures: Multiethnic/multiracial high school and college students. The Journal of Social Psychology, 136(2), 139-158.

Piaget, J. (1972). The psychology of the child. New York: Basic Books.

Pizarro, M. (2005). Chicanas and Chicanos in school: Racial profiling, identity battles, and empowerment. Austin: University of Texas Press.

Pizarro, M., \& Vera, E. M. (2001). Chicana/o ethnic identity research: Lessons for researchers and counselors. The Counseling Psychologist, 29(1), 91-117. doi: $10.1177 / 0011000001291004$

Raso, M. V., \& Sobek-Herrera, M. (2001). A Spanish novelist's perspectiva on Chicano/a literature. Journal of Modern Literature, 25(1), 17-34.

Robles, J. (2009). Barriers to success: A narrative of one Latina student's struggles. Harvard Educational Review, 79(4), 745-754.

Rodríguez, C. E. (2000). Changing race: Latinos, the census, and the history of ethnicity in the United States. New York \& London: New York University Press.

Rodriguez, N., Bingham Mira, C., Paez, N. D., \& Myers, H. F. (2007). Exploring the complexities of familism and acculturation: Central constructs for people of Mexican origin. American Journal of Community Psychology, 39(1-2), 61-77. doi: $10.1007 / \mathrm{s} 10464-007-9090-7$

Rodriguez, N., Mira, C.B., Myers, H.F., Morris, J.K., \& Cardoza, C. (2003). Family or friends: Who plays a greater supportive role for Latino college students? Cultural Diversity and Ethnic Minority Psychology, 9, 236-250.

Rodriguez, R. (1982). Hunger of memory: The education of Richard Rodriguez. New York: Bantam Dell.

Rosaldo R. (1993). Culture \& truth: The remaking of social analysis: with a new introduction. Boston: Beacon Press.

Rosales, F. A. (2000). Testimonio, Houston: Arte Publico Press. 
Roosa, M. W., Liu, F. F., Torres, M., Gonzalez, N. A., Knight, G. P., \& Saenz, D. (2008). Sampling and recruitment in studies of cultural influences on adjustment: A case study with Mexican Americans. Journal of Family Psychology, 22(2), 293-302.

Rumbaut, R. (1994). The crucible within: Ethnic identity, self esteem, and segmented assimilation among children of immigrants. International Migration Review 28(4), 748-794.

Rumberger, R.W. (1993). Chicano dropouts: A review of research and policy issues. Chapter 3. ERIC database. (ED387282). Retrieved from http://www.eric.ed.gov/ PDFS/ED387282.pdf

Rumberger, R. W., \& Larson, K. A. (1992). Keeping high-risk Chicano students in school: Lessons from a Los Angeles middle school dropout prevention program. ERIC database. (ED 369582). Retrieved from http://www.eric.ed.gov/PDFS/ED 369582.pdf

Salazar, R. (1963). Spanish-speaking Angelenos: A culture in search of a name. In M. T. Garcia (Ed.), Ruben Salazar, Border correspondent: Selected writings, 19551970. Berkeley: University of California Press.

Salazar, R. (1970). Who is a Chicano? And what is it the Chicanos Want? In M. T. Garcia (Ed.), Ruben Salazar, Border correspondent: Selected writings, 19551970. Berkeley: University of California Press.

Santiago, D. \& Cunningham, A. (2005). How Latino students pay for college: Patterns of financial aid (2003-04), Excelencia in Education and the Institute for Higher Education Policy. Washington, DC. Retrieved from http://www.edexcelencia.org/ research/how-latino-students-pay-college-patterns-financial-aid-2003-04

Santiago, D. A. (2007a). Choosing Hispanic Serving Institutions (HSI's): A closer look at Latino students' college choices. Excelencia in Education. Washington, DC. Retrieved from http://www.edexcelencia.org/research/choosing-hispanic-servinginstitutions-hsis-closer-look-latino-students $\% \mathrm{E} 2 \% 80 \% 99$-college-choices

Santiago, D. A., (2007b). Voces (Voices): A profile of today's Latino college students. Excelencia in Education and the Institute for Higher Education Policy. Washington, DC. Retrieved from http://www.edexcelencia.org/research/vocesprofile-todays-latino-college-students

Santiago, D. (2009). Enrolling vs. serving Latino students. Diverse: Issues in Higher Education, 26(16), 20.

Santrock, J.W. (2008). Life span development. New York: McGraw-Hill Companies, Inc. 
Schenk, P. S. (2007). 'I'm Mexican, remember?' Constructing identities via authenticating discourse. Journal of Sociolinguistics, 11(2), 194-220. doi: $10.1111 /$ j.1467-9841.2007.00318.x

Schneider, M. E., \& Ward, D. J. (2003). The role of ethnic identification and perceived social support in Latinos' adjustment to college. Hispanic Journal of Behavioral Sciences, 25, 539-554.

Schwartz, S. J. (2001). The evolution of Eriksonian and Neo-Eriksonian identity theory and research: A review and integration. Identity: An International Journal of Theory and Research, 1(1), 7-58.

Schwartz, S. J. (2002). In search of mechanisms of change: Integrating the constructivist and discovery perspectives on identity. Identity: An International Journal of Theory and Research, 2(4), 317-339.

Sedikides, C., Gaertner, L., \& Toguchi, Y. (2003). Pancultural self-enhancement. Journal of Personality and Social Psychology, 84, 60-79.

Shorris, E. (1992). Latinos: A biography of the people. New York/London: W.W. Norton \& Co.

Solórzano, D. (1992). An explanatory analysis of the effect of race, class and gender, on student and parent mobility aspirations. Journal of Negro Education, 61(1), 3044 .

Spencer, M. B. (2006). Phenomenology and ecological systems theory: Development of diverse groups. In W. Damon \& R. Lerner (Eds.), Handbook of child psychology $\left(6^{\text {th }}\right.$ ed.). New York: Wiley.

Spradley, J. P. (1979). The ethnographic interview. FL: Holt, Rinehart, \& Winston, Inc.

Stake, R. E. (1995). The art of case study research. In S. B. Merriam (Ed). (2002). Qualitative research in practice: Examples for discussion and analysis. San Francisco, CA: Jossey-Bass.

Sue, D. W., \& Sue, D. (1990). Counseling the culturally different: Theory and practice (2nd ed.). New York: Wiley.

Sung, B. L. (1987). The adjustment experience of Chinese immigrant children in New York City. In A. J. Fuligni, M. Witkow, \& C. Garcia (Eds.), Ethnic identity and the academic adjustment of adolescents from Mexican, Chinese, and European backgrounds. Developmental Psychology, 41 (5), 799-811.

doi: 10.1037/0012-1649.41.5.799 
Tan, A. J. (2008). Ethnic identity of Mexican American children in the post industrial age. Dissertation Abstracts International Section A: Humanities and Social Sciences, 68(8A), 1-354.

Taylor, M. C. (1927). Retardation of Mexican children in the Albuquerque schools. Unpublished master's thesis, Leland Stanford Junior University, Stanford, CA.

Tinto, V. (1987). Leaving college: Rethinking the causes and cures of student attrition. Chicago, IL: University of Chicago Press.

Tinto, V. (1993). Leaving college: Rethinking the causes and cures of student attrition (2nd ed.). Chicago: University of Chicago Press.

Trimble, J. E. (1991). Ethnic specification, validation prospects, and the future of drug research. International Journal of the Addictions, 25(2A), 149-170.

Tsai, J. L., Ying, Y.W., \& Lee, P. A. (2000). The meaning of "being Chinese" and "being American": Variation among Chinese American young adults. Journal of CrossCultural Psychology, 31(3), 302-332.

Umaña-Taylor, A. J., \& Fine, M. A. (2001). Methodological implications of grouping Latino adolescents into one collective ethnic group. Hispanic Journal of Behavioral Sciences, 23(4), 347-362. doi: 10.1177/0739986301234001

Umaña-Taylor, A. J., \& Fine, M. A. (2004). Examining ethnic identity among MexicanOrigin adolescents living in the United States. Hispanic Journal of Behavioral Sciences, 26(1), 36-59. doi: 10.1177/0739986303262143

Umaña-Taylor, A. J., Diversi, M., \& Fine, M. A. (2002). Ethnic identity and self-esteem of Latino adolescents: Distinctions among the Latino populations. Journal of Adolescent Research, 17(3), 303-327.

Unger, J. B., Ritt-Olson, A., Wagner, K., Soto, D., Baezconde-Garbanati, L. (2007). A comparison of acculturation measures among Hispanic/Latino adolescents. Journal of Youth and Adolescence, 36(4), 555-565. doi: 10.1007/s10964-0079184-4

United States Census Bureau (2011). The Hispanic population: 2010. 2010 Census Briefs. S.R. Ennis, M. Ríos-Vargas, \& N. G. Albert. Retrieved from http://www.census.gov/prod/cen2010/briefs/c2010br-04.pdf

United States Department of Education. Developing Hispanic Serving Institutions Program--TITLE $V$. Program description webpage. Retrieved from http://www2.ed.gov/programs/idueshsi/index.html 
Valenzuela, A. (1999). Subtractive schooling: U.S.-Mexican youth and the politics of caring. Albany: State University of New York Press, 1999.

Valenzuela, I. (1996). Change in the educational life of Chicano families across three generations. Education and Urban Society, 29(1), 13-34. doi: $10.1177 / 0013124596029001003$

Venegas-Garcia, M. (2010). Leadership for social change: Learning from Latina/Chicana activist educators. Unpublished doctoral dissertation. University of San Diego, San Diego.

Van Manen, M. (1990). Researching lived experience: human science for an action sensitive pedagogy. New York: State University of New York Press.

Vielma, A. (n.d.). Coping with growing up as a minority in a White-dominant environment. Autobiographical essay. Trinity University. Retrieved from http://iraa.trinity.edu/Documents/student_affairs_docs/CCI_docs/Diversity/coping \%20with\%20growing\%20up.pdf

Villarreal, J. A. (1959: 1970). Pocho. New York: Doubleday \& Company.

Vogt, W. P. (1999) Dictionary of statistics and methodology: A nontechnical guide for the social sciences. London: Sage Publications, Inc.

Vuong, M., Brown-Welty, S., \& Tracz, S. (2010). The effects of self-efficacy on academic success of first-generation college sophomore students. Journal of College Student Development, 51(1), 50-64. doi: 10.1353/csd.0.0109.

Wallace, P. M., Pomery, E. A., Latimer, A. E., Martinez, J. L., \& Salovey, P. (2010). A review of acculturation measures and their utility in studies promoting Latino health. Hispanic Journal of Behavioral Sciences, 32(1), 37-54.

Wayman, J. C. (2002). Student perceptions of teacher ethnic bias: A comparison of Mexican-American and non-Latino white dropouts and students. High School Journal, 85(3), 25-37.

Warren, C. S., Castillo, L. G., \& Gleaves, D. H. (2010). The sociocultural model of eating disorders in Mexican American women: Behavioral acculturation and cognitive marginalization as moderators. Eating Disorders, 18(1), 43-57.

Waters, M. (1990). Ethnic options: Choosing identities in America. Berkeley: University of California Press.

Yosso, T. J., Smith, W. A., Ceja, M., \& Solórzano, D. G. (2009). Critical race theory, racial microaggressions, and campus racial climate for Latino(a) undergraduates. Harvard Educational Review, 79(4), 659-690. 
Zarate, M. E., Bhimji, F., Reese, L. (2005). Ethnic identity and academic achievement among Latino(a) adolescents. Journal of Latinos and Education, 4(2), 95-114. 
Appendix A

Research Participant Consent Form 
The Lived Experiences of $3^{\text {rd }}$ Generation and Beyond U.S.-Born (3GAB-USB) Mexican Heritage College Students: Reality vs. Perception, Is There A Difference? A Qualitative Study

Richard Galván is a doctoral student in Leadership Studies at the School of Leadership \& Education Sciences (SOLES) at the University of San Diego. You are invited to participate in a research project he is conducting for the purpose of exploring the psychosocial and identity issues of multi-generation U.S.-born Mexican heritage college students and to identify problems and concerns they have in transitioning to college.

The project will involve two interviews and filling out a general demographic questionnaire that asks questions about your "lived" experiences as a U.S.-born person of Mexican descent. Filling out the demographic questionnaire and initial interview will take $60-90$ minutes. A second follow-up interview will last about 60 minutes or less, and will also include some questions about you, such as elaborating on a question from the first interview, and allowing you the opportunity to review your own data, verify its accuracy, and offer insight. Changing your answer will also be an option during the second follow-up interview.

The interview will take place at a time and place convenient for you. Participation is entirely voluntary and you can refuse to answer any question and/or quit at any time. Should you choose to quit, no one will be upset with you and your information will be destroyed right away. If you decide to quit, nothing will change about your status in school.

The information you give will be analyzed and studied in a manner that protects your identity. That means that a code number will be used and that your real name will not appear on any of the study materials. All information you provide will remain confidential and locked in a file cabinet in the researcher's office for a minimum of five years before being destroyed.

There may be a risk that participating in the interviews may make you feel tired. Sometimes people feel anxious or sad when talking or reflecting on the things you will be asked about. If you would like to talk to someone about your feelings, you can call the San Diego Mental Health Hotline at 1-800-479-3339. 
Remember, you can stop the interview at any time you feel tired or for any other reason.

The benefit to participating will be in knowing that you helped contribute to a better understanding of U.S.-born Mexican college students by talking about your lived experience which will provide a new non-immigrant perspective to the academic literature and help others learn how to better respond to the issues, concerns, and problems, faced by the non-immigrant segment of the Mexican heritage population of the United States.

If you have any questions about this research, please feel free to contact me, Richard Galván by phone (619) 972-7909, or email rgalvan02@gmail.com. You may also contact my faculty adviser, Dr. Johanna S. Hunsaker at the University of San Diego (619) 260-4858, or email hunsaker@sandiego.edu

I have read and understand this form, and consent to the research it describes to me. I have received a copy of this consent form for my records.

Signature of Participant

Date

Name of Participant (Printed)

$\overline{\text { Signature of Principal Investigator }}$

Date 
Appendix B

General Demographic Information Form 
- Age:

- Place of Birth:

- Gender (Please Circle): Male Female

- Marital Status (Please Circle): Single Married

- Single Parent (Please Circle): Yes No

- Grade Level (Please Circle): Junior Senior

- K-12 Education (Please Circle): Private School Public School Charter School

- Community College Transfer? (Please Circle): Yes No

- $\quad 1^{\text {St }}$ Generation College Student? (Please Circle): Yes No

- Major/Minor (If Applicable):

- GPA:

- Plans After College:

Graduate School (Please Circle): Yes No

What Field of Study

Seek Employment (Please Circle): Yes No

What Occupation

Undecided (Please Circle): Yes No

- U.S.-Born Generational Status (Please Circle):

3rd Generation

4th Generation

Other (Please Specify Which Generation)

- Both Parents of Mexican Heritage (Please Circle): Yes No

Both Grandparents of Mexican Heritage (Please Circle): Yes No

Other (Great Grandparents, etc.) Yes No (If Known)

- Parent(s) Level of Education (Please Circle): 
Mother: High School College Other

Father: High School College Other

- Parent(s) Occupation:

Mother: Father

- Native Language Spoken (Please Circle):

English Spanish

- Do You Speak Both English And Spanish (Please Circle): Yes No If Not, Do you Understand Spanish? (Please Circle): Yes No

- Are You Employed? (Please Circle): Yes No IfYes, Full Time Part Time

- Do You Receive Financial Aid? (Please Circle): Yes No

If Yes, What Type? Grants Loans Scholarships Work Study Other

- Yearly Family Income (Please Circle):

$\$ 10,000-\$ 19,000$

$\$ 20,000-\$ 40,000$

$\$ 41,000-\$ 60,000$

$\$ 61,000-\$ 80,000$

$\$ 81,000-\$ 100,000$

$\$ 101,000$ and above

If You Are An Independent Student, Please Also Circle Here: My Income

- Were You Raised In A Single Parent Household? (Please Circle) Yes No

- Other Siblings? (Please Circle): Yes No

How Many (If Applicable)? Brothers Sister 
Appendix C

Demographic Profile of Participants (Tables 1 -3) 
Table 1.

Demographic Profile of Participants

\begin{tabular}{|c|c|c|c|}
\hline Demographics & Brynn & Mandy & Maria \\
\hline Generational Status & 4 th & 8 th & 3 rd \\
\hline Age & 22 & 31 & 24 \\
\hline Place of Birth & Sun Valley, CA & El Cajon, CA & Redwood City, CA \\
\hline County of Residence & San Diego & San Diego & San Mateo \\
\hline Gender & Female & Female & Female \\
\hline Marital Status & Single & Single & Single \\
\hline Single Parent & Yes & No & Yes \\
\hline Grade Level & Senior & Senior & Junior \\
\hline K-12 Education & Public School & Public School & Public School \\
\hline Major/Minor & Mathematics & PoliSci-CrimJustice & Sociology \\
\hline GPA & 3.2 & 3.47 & 3.3 \\
\hline Receiving Financial Aid & Yes & Yes & Yes \\
\hline Language Spoken & English & English & English \\
\hline Bilingual (English/Spanish) & No & No & Bilingual \\
\hline Understand Spanish & Yes & No & Yes \\
\hline Community College Transfer & No & Yes & Yes \\
\hline $\begin{array}{l}\text { 1st Generation College Student } \\
\text { Plans After College }\end{array}$ & Yes & No & Yes \\
\hline A) Graduate School & Yes & Yes & $\mathrm{N} / \mathrm{A}$ \\
\hline Field of Study & Education & Law & N/A \\
\hline B) Seek Employment & Yes & Yes & Yes \\
\hline C) Undecided & N/A & N/A & Yes \\
\hline Parents Level of Education & & & \\
\hline Mother & Some High School & College & Other \\
\hline $\begin{array}{l}\text { Father } \\
\qquad \text { Parents Occupation }\end{array}$ & Some High School & College & High School \\
\hline Mother & Machinist & Accounting Supervisor & Postal Worker \\
\hline Father & Deceased & Periodontist & Unemployed \\
\hline $\begin{array}{l}\text { Are You Employed } \\
\text { Family Income }\end{array}$ & Yes & Yes & Yes \\
\hline If Living With Parents & Independent & Not Stated & Independent \\
\hline Student Income & $\$ 10,000-\$ 19,000$ & $\$ 10,000-\$ 19,000$ & $\$ 10,000-\$ 19,000$ \\
\hline $\begin{array}{c}\text { Raised in Single Parent Home } \\
\text { Other Siblings }\end{array}$ & Yes & Yes & No \\
\hline Brothers & 0 & 2 & 2 \\
\hline Sisters & 2 & 1 & 0 \\
\hline
\end{tabular}


Table 2 .

Demographic Profile of Participants

\begin{tabular}{|c|c|c|c|}
\hline Demographics & William & Amber & Lisa \\
\hline Generational Status & 3rd & 3.5 & 3.5 \\
\hline Age & 20 & 22 & 21 \\
\hline Place of Birth & Oceanside, $\mathrm{CA}$ & East Los Angeles, CA & West Covina, CA \\
\hline County of Residence & San Mateo & Los Angeles & Los Angeles \\
\hline Gender & Male & Female & Female \\
\hline Marital Status & Single & Single & Single \\
\hline Single Parent & No & No & No \\
\hline Grade Level & Sophomore & Junior & Junior \\
\hline K-12 Education & Public School & Public School & Public School \\
\hline Major/Minor & Biology & Sociology & Kinesiology-Pedagogy \\
\hline GPA & 3.2 & 3.59 & 3.3 \\
\hline Receiving Financial Aid & Yes & Yes & No \\
\hline Language Spoken & English & English & English \\
\hline Bilingual (English/Spanish) & No & No & No \\
\hline Understand Spanish & Yes & Yes & A Little \\
\hline Community College Transfer & Will Be & Yes & Yes \\
\hline $\begin{array}{c}\text { 1st Generation College Student } \\
\text { Plans After College }\end{array}$ & No & No & No \\
\hline A) Graduate School & Yes & Yes & $\mathrm{N} / \mathrm{A}$ \\
\hline Field of Study & Biology & College Counseling & N/A \\
\hline B) Seek Employment & Yes & Already Employed & Yes \\
\hline C) Undecided & $\mathrm{N} / \mathrm{A}$ & N/A & Yes \\
\hline Parents Level of Education & & & \\
\hline Mother & College & College & College \\
\hline $\begin{array}{l}\text { Father } \\
\quad \text { Parents Occupation }\end{array}$ & High School & College & High School \\
\hline Mother & Paralegal & School Clerk & Teacher's Assistant \\
\hline Father & House Painter & A/C Maintenance & Carpenter \\
\hline $\begin{array}{l}\text { Are You Employed } \\
\text { Family Income }\end{array}$ & Yes & Yes & Yes \\
\hline If Living With Parents & Lives w/Relative & Not Stated & $\$ 61,000-\$ 80,000$ \\
\hline Student Income & $\$ 10,000-\$ 19,000$ & $\$ 20,000-\$ 40,000$ & Under $\$ 10,000$ \\
\hline $\begin{array}{c}\text { Raised in Single Parent Home } \\
\text { Other Siblings }\end{array}$ & Yes & Yes & No \\
\hline Brothers & 0 & 2 & 1 \\
\hline Sisters & 0 & 0 & 1 \\
\hline
\end{tabular}


Table 3.

Demographic Profile of Participants

\begin{tabular}{|c|c|c|c|}
\hline Demographics & Jessica & Jamey & Samantha \\
\hline Generational Status & $3 \mathrm{rd}$ & 3 rd & 3 rd \\
\hline Age & 19 & 20 & 19 \\
\hline Place of Birth & Redwood City, CA & Palo Alto, CA & Palo Alto, CA \\
\hline County of Residence & San Mateo & San Mateo & San Mateo \\
\hline Gender & Female & Female & Female \\
\hline Marital Status & Single & Single & Single \\
\hline Single Parent & No & No & No \\
\hline Grade Level & Sophomore & Sophomore & Sophomore \\
\hline K-12 Education & Public School & Public School & Public School \\
\hline Major/Minor & Fashion/CrimJustice & Psychology & Biology \\
\hline GPA & 3.5 & 3.2 & 3.33 \\
\hline Receiving Financial Aid & Yes & Yes & No \\
\hline Language Spoken & English & English & English \\
\hline Bilingual (English/Spanish) & Bilingual & No & Bilingual \\
\hline Understand Spanish & Yes & Yes & Yes \\
\hline Community College Transfer & Will Be & Will Be & Will Be \\
\hline $\begin{array}{c}\text { 1st Generation College Student } \\
\text { Plans After College }\end{array}$ & Yes & No & No \\
\hline A) Graduate School & Yes & N/A & Yes \\
\hline Field of Study & Fashion/CrimJustice & N/A & Biology \\
\hline B) Seek Employment & Not Sure & N/A & No \\
\hline $\begin{array}{l}\text { C) Undecided } \\
\text { Parents Level of Education }\end{array}$ & N/A & Yes & N/A \\
\hline Mother & Other & College & College \\
\hline $\begin{array}{l}\text { Father } \\
\text { Parents Occupation }\end{array}$ & Other & N/A & N/A \\
\hline Mother & $\mathrm{N} / \mathrm{A}$ & HS Biology Teacher & Project Manager \\
\hline Father & N/A & $\mathrm{N} / \mathrm{A}$ & N/A \\
\hline $\begin{array}{l}\text { Are You Employed } \\
\text { Family Income }\end{array}$ & Yes & Yes & No \\
\hline If Living With Parents & Lives w/Relative & $\$ 81,000-\$ 100,000$ & $\$ 101,000 \&$ Above \\
\hline Student Income & $\$ 10,000-\$ 19,000$ & Under $\$ 10,000$ & N/A \\
\hline $\begin{array}{c}\text { Raised in Single Parent Home } \\
\text { Other Siblings }\end{array}$ & By Grandmother & Yes & Yes \\
\hline Brothers & 0 & 0 & 0 \\
\hline Sisters & 0 & 2 & 1 \\
\hline
\end{tabular}


Appendix D

Recruitment Flyer 


\title{
STUDY PARTICIPANTS NEEDED
}

\author{
The Lived Experiences of U.S. - Born $3^{\text {rd }}$ Generation and Beyond, Mexican Heritage \\ College Students: Reality vs. Perception, Is There A Difference? \\ A Qualitative Study \\ By Richard Galvan Doctoral Candidate, \\ University of San Diego, School of Leadershıp and Education Sciences
}

\section{Purpose of the Study}

The purpose of this study is to describe the psychosocial and identity issues of multi-generation native-born Mexican heritage college students, and to identify problems and concerns they have in transitioning to college. An additional purpose of the study, is to clarify in the academic literature that although Mexican/Latinos are all classified under one group, there are many diverse/different worldviews and life experiences within the cultures, which need to be explored and discussed when studies are conducted on these and other ethnic populations. Because of the lack of research on U.S.-born individuals among the Mexican U.S. population, little is known about how factors such as: multigeneration, a non-immigrant experience, family dynamics, racial and ethnic identity, might explain their "lived" experience. Therefore, a qualitative approach will be used in order to build a picture of the identity elements involved among the participants of the study, in order to examine the range of lived experiences they have had from birth through college. It will require one in-depth interview, and a possible follow-up interview to review or change responses. The participant's identity will remain anonymous by using code names as identifiers. The total time commitment will be approximately 90 minutes, and the researcher will drive up for the interviews.

\section{Participants}

Participants recruited will be U.S.--born $3^{\text {rd }}$ generation and beyond, individuals of Mexican heritage who are juniors and seniors at universities in California. The goal is to obtain an equal number of male and female participants. There are three requirements the study sample MUST meet: (1) The individuals are U.S.-born and are of Mexican heritage, (2) the parents must also be U.S.-born and of Mexican heritage, and (3) grandparents must be of Mexican heritage. This research project will focus on college juniors and seniors who are prepared to discuss their experience in a college setting over several years. The participants will be the "experts" in defining their own identity, the challenges faced, and their lived experience as opposed to someone's "perception" of it.

\section{Researcher Contact Information}

For more information or anyone interested in being a participant in this dissertation study, please contact Richard Galván at (619) 9XX-7XX9 or email rgalvan02@snail.com 
Appendix E Interview Guide 


\section{Personal}

1. Tell me about yourself (A brief biography).

2. What language was spoken at home?

3. How well do you understand Spanish?

4. Tell me about some of your earlier school experiences (K-12).

5. Describe memorable experiences in your life.

\section{$\underline{\text { Identity }}$}

6. How do you describe yourself ethnically?

7. Does the way you describe yourself ethnically, change situationally?

8. How do you feel this self-label helps or hinders your ethnic identity?

9. How much did the perception of others influence your self-label?

10. There are those that say why use a self-label, it only creates further separation/alienation. Why not be just "American?"

11. In 1973, a Professor named Alvarez from UCLA wrote about "hybridity," meaning the U.S.-born Mexican lives in two worlds because of his Mexican ethnicity and being born in the United States and because of this, he/she must learn to navigate both of these worlds to be successful. What do you think?

12. Alvarez also wrote that if the U.S.-born Mexican were not careful, "outsiders" would write them out of their "existence" meaning, they would be lumped in with other groups and lose their voice/identity/history. What are your thoughts?

13. Have you ever felt discriminated against or been the victim of racial comments? 
14. What about discrimination, or racial comments (internal racism) from fellow Mexicans or other Latino subgroups (e.g., Puerto Ricans; Central Americans [Salvadorians, Guatemalans]; South Americans [Brazil, Argentina]; Spain, etc.)?

15. Educated Latina/o(s) have spoken about feeling distant from family and friends as they navigate academia and achieve their goals. It is a problem for them because they do not want to lose who they are (Identity). Do you feel the same ambivalence?

\section{School Experience}

16. When did you know you wanted to attend college?

17. Who encouraged you to attend college?

18. All college students in the beginning feel a sense of "not belonging or alienation." How much does your ethnicity enhance or alleviate those feelings?

19. How did you feel when you arrived on campus?

20. What are the significant moments (both good and bad) of your freshman year?

21. Describe your overall experience at this school.

22. What challenges/hardships have you encountered in your educational experience?

\section{$\underline{\text { Social Support }}$}

23. Who is your support group?

24. Do you feel that your family members and friends understand your needs (frustrations, anxieties, doubts)?

25. Tell me about any mentors or individuals on campus who have been there for you? 
26. During your time on campus, have you participated in campus socializing activities?

27. Do you feel embraced by the campus community?

\section{Personal Growth}

28. In what ways do you feel you have grown while attending college?

29. Do you feel this growth was enhanced or limited by the school you attended?

30. In retrospect, what would you do differently regarding your college education?

\section{$\underline{\text { Recommendations }}$}

31. What do you feel would help students such as yourself in the transition to college?

32. What programs or interventions would you recommend?

33. At what level should they be implemented (K-12, College, etc.)?

\section{Finale}

34. Is there anything you would like to add? 
Appendix F

Recruitment Electronic Mail Sent to Faculty and Campus Organizations 


\section{Hello Professor/Organization,}

My name is Richard Galvan, and I am a doctoral candidate at the University of San Diego School of Leadership and Education Sciences (SOLES). I am conducting a study on 3rd generation and beyond U.S.-born Mexican heritage college students. A literature review conducted prior to this study, revealed there are no in-depth studies in the academic literature on multigenerational Americans of Mexican descent or for that matter, on Latinos in general, which I believe is one of the major reasons this population is still misunderstood in education, society, and government policy. I would appreciate it if you could disseminate this information to anyone who might like to participate if they meet the criteria of the study.

Below is a synopsis of the study. My hope is to elaborate in the literature that although Mexican/Latınos are all classified under one group, there are many diverse/different worldviews, and life experiences within the cultures, which need to be explored and elaborated on when studies are conducted on these and other ethnic populations. I begin with Mexican heritage because they are the most numerous in the Latino category, and I myself am 3rd generation. I can be reached at (619) 9XX-7XX5 or by email rgalvan02@snail.com if you would like to contact me. I thank you for your time, and please excuse the cold call.

Respectfully,

Richard Galvan

The Lived Experiences of $3^{\text {rd }}$ Generation and Beyond, U.S. - Born Mexican Heritage College Students: Reality vs. Perception, Is There A Difference? A Qualitative Study

\section{Purpose of the Study}

The purpose of this study is to describe the psychosocial and identity issues of multigeneration native-born Mexican heritage college students and to identify problems and concerns they have in transitioning to college Because of the lack of research on US - born individuals among this population, little is known about how factors such as multigeneration, a non-immigrant experience, family dynamics, racial and ethnic identity, might explain their "lived" expenence A qualitative approach (in-depth interview) will be used in order to build a picture of the identity elements of this subgroup allowing for an examination of the range of lived experiences they have had from birth through college It will require one in-depth interview, and a follow-up to review or change responses The participant's identity will remain anonymous by using code names as their identifiers Total time commitment will be approximately 1 hours and 30 minutes

\section{Participants}

Participants recruited will be U S -born $3^{\text {rd }}$ generation and beyond, individuals of Mexican heritage who are college students The goal is to obtain an equal number of male and female participants, and a mixture of university and community college students There are three requirements the study sample MUST meet (1) The individuals are U S born and are of Mexican heritage, (2) the parents must also be U S -born and of Mexican heritage, and (3) grandparents must be of Mexican heritage The participants will be the "experts" in defining their own identity, the challenges faced, and their lived expertence as opposed to someone's "perception" of $1 \mathrm{t}$

\section{Researcher Contact Information}

For more information or anyone interested in being a participant in this dissertation study, please contact Richard Galvan at (619) 9XX-7XX9 or email rgalvan02@snail com 
Appendix G

Electronic Mail Sent to Potential Sample Participants 


\section{Hi Student Name,}

Thank you for responding and your interest! Basically the study is a one hour interview and maybe a follow-up (depending if you or I want to add anything) where I ask you some questions, but you are more than welcome to talk about your "lived" experience (which is the point of the study). I want to hear what you have to say. The first part is the demographic sheet, which I have attached. Once you send it back and you meet the criteria, we can schedule a day to do the interview. Below is more information on the study.

Regards,

\section{Richard Galvan}

At this time, the requirements of the study have to be exact because previous studies on "Mexican Americans" have been a mixture of varıous Latino ethnicities or a combination of Immigrant/U.S.-born Mexicans, leading to further confusion in the academic literature when discussing Mexican(o)s, Chicanos, Mexican-Americans and all other ethnicities under the Latino category. The intention of the study is to elaborate in the academic literature that although Mexican/Latinos are all classified under one group, there are many diverse/different worldviews, and life experiences within the cultures, which need to be explored and elaborated on when studies are conducted on these and other ethnic populations. I begin with Mexican heritage because they are the most numerous in the Latino category, and I myself am 3rd generation.

\section{The Lived Experiences of $3^{\text {rd }}$ Generation and Beyond, U.S. - Born Mexican Heritage College Students: Reality vs. Perception, Is There A Difference? A Qualitative Study}

\section{Purpose of the Studv}

The purpose of this study is to describe the psychosocial and identity issues of multigeneration native-born Mexican heritage college students and to identify problems and concerns they have in transitioning to college Because of the lack of research on U S -born individuals among this population, little is known about how factors such as mult1generation, a non-immigrant expenence, family dynamics, racial and ethnic identity, might explain their "lived" expenience A qualitative approach (in-depth interview) will be used in order to build a picture of the identity elements of this subgroup allowing for an examination of the range of lived experiences they have had from birth through college It will require one in-depth interview, and a follow-up to review or change responses The participant's identity will remain anonymous by using code names as their identifiers Total time commitment will be approximately 1 hours and 30 minutes

\section{Participants}

Partıcipants recruited will be US -born $3^{\text {rd }}$ generation and beyond, individuals of Mexican heritage who are college students The goal is to obtain an equal number of male and female participants, and a mixture of university and community college students There are three requirements the study sample MUST meet (1) The individuals are U S born and are of Mexican heritage (2) the parents must also be U S -born and of Mexican heritage, and (3) grandparents must be of Mexican heritage The participants will be the "experts" in defining their own 1dentity, the challenges faced, and their lived expenence as opposed to someone's "perception" of it

\section{Researcher Contact Information}

For more information or anyone interested in being a participant in this dissertation study, please contact Ruchard Galvan at (619) 9XX-7XX9 or ema1l rgalvan02@snarl com 


\author{
APPENDIX H \\ National Center for Education Statistics. \\ Status and Trends in the Education of Racial and Ethnic Minorities, \\ Table $2 b$. \\ (NCES 2010-015)
}


Number, percentage, and percentage distribution of U.S. population, by nativity and race/ethnicity with Hispanic and Asian subgroups: 2007

\begin{tabular}{|c|c|c|c|c|c|}
\hline \multirow[b]{2}{*}{ Race/ethnicity and subgroup } & \multicolumn{5}{|c|}{ Born outside the United States ${ }^{1}$} \\
\hline & $\begin{array}{c}\text { Total } \\
\text { population }\end{array}$ & $\begin{array}{l}\text { Born } \\
\text { within } \\
\text { the } \\
\text { United } \\
\text { States } \\
\end{array}$ & Number & Percent & $\begin{array}{l}\text { Percentage } \\
\text { distribution }\end{array}$ \\
\hline Total $^{2}$ & $301,621,200$ & 86.1 & $41,820,700$ & 13.9 & 100.0 \\
\hline White & $198,594,500$ & 95.4 & $9,097,000$ & 4.6 & 21.8 \\
\hline Black & $36,624,900$ & 91.8 & $3,002,900$ & 8.2 & 7.2 \\
\hline Hispanic & $45,378,600$ & 56.4 & $19,806,300$ & 43.7 & 47.4 \\
\hline Mexican & $29,189,300$ & 59.5 & $11,812,300$ & 40.5 & 28.3 \\
\hline Puerto Rican & $4,114,700$ & 64.8 & $1,448,300$ & 35.2 & 3.5 \\
\hline Cuban & $1,608,800$ & 37.5 & $1,004,900$ & 62.5 & 2.4 \\
\hline Dominican & $1,198,800$ & 37.9 & 744,000 & 62.1 & 1.8 \\
\hline Salvadoran & $1,473,500$ & 33.3 & 983,400 & 66.7 & 2.4 \\
\hline Other Central American & $2,059,100$ & 31.2 & $1,417,000$ & 68.8 & 3.4 \\
\hline South American & $2,500,800$ & 28.9 & $1,779,000$ & 71.1 & 4.3 \\
\hline Other Hispanic or Latino & $3,233,500$ & 80.9 & 617,300 & 19.1 & 1.5 \\
\hline Asian & $13,100,900$ & 30.8 & $9,064,700$ & 69.2 & 21.7 \\
\hline Asian Indian & $2,578,200$ & 26.3 & $1,901,000$ & 73.7 & 4.6 \\
\hline Chinese $^{3}$ & $3,022,600$ & 28.2 & $2,170,100$ & 71.8 & 5.2 \\
\hline Filipino & $2,383,900$ & 29.6 & $1,678,000$ & 70.4 & 4.0 \\
\hline Japanese & 783,400 & 56.5 & 340,900 & 43.5 & 0.8 \\
\hline Korean & $1,350,500$ & 22.6 & $1,044,900$ & 77.4 & 2.5 \\
\hline Vietnamese & $1,478,300$ & 32.3 & $1,000,900$ & 67.7 & 2.4 \\
\hline Other Asian & $1,504,000$ & 38.2 & 928,900 & 61.8 & 2.2 \\
\hline Native Hawaiian/Pacific Islander & 404,200 & 59.8 & 162,700 & 40.2 & 0.4 \\
\hline American Indian/Alaska Native & $2,021,700$ & 98.4 & 32,300 & 1.6 & 0.1 \\
\hline Two or more races & $4,785,900$ & 92.6 & 356,000 & 7.4 & 0.9 \\
\hline \multicolumn{6}{|c|}{$\begin{array}{l}{ }^{1} \text { United States refers to the } 50 \text { states and the District of Columbia. } \\
2 \text { Total includes other race/ethnicity categories not separately shown. } \\
{ }^{3} \text { Excludes Taiwanese. Taiwanese is included in the "Other Asian" category. } \\
\text { NOTE: Population estimates may differ from those in other tables due to time of year of } \\
\text { estimation. Race categories exclude persons of Hispanic ethnicity. Detail may not sum to totals } \\
\text { because of rounding. } \\
\text { SOURCE: U.S. Department of Commerce, Census Bureau, American Community Survey, } 2007 .\end{array}$} \\
\hline
\end{tabular}




\section{APPENDIX I}

National Center for Education Statistics.

Status and Trends in the Education of Racial and Ethnic Minorities, Table 2c.

(NCES 2010-015) 
Number, percentage, and percentage distribution of U.S population under age 18, by nativity and race/ethnicity with Hispanic and Asian subgroups:

2007

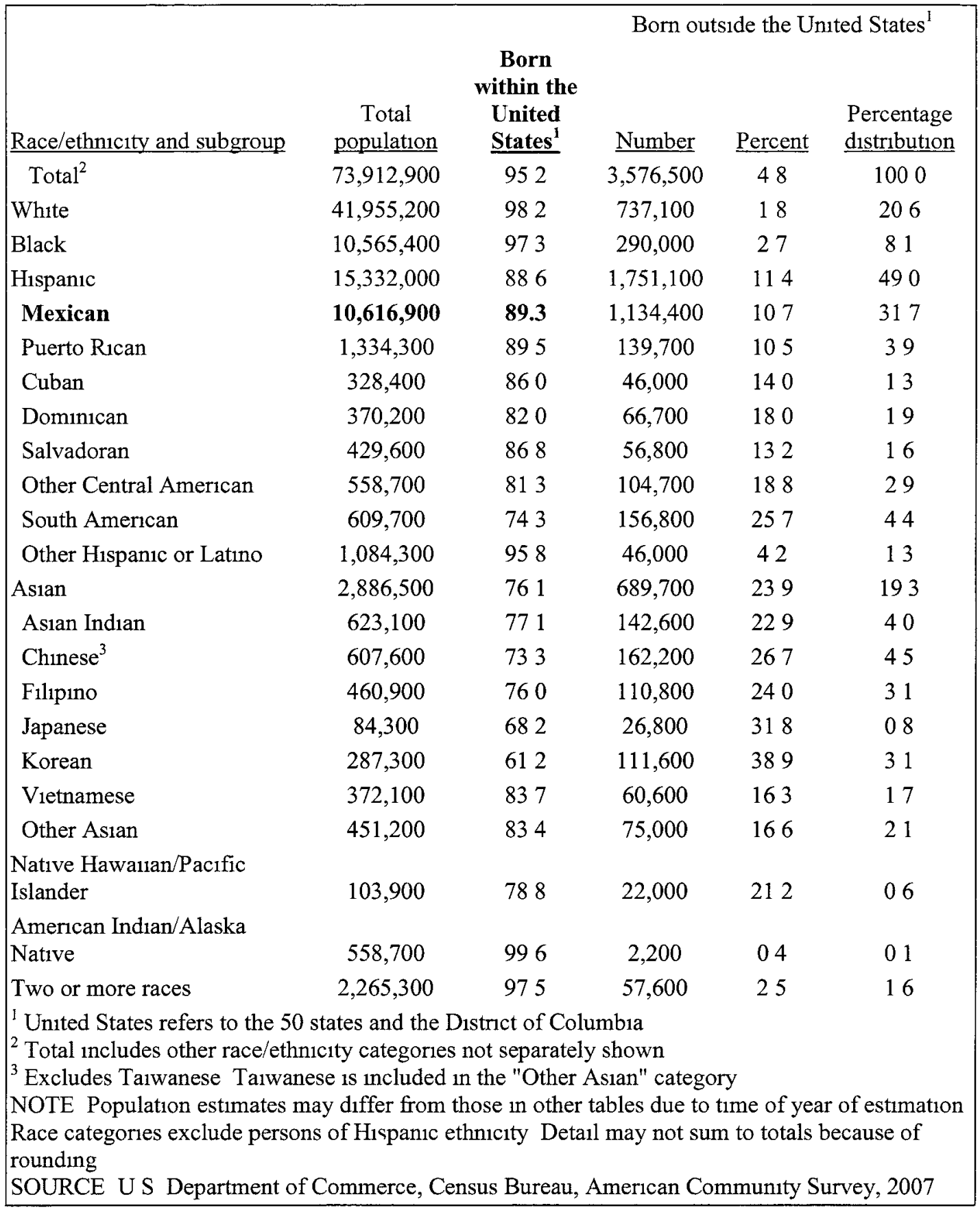

